Portland State University

PDXScholar

$1-1-2011$

\title{
A Macroergonomics Approach Examining the Relationship between Work-family Conflict and Employee Safety
}

Lauren Ann Murphy

Portland State University

Follow this and additional works at: https://pdxscholar.library.pdx.edu/open_access_etds

Part of the Psychology Commons

Let us know how access to this document benefits you.

Recommended Citation

Murphy, Lauren Ann, "A Macroergonomics Approach Examining the Relationship between Work-family Conflict and Employee Safety" (2011). Dissertations and Theses. Paper 214.

https://doi.org/10.15760/etd.214

This Dissertation is brought to you for free and open access. It has been accepted for inclusion in Dissertations and Theses by an authorized administrator of PDXScholar. Please contact us if we can make this document more accessible: pdxscholar@pdx.edu. 


\begin{abstract}
A Macroergonomics Approach Examining the Relationship between Work-family Conflict and Employee Safety
\end{abstract}

\title{
by
}

Lauren Ann Murphy

A dissertation submitted in partial fulfillment of the requirements for the degree of

\author{
Doctor of Philosophy \\ in \\ Applied Psychology
}

\section{Dissertation Committee: \\ Leslie Hammer, Chair \\ Eileen Brennan \\ Charlotte Fritz \\ Cynthia Mohr \\ Donald Truxillo}

Portland State University

(C) 2011 


\begin{abstract}
In 2008, there were more than 5,200 workplace fatalities in the United States (BLS, 2010b). During the same time period, U.S. employees missed almost 1.1 million days from work (BLS, 2010c). Accidents are unexpected outcomes that result not only from individuals' behaviors, but also from contextual factors (Krause, 1997; Reason, 1990). Therefore, unsafe behaviors have to be interpreted according to a combination of what is occurring in the environment and what the individual is doing in that environment. The present study sought to create a more comprehensive model of safety by means of macroergonomics. Macroergonomics utilizes sociotechnical systems theory to posit that a work system is composed of a personnel subsystem (i.e., ways individuals perform tasks), a technological subsystem (i.e., tasks to be performed), and external factors (Hendrick, 2002a).

Perceived control over work hours, an aspect of the technological subsystem, was examined as an antecedent of work-family conflict. Supervisor instrumental support, an aspect of the personnel subsystem, was examined as a moderator of the relationships between perceived control over work hours and work-family conflict. Supervisors have an imperative role in employees' perception of control over their work hours (Kelly \& Moen, 2007). Supervisor instrumental support was also hypothesized to moderate the relationships between work-family conflict and safety performance. Supervisors who support their employees in their work-family matters exceed mandatory requirements set forth to protect workers' safety and health (Mearns, Hope, Ford, \& Tetrick, 2010).
\end{abstract}


A majority of the 360 participants in the present study were grocery store employees who worked in the front end of the store as cashiers. Job tenure in this particular grocery store chain was an average of 7 years $(S D=5.96)$ and the average number of hours worked per week was $31(S D=8.55)$. The employees were an average age of 38 years old $(S D=15.25)$. Two hundred and sixty-two $(73 \%)$ of the participants were female, 330 (92\%) were White, $196(55 \%)$ employees were married or living as married, $146(41 \%)$ employees identified themselves as parents with children living at home, and 58 (16\%) employees provided elder care.

The data were analyzed using a moderated mediation model. An employee's perceived control over his/her work hours was negatively associated with work-to-family and family-to-work conflict. Work-to-family conflict was not significantly associated with either safety compliance or participation. In contrast, family-to-work conflict was significantly associated with both safety compliance and participation. These findings replicate Cullen and Hammer's (2007) findings that family-to-work conflict, but not work-to-family conflict, is negatively associated with safety compliance and participation. The replication of these significant findings gives support to macroergonomics' assertion that external forces (i.e., family) can affect the safety of employees.

All of the meditating and moderating relationships proposed in this dissertation were not significant. I conducted post hoc analyses to determine other possible significant paths in the model examined. The FSSB dimension of supervisor instrumental support was found to positively affect both safety compliance and participation. Supervisor 
instrumental support was also found to directly affect work-to-family conflict. Overall FSSB and its subdimensions demonstrated similar patterns in the hypothesized relationships and in additional relationships examined.

Numerous implications can be recognized from this dissertation. First, interdisciplinary approaches to safety research are emerging and important in the pursuit of safer work environments. Macroergonomics and I/O psychology have commonalities that lend themselves to a good partnership where researchers can learn from each other and collaborate to advance the study of safety. Second, organizations need to focus on the stressors their employees experience as part of their safety programs, and numerous studies, including this dissertation, have found that family-to-work conflict impacts safety compliance and participation. Future safety research may incorporate macroergonomics, which emphasizes that focusing on one adverse aspect of the system may not be enough to create valuable change if there are other adverse factors still creating demands elsewhere in the system. This will allow for a more comprehensive model that ensures certain aspects of the system are not neglected, which can reduce effectiveness of constructs used to create positive changes. 


\section{DEDICATION}

I dedicate this dissertation to my loving family and the friends who have supported me through the entire graduate school process. I would not have been able to accomplish all I have in my life without the love and support of my parents, Carol and Gerard Murphy. I would like to especially thank my twin sister, Jaclyn, who has completed her $\mathrm{PhD}$ in chemistry before I have completed my own in psychology. She has paved the way with invaluable advice concerning both graduate school and life, and I hope she is as proud of me as I am of her. Also, a special thank you to my younger brother, Denis, who has more world knowledge than I ever will and who has made me laugh through it all. 


\section{ACKNOWLEDGEMENTS}

I would like to thank my committee members: Eileen Brennan, Charlotte Fritz, Cynthia Mohr, and Donald Truxillo. It is with their thoughtful suggestions and their knowledgeable guidance that I was able to complete this dissertation. I would also like to express my sincere gratitude to Drs. Yueng-hsiang (Emily) Huang and Michelle Robertson at the Liberty Mutual Research Institute for Safety (LMRIS). It is their support that made this process a little smoother. It is also through the interdisciplinary environment of LMRIS and the particular interest of Dr. Robertson that I learned of macroergonomics as a way to improve safety by utilizing different aspects of the work system. Thank you, Dr. Todd Bodner of Portland State University and Jin Lee of the University of Connecticut, for being sounding boards for the statistical questions I had regarding moderated mediation in Amos. To Leslie Hammer, I especially offer my gratitude for her dedication as an advisor and mentor. It is because of the numerous opportunities she has presented me that I have been able to learn and improve as a researcher. 


\section{TABLE OF CONTENTS}

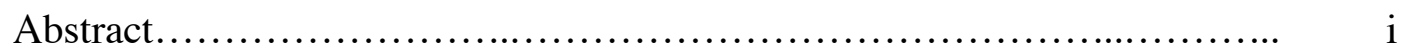

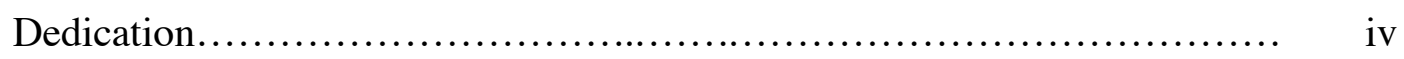

Acknowledgements................................................ $\quad \mathrm{v}$

List of Tables................................................... ix

List of Figures................................................. $\quad$ X

Chapter 1: Introduction.......................................... 1

Description of the Present Study .................................. 3

Contributions of the Present Study............................... 4

Chapter 2: Macroergonomics Approach............................... 11

Definition of Macroergonomics................................... 11

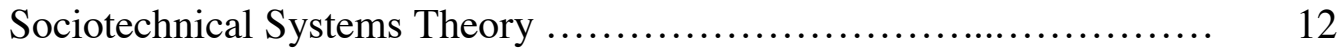

Resources Theories............................................... 17

Macroergonomics' Relevance to the Present Study....................... 20

Macroergonomics' Relevance to Organizational Psychology............ 21

Chapter 3: Work-family Conflict.................................... 23

Changing Nature of Work........................................ 24

Conceptualization of Work-family Conflict......................... 27

Theoretical Foundations of Work-family Conflict.................... 30

Chapter 4: Perceived Control over Work Hours........................ 34

Workplace Flexibility as a Proxy for Control...................... 34

Defining Control............................................. 35

Precise Measurement of Control.................................. 38

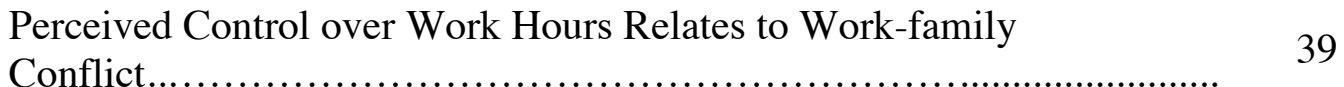

Chapter 5: Safety Performance.................................... 44

Conceptualization of Safety Performance........................... 45

A Systems Approach to Safety.................................. 48 
Antecedents of Safety Performance............................... 49

Work-family Conflict and Safety Performance........................ 52

Work-family Conflict Mediates the Relationship between Control and Safety.

Chapter 6: Supervisor Support.

Family-supportive Supervisor Behaviors (FSSB)....

Supervisor Support Buffers the Effects of Work-family Conflict on Safety Performance.

Support Moderates the Relationship between Work Hour Control and Work-family Conflict.....

Chapter 7: Organizational Context.

Characteristics of Grocery Stores and the Workers

Characteristics of Low-wage Workers...

Chapter 8: Method

Procedure

Participants.

Measures

Chapter 9: Results

Analytic Approach.

Preliminary Analyses.

Hypothesis Testing. 96

Additional Analyses

Summary of Results

Chapter 10: Discussion.

Direct Effects

Mediating and Moderating Relationships

Post Hoc Analyses.

Theoretical Implications.

Practical Implications.

Potential Limitations. 
Future Directions............................................. 125

Conclusion................................................... 129

References................................................... 151 


\section{LIST OF TABLES}

Table 1. Means, Standard Deviations, and Range of Continuous Demographic Variables..............................................

Table 2. Frequency of Categorical Demographic Variables................ 132

Table 3. Measures................................................. 134

Table 4. Means, Standard Deviations, and Range of Scale Variables......... 137

Table 5. Means, Standard Deviations, and Correlations.................... 138

Table 6. Comparison for Alternative Factor Structure Models for Work-

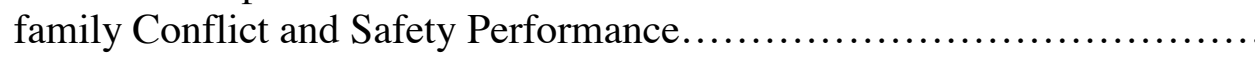

Table 7. Summary of Hypotheses...................................... 141

Table 8. Path Coefficients for Direct Effects, Indirect Effects, and 142

Moderations $\ldots \ldots \ldots \ldots \ldots \ldots \ldots \ldots \ldots \ldots \ldots \ldots \ldots \ldots \ldots \ldots \ldots \ldots \ldots \ldots \ldots \ldots \ldots \ldots \ldots \ldots$
Table 9. Path Coefficients for Additional FSSB Analyses in Comparison to Supervisor Instrumental Support......................................

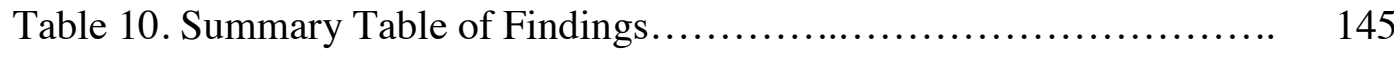




\section{LIST OF FIGURES}

Figure 1. Cullen and Hammer (2007) Model................................ 146

Figure 2. Conceptual Model............................................... 147

Figure 3. Structural Equation Model................................... 148

Figure 4. Hypothesized Model............................................. 149

Figure 5. Hypothesized Model Depicting Significant and Non-significant 150

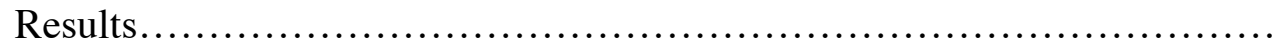




\section{Chapter 1: Introduction}

According to the Bureau of Labor Statistics (BLS, 2010b), there were more than 5,200 workforce fatalities in 2008. Additionally, the number of nonfatal workplace injuries and illnesses in the United States held at around four million cases each year from 2003 to 2007 (BLS, 2010a). While there was a decline to just under 3.7 million nonfatal workplace injuries and illnesses in 2008, such a large number of injuries and illnesses being suffered by workers is still of great concern. It is even more worrisome when one realizes that these numbers are not indicative of all workplace incidents. It has been demonstrated that the BLS undercounts the number of injuries associated with acute or chronic conditions (Probst, Brubaker, \& Barsotti, 2008; Rosenman et al., 2006). Also, an audit performed of workplace injuries reported to the Occupational Safety and Health Administration (OSHA) found that up to two thirds of all workplace injuries and illnesses are not reported by employees (U.S. Government Accountability Office, 2009). Employees may not report workplace safety incidents because of such reasons as loss of valuable incentives or fear of disciplinary actions (Beus, Payne, Bergman, \& Arthur, 2010).

The statistics regarding human suffering should be enough to engage researchers of all disciplines in this area of study. One would think industrial/organizational (I/O) researchers would be especially interested since there are additional direct and indirect costs associated with workplace safety incidents that are incurred by not only the affected employees but by their organizations as well (Barling, Loughlin, \& Kelloway, 2002;

Casillas, Robbins, McKinniss, Postlethwaite, \& Oh, 2009). Productivity is obviously 
affected when employees are absent from work because of injuries or illnesses. During 2008, U.S. employees missed almost 1.1 million days from work (BLS, 2010c). Other costs associated with occupational injuries and illnesses include lost wages, medical (e.g., worker's compensation) and administrative costs (e.g., work stoppages, labor turnover, and new worker hiring and training) for the organization, and possible property damage (Casillas et al., 2008; Yakovlev \& Sobel, 2010). The National Safety Council (2006) estimated that workplace injuries in the United States alone cost over \$140 billion annually.

The Occupational Safety and Health Act (OSH Act) of 1970 was put into effect "to assure safe and healthful working conditions for working men and women" (OSHA, 2010, "Introduction"). This is achieved by such provisions as: (a) having employers keep accurate records and reports regarding job-related injuries, illnesses, and deaths; (b) educating employers and their employees to recognize, avoid, and control possible unsafe or unhealthful work situations; and (c) developing workplace safety and health standards (Cohen \& Margolis, 1973). Cohen and Margolis (1973) revealed that specific provisions of the OSH Act recognize psychological issues, including the evaluation of job stressors that can potentially cause illness, disease, or loss of functional capacity in aging adults and psychological, behavioral, and motivational factors that can be included when examining ways to remedy worker safety and health problems.

Despite the recognition by the OSH Act of the importance of psychological issues in affecting workplace safety, it has been only recently that researchers in the fields of psychology and business have begun to examine the effects of the psychosocial 
environment on worker safety (Cullen \& Hammer, 2007). This research demonstrates that safety outcomes depend on more than just workers' compliance with safety rules and procedures (Cullen \& Hammer, 2007). It also includes such constructs as organizational safety climate (Zohar, 1980, 2000), supervisory support (Hofmann \& Morgeson, 1999), job insecurity (Probst \& Brubaker, 2001), and leadership style (Barling et al., 2002). By combining the human factors/ergonomics aspect of examining safety performance, which is the area where safety research was initially considered, and the psychosocial factors that the field of psychology examines, a systems approach can be used in order to attain a more comprehensive model that can be utilized by safety researchers.

\section{Description of the Present Study}

Work-family conflict is a stressor that can interrupt routine activities, causing missteps and leading to negative consequences (Cullen \& Hammer, 2007). The current study, based on the Cullen and Hammer (2007) model (depicted in Figure 1) in which safety performance was first examined in relation to work-family conflict, has been designed using psychological and ergonomic principles in order to construct an inclusive model that contains essential components of a system that complement each other to have the greatest impact on safety. Work-family conflict involves issues from the nonwork domain that can interfere during work and vice versa. It is created by occurrences in the external environment (i.e., the family/nonwork domain) and by occurrences in the work environment. In the field of $\mathrm{I} / \mathrm{O}$ psychology it is a well-studied construct that is of great importance given the changing nature of work (e.g., more dual-earner couples, a higher number of hours being worked, etc.). Work-family conflict is consistent with the 
macroergonomic definition of an external factor because work-family conflict can permeate an organization through individual workers and an organization must be responsive to it in order to be successful (Hendrick, 2002a). In the current model for this study, which is displayed in Figure 2, work-family conflict acts as the mediator between employees' perceived control over work hours and safety performance. Familysupportive supervisor behaviors (FSSB) are proposed to moderate at two points in the

model: the relationships between perceived control over work hours and work-to-family and family-to-work conflict and the relationships between work-to-family and family-towork conflict and safety compliance and participation.

\section{Contributions of the Present Study}

The goal of the present study is to enhance the conceptual model that links workfamily conflict to employee safety performance first conceptualized by Cullen and Hammer (2007) using a systems approach. They established that family-to-work conflict is associated with decreased safety compliance and decreased safety participation. In other words, individuals who experience disruptions at work as a result of family issues are less likely to follow safety rules and do not willingly participate in discretionary safety meetings because they experience higher levels of stress and have less cognitive ability to focus on safety. There are three ways this dissertation will try to accomplish the goal of enhancing our understanding of the work-family conflict - safety performance relationship. The first way is to examine supervisor instrumental support as a moderator of the already established work-family conflict - safety performance relationship. Researchers have theorized that work-family conflict transmits demands from one 
domain to another, and more resources must be devoted to the domain in which higher demands are present, leaving fewer resources to be used in other domains (Bakker, Demerouti, \& Dollard, 2008). If people have higher demands in their family lives like not having enough finances to spend on child care, these demands can deplete resources that are normally reserved for the work domain and a lack of resources is associated with emotional and physical exhaustion (Bakker, Demerouti, \& Euwema, 2005), which can negatively impact safety outcomes. General supervisor support has been found to play an imperative role in helping employees reduce their work-family conflict (Eby, Casper, Lockwood, Bordeaux, \& Brinley, 2005), with supervisor support theorized to be one aspect of the work system that can be used as a resource to reduce demands from the external environment. A strength of this study is the examination of support specifically geared toward work-family issues using a recently developed measure called familysupportive supervisor behaviors (FSSB; Hammer, Kossek, Anger, Bodner, \& Zimmerman, 2011; Hammer, Kossek, Yragui, Bodner, \& Hanson, 2009). Supervisors engaging in behaviors that make their employees aware of their concern and willingness to help when work-family issues arise is hypothesized to buffer the relationship between work-family conflict and safety performance.

A second way to enhance the Cullen and Hammer (2007) model is to examine family-supportive supervisor behaviors (FSSB) as a moderator of the relationship between perceived control over work hours and work-family conflict. This aspect of the overall model is examining the interactive effect of supervisor instrumental support and perceived control over work hours on work-family conflict. Both support and control are 
conceived as different aspects of the work system that contribute to a reduction in workfamily conflict (i.e., a transmission of demands between domains). The design of working times is a relevant topic studied in macroergonomics (International Ergonomics Association, 2000) that is pertinent to this dissertation because work hours can vary greatly in grocery stores, which can have major effects on employees' health, safety, productivity, and well-being. In past research, supervisor support has been examined more as a predictor of work-family conflict than it has as a moderator of the relationship between employee perceived control over work hours and work-family conflict.

A third way this study will contribute to the work-family conflict and safety performance relationship is to propose a macroergonomics model of work-family conflict and employee safety. The overall model has been conceived using the macroergonomics approach, which is a systems approach that utilizes organizational and management factors in order to improve the safety, health, and productivity of workers. Each aspect of the model was determined using sociotechnical systems theory, an integral part of macroergonomics, to ensure that all aspects of the work system are utilized to deal with demands that are interfering with important employee outcomes (e.g., safety compliance and safety participation).

A wide net was cast in order to extract pertinent information regarding the areas of work-family conflict and safety, including examining the psychology and ergonomics literatures. There is little research that has been conducted examining the influence of work-family conflict on safety performance. As a result, the present study is contributing to the work-family conflict and safety research areas in numerous ways. First, the impact 
of work-family conflict on safety outcomes is a new research area that has just begun to be explored. There are only two known studies that have examined the relationship between work-family conflict and safety performance (i.e., Cullen \& Hammer, 2007; Daniels, 2007). The present study will contribute evidence to strengthen the Cullen and Hammer (2007) model through the examination of supervisor instrumental support as a moderator that will buffer both the perceived control over work hours - work-family conflict relationships and the work-family conflict - safety performance relationships, leading overall to increased safety behaviors.

Second, the macroergonomics approach (Hendrick, 1997) is fairly new in the literature in general. Researchers examining the work-family interface have explained issues involving the interaction between the work and family domains using systems theories, such as Bronfenbrenner's ecological systems theory (1989). Such a systems theory is limited in the benefits it produces in that it does not identify specific aspects of the work environment that can be changed to increase positive interactions between the work and family domains. The macroergonomics approach, which applies sociotechnical systems theory, is applicable to I/O psychology given its focus on the work system as the core of the theory and its consideration of what changes can be made within the work system to create a safe and productive environment while contributing to employees' health and well-being.

Third, examining variables that influence the relationship between work-family conflict and its consequences is as important as focusing on the main effects of workfamily conflict (Allen, Herst, Bruck, \& Sutton, 2000). In the present study, employees' 
perception of control over work hours is being examined as a predictor of work-family conflict and supervisors' use of instrumental support is being examined as a moderator of the perceived control over work hours - work-family conflict relationships and the workfamily conflict - safety performance relationships. Studies examining predictors of workfamily conflict have been the most prevalent (Eby et al., 2005) and as Allen et al. (2000) stated, "middle-range" studies that explore "limited combinations of people and situations, including possible moderators such as organizational and personal characteristics, would be valuable" in the development of work-family conflict theory (p. 302). I have therefore taken the approach of examining a specific type of support as a moderator in addition to a specific type of control as a predictor of the work-family conflict relationships in the model in order to determine ways to alleviate negative effects on safety performance.

Fourth, low-wage workers are an underrepresented population in work-family research, and service workers are often overlooked in safety studies as researchers examine industries that involve high safety risks, such as chemical plants and construction. Yet a number of the top causes of serious workplace injuries each year, as identified by the 2010 Workplace Safety Index created by Liberty Mutual in collaboration with BLS and the National Academy of Social Insurance, are applicable to such low-wage positions as cashiers and stock people. In 2008, overexertion, which includes injuries related to holding, carrying, pushing, pulling, lifting, or throwing, was ranked number one and cost businesses $\$ 13.40$ billion in direct costs. Bodily reaction, ranked third, results from standing, sitting, slipping or tripping without falling, reaching, 
bending, or climbing and cost businesses $\$ 5.40$ billion. Repetitive motion injuries cost businesses $\$ 1.83$ billion. With over 40 million jobs (one in three) in the United States classified as low-wage jobs, and with a majority of low-wage workers employed in service industries (Acs \& Nichols, 2007), it is important to examine safety in regard to this large population.

In Chapter 2, the theoretical foundation for the model is discussed using the macroergonomics approach, which applies sociotechnical systems theory. Throughout the subsequent five chapters, empirical and theoretical arguments are made for the hypotheses. The conceptualization of work-family conflict and its corresponding empirical literature is examined in Chapter 3. In Chapter 4, literature pertaining to perceived control over work hours as a predictor of work-family conflict is reviewed. In Chapter 5, the conceptualization of safety performance using Borman and Motowidlo's (1993) two-component model of performance is discussed and relevant safety literature is reviewed. In Chapter 6, the general support literature is reviewed as a foundation to discuss the instrumental support component of family-supportive supervisor behaviors (FSSB). In Chapter 7, the organizational context, which includes the nature of grocery stores and the characteristics of grocery store workers and low-wage workers in general, is described in detail because type of industry plays a large role in the constructs being examined in the overall macroergonomics model of work-family conflict and employee safety. The research method is described in detail in Chapter 8 . The results of all the hypotheses will be reviewed in Chapter 9. Finally, I will finish with a discussion of the 
implications of the findings, potential limitations of the study, possible areas for future research, and a conclusion in Chapter 10 . 


\section{Chapter 2: Macroergonomics Approach}

\section{Definition of Macroergonomics}

Human factors and ergonomics $(\mathrm{HF} / \mathrm{E})$ is defined as "the scientific discipline concerned with the understanding of interactions among humans and other elements of a system, and the profession that applies theory, principles, data, and other methods to design in order to optimize human well-being and overall system performance” (International Ergonomics Association, 2000, "What is Ergonomics"). The goal of ergonomics is to improve the human condition, including productivity, safety, health, comfort, and quality of life (Hendrick, 2002a). A subdiscipline of ergonomics is macroergonomics, which consists of the analysis, design, and evaluation of work systems (Hendrick, 1997, 2002a; Hendrick \& Kleiner, 2001). Macroergonomics is based on a combination of industrial/organizational psychology, social psychology, and systems theory, and it focuses on the entire organization (Karwowski, Kantola, Rodrick, \& Salvendy, 2002; Zink, 2002).

Macroergonomics is a human-centered approach because it systematically considers workers' professional and psychosocial characteristics in the design of the work system. There has been too much focus on the technological imperative, which presents the idea that technology has a "compelling influence" on work structure and should therefore determine work system design (Baron \& Greenberg, 1990).

Macroergonomics moves beyond the technological imperative by determining ways to design the work system with employees in mind (Hendrick, 1997; Hendrick \& Kleiner, 2001; Hendrick, 2002a). The purpose is to produce a fully "harmonized" work system 
that improves numerous aspects of organizational performance and effectiveness (Hendrick, 2002a). A broad conceptualization through macroergonomics allows for the examination of accidents and injuries occurring as a result of the interface between workers and their environment (Imada, 2002). As Imada (2002) stated, “A more robust model acknowledges that accidents and human error have multiple causal factors that extend well beyond the scene of the event" (p. 151).

\section{Sociotechnical Systems Theory}

Theoretical strengths and weaknesses. Sociotechnical systems theory is utilized in macroergonomics and the key is to select a work system design that is compatible with both the characteristics of the relevant external environment and the psychosocial and skill characteristics of the workers, then to employ available technology that is congruent with each (Emery \& Trist, 1960). Although there have been criticisms made of sociotechnical systems theory, primarily because its propositions lack specificity and there have been few empirical tests and conceptual developments in the past two decades (Parker, Axtell, \& Turner, 2001; Parker \& Wall, 1998), the theory has informed past job design research (Friedlander \& Brown, 1974; Rousseau, 1977) and persists in presenting a meta-theoretical perspective that informs current job design research (Grant, Fried, \& Juillerat, 2010). Sociotechnical systems theory is most recognized for (Holman, Clegg, \& Waterson, 2002): (a) a set of design principles (Cherns, 1976, 1987), (b) a set of criteria for creating a well-designed job, and (c) the innovation of autonomous work groups (Emery, 1964). The design principles include: variances in work processes should be dealt with at the source; boundaries should not exist that hinder the sharing of 
information, knowledge, and learning; and methods of working should be minimally specified (Holman et al., 2002). A well-designed job consists of social support, recognition, some level of decision-making owned by front-line employees, opportunities for learning, and a reasonable level of demand (Holman et al., 2002). Given the metatheoretical perspective of the sociotechnical systems model, and concern over the criticisms discussed previously (Torraco, 2005), resource theories will be discussed to supplement the macroergonomics model of this dissertation. Sociotechnical systems theory creates the structure of the system by indicating the necessity of having social as well as technical components accounted for, but other theories are needed to explain the mechanism for how each system component interacts with or affects the others. In my model I will use the job demands-resources model and the conservation of resources theory to explain demands and resources as mechanisms specifying how each system component affects the others.

Taking context into consideration is very important in sociotechnical systems theory. There is also a growing recognition in the job design literature of the necessity of prescribing the best work characteristics to examine or change, given the context of the work environment, because there are no one-size-fits-all solutions (Morgeson, Dierdorff, \& Hmurovic, 2010; Parker et al., 2001). This has not always been the case, with dramatic changes in work context and job environments that have occurred over the past few decades being mostly neglected in the job design literature (Johns, 2006; Holman et al., 2002; Parker et al., 2001; Rousseau \& Fried, 2001). Examples of context, which are described by Johns (2006) as situational opportunities and constraints that affect 
behaviors and attitudes, include technology, social interactions and relationships, operational and environmental uncertainty, group norms and group characteristics, and information technology (Fried, Grant, Levi, Hadani, \& Slowik, 2007). Morgeson et al. (2010) proposed that occupational contexts emphasize different values, which likely shape the job characteristics common in specific occupations and the way individuals react to those job characteristics. Grant et al. (2010) suggested that researchers incorporate contextual changes by considering temporal characteristics of jobs, analyzing new social and knowledge characteristics of jobs, and exploring more macroscopic environmental variables as antecedents of job design and moderators of its effects.

Description of theory. Sociotechnical systems can range from a single individual using a hand tool to a multinational organization, but usually consists of two or more people interacting with some form of: (a) job design, (b) software and/or hardware, (c) internal environment, (d) external environment, and/or (e) organizational design that fit into the work system (Hendrick, 2002a). Job design consists of work modules, knowledge, tasks, skill requirements, opportunity for social interaction, and also factors from Hackman and Oldham's (1976) job characteristics model (i.e., meaningfulness obtained from skill variety and task identity, and autonomy and feedback). Software refers to management-based factors (i.e., policies/rules, procedures, manuals) and hardware is typically tools, equipment, machines, workspaces, and buildings (Robertson, 2002). The internal environment can be thought of as psychosocial factors, including cognitive complexity, and physical parameters (i.e., noise, temperature, air quality, humidity, illumination, and vibration). The external environment consists of elements 
that can permeate an organization and to which an organization must be responsive in order to be successful (Hendrick, 2002a). The degree of stability or change of cultural, economic, and political factors is particularly important for an organization to be aware of when it comes to the external environment. Organizational design is comprised of organizational structure and processes (Hendrick, 2002a).

The work system is composed of people in the form of a personnel subsystem (also referred to as a social subsystem) and technology in the form of a technological subsystem (also referred to as a technical subsystem). The personnel subsystem defines the ways individuals perform tasks and the technological subsystem defines the tasks to be performed (Hendrick, 2002a; Kleiner, 2008). More specifically, the technological subsystem is defined as "the techniques used by an organization or its subunits to transform inputs into outputs" (Billings, Klimoski, \& Breaugh, 1977, p. 319). The two subsystems interact with each other and are mutually interdependent. Macroergonomics diligently avoids a technology-driven approach by designing to support human capabilities, limitations, and other characteristics (Hendrick, 2002a). For example, if the technological subsystem became dominant, more work functions would be automated and the leftover functions would be given to workers, which suboptimizes the overall system.

A change in one of the sociotechnical characteristics will affect the other characteristics and impact the entire work system in unanticipated and suboptimal ways (Hendrick, 2002a). Appelbaum (1997) referred to these changes as "demands" in the system, and when a change in one subsystem occurs, that change must be accommodated 
by the other subsystems. Demands result particularly from external influences because organizations are embedded in "open sociotechnical systems" that must interact with the external environment (Appelbaum, 1997; Emery \& Trist, 1965). Along the same lines, work-family conflict is "a within-person across-domains transmission of demands and consequent strain from one area of life to another" (Bakker et al., 2008, p. 901).

Therefore, external environmental demands in the current study are framed as family and personal issues that spill over and interfere with work. These nonwork demands enter the work environment through the worker (e.g., Davis, 1982), and can influence what occurs within the work system. Cullen and Hammer (2007) found that when individuals' family lives negatively impact work (i.e., family-to-work conflict), their safety performance suffers as a result. Research completed utilizing sociotechnical systems theory has identified the interdependence of a person's work and nonwork lives (Spink, 1975). Examining external demands allows researchers to be in a better position to learn about the work system because demands that lie both inside and outside the work system can greatly affect what occurs within the system (Spink, 1975).

Emery and Trist (1965) suggested that detailed attention to both the social and technological systems is necessary to counter external demands, and they revealed that improving the technological subsystem alone does not always result in higher effectiveness and productivity. As Appelbaum (1997) explained, “...certain social systems are more apt at coping to meet these demands" (p. 458). Therefore, in order to deal with the demands of one subsystem, the other subsystems pool together "resources" so the entire work system returns to harmonization. Demands are explicitly discussed in 
macroergonomics, while resources, though not explicitly named, are an important part of macroergonomics as well. Resources, as defined by Voydanoff (2004), are "structural or psychological assets that may be used to facilitate performance, reduce demands or generate additional resources" (p. 398-399). In this dissertation, the resources chosen to counteract work-family conflict as a transmission of demands from one domain to another are supervisor instrumental support and perceived control over work hours. Both the personnel and technological subsystems are framed as a moderator and a predictor, respectively, that work as interacting resources within the work system to positively affect employees' work-family conflict.

\section{Resources Theories}

Holroyd and Lazarus (1982) defined psychological stress as "a judgment that environmental and/or internal demands tax or exceed the individual's resources for managing them" (p. 22). Stress depletes valuable resources, and not having enough resources makes it difficult to maneuver through the different types of environments that individuals encounter on a daily basis (i.e., work and home environments; Hofmann \& Stetzer, 1996).

The demand-control (DC) model (Karasek, 1979) has been heavily researched as a work stress model in occupational health psychology (de Lange, Taris, Kompier, Houtman, \& Bongers, 2003), and in relation to ergonomics, with mixed findings. The DC model posits that the combination of job demands and job control result in psychological strain, especially the combination of high job demands and low job control. Karasek and Theorell (1990) modified the DC model by adding support (from supervisors and 
colleagues) as a buffer between the effect of demand and control on outcomes to create the demand-control-(support) (DC/S) model (de Lange et al., 2003). Out of 45 studies that de Lange et al. (2003) deemed "high-quality" (i.e., longitudinal, length of time lags between study waves, quality of measures, statistical analysis, and nonresponse analysis), only 19 studies reported modest support for the DC/S model, which is similar to the findings of cross-sectional studies. Therefore, a more current model was chosen to explain the role of demands and resources in the relationships of this study.

The job demands-resources model defines job demands as "physical, social, or organizational aspects of the job that require sustained physical or mental effort and are therefore associated with certain physiological and psychological costs" (Demerouti, Bakker, Nachreiner, \& Schaufeli, 2001, p. 501). Job resources are defined as "physical, psychological, social, or organizational aspects of the job that may do any of the following: (a) be functional in achieving work goals; (b) reduce job demands in the associated physiological and psychological costs; (c) stimulate personal growth and development" (Demerouti et al., 2001, p. 501). Individuals are confronted with certain demands from their jobs that must be countered with available resources in order for them to be successful at work. Not having sufficient resources will lead to negative consequences (e.g., stress, emotional and/or physical exhaustion) as demands exceed what individuals can handle. The same is true for sociotechnical systems theory in that demands in the work system can cause a misalignment of the subsystems that creates a suboptimal work environment for employees. When the work environment is suboptimal, the following can be expected to be somewhat deficient: (a) adherence to safety 
standards and procedures that can result in lost time accidents and injuries; (b) quality; (c) productivity; and (d) motivation, job satisfaction, and perceived quality of work life (e.g., perceived stress, psychosocial comfort, etc; Hendrick, 2002a). In order to bring the work system back into alignment, resources from functioning subsystems are used to fix the subsystem(s) overwhelmed with demands.

The job demands-resources model fails to acknowledge that demands and resources are also found outside the work environment, which can subsequently impact job performance. Hobfoll $(1989,1998,2001)$ proposed through the conservation of resources $(\mathrm{COR})$ theory that people try to acquire, maintain, and protect resources. More specifically, COR theory deals with people's innate and learned desires to conserve the quality and quantity of their resources and to avoid any circumstance that may risk those resources (Hobfoll, 1988). As will be made apparent, COR theory can be used to explain the depletion of resources in work-family relationships. It can also be used to explain the replenishment of resources through perceived control over work hours and supervisor instrumental support during work.

Resources are valued objects, personal characteristics, conditions, or energies (Hobfoll, 1989). They can be external to the person, such as financial assets, or internally possessed, such as personality traits. Objects have a direct use or they convey status, such as food or a nice car, respectively. Personal characteristics, like self-esteem, are valued because they aid stress resistance. Conditions are resources to the extent that they are desired, such as tenure and marriage. Energies, such as time, money, and knowledge, help people gain other resources. 
Resources can be found in both work and nonwork domains. For example, conditions like tenure and marital status are coveted work and family resources, respectively (Grandey \& Cropanzano, 1999). Individuals are compelled to protect their resources from three possible circumstances: (a) when resources are threatened, (b) when resources are lost, or (c) when individuals do not receive the results they expected after investing their resources (Hobfoll, 1989). Resources can be threatened or depleted by such things as stress, ill health, decreased well-being, or even an unfavorable work environment (Hobfoll, 1998). As a consequence of the loss of certain resources, additional resources are then needed in order to: (a) regain what has been lost to improve personal situations and (b) gain new resources to avoid future distress. When daily distress threatens resources, it usually leads to the loss of internal resources, such as positive mood and energy (Sonnentag, 2001). If individuals do not attempt to protect or replace their resources, they can experience such negative consequences as burnout (Grandey \& Cropanzano, 1999; Shirom, 2003).

\section{Macroergonomics' Relevance to the Present Study}

The technological subsystem can be mistaken for aspects relating strictly to "technology," but technological (or technical) refers to "non-human," which includes structural aspects of work (Trist, 1981). Dimensions of technology that are strongly related to work characteristics include autonomy, skill variety, and task significance (Brass, 1985; Morgeson et al., 2010). Work hours are a component of any given work environment that varies depending on the job type and the schedule of individual employees. 
A key component of the personnel subsystem is management, and there is a growing body of research concerning the influence of supervisors in both the workfamily and safety literatures (Allen, 2001; Zohar, 2003). Supervisor instrumental support is imperative because even if an organization provides its employees with the ways and means of controlling their own work hours or other ways to alleviate their work-family conflict, employees will not be able to take full advantage of such policies or options if their direct supervisors, whom employees interact with on a daily basis and receive rewards and punishments from, do not give their full consent and assistance.

Having control as a component of the technological subsystem and support as a component of the personnel subsystem is more likely to reduce the demands in the system because the subsystems complement each other and work together to create a positive change. As Hendrick (2002a) stated, “This harmonization enables the likelihood of optimal system functioning and effectiveness, including productivity, quality, system safety, and employee psychosocial comfort, health, intrinsic motivation, commitment, and perceived high quality of work life" (p. 19).

\section{Macroergonomics' Relevance to Organizational Psychology}

While organizational psychology has such objectives as improving motivation and job satisfaction, enhancing organizational climate and leadership, and fostering teamwork, macroergonomics primarily seeks to design work systems that are compatible with an organization's sociotechnical system characteristics and "then to ensure that micro-ergonomic elements are designed to harmonize with the overall work system structure and processes" (Hendrick, 2002a, p. 5). The macroergonomics model of work- 
family conflict and employee safety has been conceptualized to determine which elements found in the subsystems of the work system have a large positive impact on employee safety. Once it is determined which elements will fit the employees' needs, then technology can be brought in as a way to enhance those elements and optimize the system without disregarding those needs.

I next turn to a discussion of work-family conflict as a key individual factor that can enter the work system and disrupt safety performance. 


\section{Chapter 3: Work-family Conflict}

Nomaguchi (2009) analyzed two national surveys and found that work-family conflict had increased among employed parents from 1977 to 1997. This may be due, in part, to workers experiencing changes in their families, with more extensive caregiving responsibilities for children (Cohen \& Bianchi, 1999) and elderly relatives (National Alliance for Caregiving and American Association of Retired Persons, 2004). Also, the number of stereotypical nuclear families with two parents, a female homemaker and a male breadwinner, and two children has been steadily dwindling over the past decade while the number of other types of families (e.g., dual-earner couples, divorced parents with joint custody, gay and lesbian families, single parents, and stepfamilies) has increased (Bianchi \& Milkie, 2010). Research has estimated that $85 \%$ of employees have some day-to-day family responsibility (Bond, Galinsky, \& Swanberg, 1998). Employees have also been experiencing higher demands for their time from work organizations while receiving less in terms of wage growth, benefits, and job security (Moen \& Roehling, 2005; Rubin \& Brody, 2005). Consequently, the allocation of time to paid and unpaid work has become more similar among men and women, with the gender gap in unpaid work (i.e., child care, cooking, cleaning) narrowing considerably (Sayer, 2005). This is linked to the problem of too many hours being worked by all adults in the family and the inflexibility in work hours for some employees, which leaves insufficient time and energy for family life (Bianchi \& Milkie, 2010; Jacobs \& Gerson, 2004). There are other trends, such as increased labor force participation, higher education levels for women, and more time pressure on the job, that are linked to higher levels of work- 
family conflict (Bianchi \& Milkie, 2010). Experiencing work-family conflict can be intense for those who are subjected to it (Blair-Loy, 2003), especially since the structures of work and family are hard to change, particularly for lower income couples (Bianchi \& Milkie, 2010).

This chapter begins with a review of the changing nature of work, considering what was expected of employees in the past and what is expected of them now. These changes are important to explore because they not only alter the way people work, but they also alter the way people operate in the family/nonwork domain. Such changes lead employees to expect more from their organizations in terms of control and support for integrating these different domains. I will then review the concept of work-family conflict and discuss the theoretical foundations that have been utilized in the past to explain connections between the work and family domains. Comparisons and distinctions will be made between ecological systems theory and sociotechnical systems theory to explain that there are other theories to explore to help determine effective ways to reduce work-family conflict when things like the work environment and family composition are changing and technology is rapidly developing.

\section{Changing Nature of Work}

The industrial era was characterized by the automation of work tasks, which alienated workers to the point that they felt separated from their tasks, from the results of the tasks being completed, and from other employees (Bradley, 2002). During this era, work was primarily a way to earn money (Bradley, 2002). Every decade after the industrial revolution has had distinctive defining characteristics. For example, the 1960s 
were defined by innovation and challenging the established norm; the 1970s were defined by conflict between employee and employer and industrial strife; the 1980s were defined by the enterprise culture with privatizations, strategic alliances, etc.; and the 1990s were defined by the short-term contract culture with outsourcing, a "flexible workforce," long working hours, and globalization (Cooper, 1998).

As a continuation of what occurred in the 1990s, and with the growth of a 24/7 economy (Presser, 2003), today's employees are required to work longer hours across many occupations (Bluestone \& Rose, 1998; Rones, Ilg, \& Gardner, 1997), work at a faster pace, and meet tighter deadlines (National Research Council, 2004). This may lead to inflexibility in work hours that leaves insufficient time and energy for family life (Jacobs \& Gerson, 2004). Despite the increase in requirements, job tenure and job stability have been declining for many workers (Cooper, 1999; Neumark, Polsky, \& Hansen, 1997; Sauter et al., 2002). Related to declining job tenure and job security, changes seen today include companies that have been restructured because of economic changes and this has led to: (a) a reliance on nontraditional employment practices that include temporary workers and contractor-supplied labor, with the rate of job growth in the temporary help industry far exceeding the rate of overall job growth (CRS, 1999); (b) downsized workforces; and (c) adoption of more flexible and lean production technologies (Sauter et al., 2002). Given that there are more flexible work processes and fewer repetitive and/or physically strenuous jobs, which are attributed to the decline of manufacturing jobs and the rise of service and knowledge work, higher qualifications are being demanded (Sauter et al., 2002). Such changes have led to increased responsibility, 
more learning opportunities, and increased flexibility afforded to some employees in many jobs that allow them to perform work when and where they desire (Schieman, Milkie, \& Glavin, 2009). These are seen as positive developments that may lead to improved satisfaction and well-being (Sauter et al., 2002). Another positive aspect of the changing nature of work is that more women, older workers, and ethnic minorities are becoming workers in today's society (Sauter et al., 2002).

Changes today also include rapid technology development that influences many aspects of the work environment. Software programs are being sold throughout the world that allow work tasks to be carried out in the same way (Bradley, 2002). Organizations are building electronic networks that lead to: (a) reallocation of power in the organization (i.e., organizations are becoming flatter so that there are fewer levels in the hierarchy), (b) direct communication between the different levels of an organization, (c) barriers disappearing between an idea and its execution, (d) continuous change of structure and roles, and (e) openness to the surrounding world (Bradley, 2002). The changing nature of work also entails a steady increase in telecommuting (i.e., working from home; Bureau of the Census, 1998). As an example of the differential impact technology can have on workers, telecommuting has been found to decrease work-tofamily conflict (Golden, Veiga, \& Simsek, 2006) while also increasing family-to-work conflict (Golden et al., 2006) and feelings of social isolation because of decreased social interactions with coworkers and supervisors (Cooper \& Kurland, 2002; Pool, 1990).

There is a decrease in permanent, full-time employees who are at the core of an organization with a wide range of benefits and employment rights (Bradley, 2002). The 
peripheral workforce consists of part-time workers, contract workers, outsourced workers, self-employed consultants, and temporary and agency employees (Barnatt, 1997). These peripheral employees are "free agents" in that they are responsible for their own security, skills development, and personal marketing. They are considered strong workers when they are in good health and are experiencing good times, but they are in a high-risk situation if they experience health and family problems that can reduce their energy and motivation (Bradley, 2002). Part-time workers compose a considerable percentage (i.e., 30\%) of the grocery store industry, $48 \%$ of this study's sample, and like grocery store employees in general, they have special considerations concerning the interaction of their work and family lives that need to be taken into account. These considerations will be discussed in depth when I describe the current study's participants.

\section{Conceptualization of Work-family Conflict}

Work-family conflict is a role demand, specifically it is a role conflict. Greenhaus and Beutell (1985) defined work-family conflict as "a form of interrole conflict in which the role pressures from work and family domains are mutually incompatible in some respect" (p. 77). According to role theory, everyone has different roles in their lives, with roles being defined as sets of perceived expectations about people's behavior. Some roles are self-defined by people from their own expectations and based on past experiences.

Other roles are "negotiated" through people's social interactions with others in their lives. Multiple roles can create demands on people when there are not enough resources or time to do everything that needs to be done in each role. 
Studies examining work-family conflict in the 1980 s conceptualized it as a unidimensional construct (e.g., Bedeian, Burke, \& Moffett, 1988; Cooke \& Rousseau, 1984; Kopelman, Greenhaus, \& Connolly, 1983). The current operational definition of work-family conflict is consistent with Frone, Russell, and Cooper's (1992) bi-directional conceptualization: work-to-family conflict is the interference of the work domain with the family domain and family-to-work conflict is the interference of the family domain with the work domain. Meta-analyses of the work-family literature find that measures clearly specifying both directions perform better than general measures that combine work-to-family and family-to-work conflict into a global scale (Allen et al., 2000; Kossek \& Ozeki, 1998). The antecedents of work-to-family conflict include job stressors and job involvement and the antecedents of family-to-work conflict include family stressors and family involvement (Greenhaus \& Beutell, 1985; Frone et al., 1992).

There are three sources of work-family conflict: time, strain, and behavior (Greenhaus \& Beutell, 1985). Time-based conflict occurs when time pressures in one role limit the amount of time an individual has to allocate to another role. Antecedents of time-based conflict include inflexible work schedules, the number of hours worked per week, and the number and age of dependent children living at home (Greenhaus \& Beutell, 1985). Strain-based conflict occurs when strain in one role affects an individual's successful performance of role responsibilities in another role. Poor supervisor support, role ambiguity, absence of spousal or familial support, and family disagreements regarding gender roles are examples of strain-based conflict (Hammer, Kossek, Zimmerman, \& Daniels, 2007). Behavior-based conflict occurs when behavioral patterns 
in one role are incompatible with behavioral patterns in another role, and it is the least studied form of conflict. Individuals who experience negative consequences as a result of not meeting role demands will then experience stress (Greenhaus \& Beutell, 1985).

When investigating individual outcomes, work-family conflict negatively affects well-being (Hammer, Cullen, Neal, Sinclair, \& Shafiro, 2005) and life satisfaction (Duxbury \& Higgins, 1991), while increasing depression (Hammer et al., 2005; Major, Klein, \& Ehrhart, 2002), alcohol use (Frone, Russell, \& Cooper, 1993), and psychological strain (Barling, MacEwen, Kelloway, \& Higginbottom, 1994). Regarding the family domain, research has found that work-family conflict negatively affects family well-being (Parasuraman, Greenhaus, \& Granrose, 1992), marital well-being (MacEwen \& Barling, 1994), and family performance (Frone, Yardley, \& Markel, 1997). Research has shown that, with regard to the work domain, work-family conflict increases absenteeism (Hammer, Bauer, \& Grandey, 2003), work distress (Frone et al., 1992), and burnout (Burke, 1994) while negatively affecting job performance (Frone et al., 1997), job satisfaction, and organizational commitment (Netemeyer, Boles, \& McMurrian, 1996; Good, Sisler, \& Gentry, 1988).

A majority of work-family conflict research conducted from 2000 to 2010 has examined work-family conflict as a dependent variable predicted by occupational conditions (Bianchi \& Milkie, 2010). While research has also shown that work-to-family conflict typically arises from work conditions and family-to-work conflict typically arises from nonwork conditions, Byron (2005) showed in her meta-analysis that some work and family factors have "simultaneously disruptive effects" within both the work and family 
domains (p. 190). Work-family conflict has also been increasingly used as a moderator or mediator variable in studies investigating relationships among work conditions, family experiences, and well-being (Bianchi \& Milkie, 2010; Hammer et al., 2011). This is in line with this study's examination of work-family conflict as a mediator between perceived control over work hours and safety performance.

\section{Theoretical Foundations of Work-family Conflict}

Most of the theoretical work developed in work-family conflict research follows a role conflict orientation (Bianchi \& Milkie, 2010), as discussed when work-family conflict was defined. The following two theories discussed in relation to work-family conflict are utilized in this dissertation. The job demands-resources perspective, which is linked to role theory, has been used to examine occupational conditions that either solve problems (i.e., job resources used to promote work-family balance) or contribute to difficulties (i.e., job demands that interfere with family life; Bianchi \& Milkie, 2010; Demerouti et al., 2001). Also related to resources, Grandey and Cropanzano (1999) advocated for COR theory to be utilized in work-family research. The daily stress of work-to-family conflict can deplete people's energy or time resources if an individual works overtime, brings work home to finish, or thinks about work-related issues at home in order to get ahead for the next day (Hobfoll \& Shirom, 2001). Zohar, Tzischinski, and Epstein (2003) found that dealing with situational constraints or time pressures at work caused individuals to feel fatigued at home, which resulted in reduced internal resources. Other research has shown that unpredictable work routines like work variability (e.g., working weekends, rotating shifts, working a greater number of hours, or working longer 
days) are associated with higher work-family conflict (Carlson \& Perrewe, 1999; Fox \& Dwyer, 1999). Family-to-work conflict can occur when family issues, like child care or relationship problems, draw on a person's valuable resources and then those depleted resources create work problems.

Border and boundary theories examine the flexibility and permeability between two spheres (e.g., work and family; Ashforth, Kreiner, \& Fugate, 2000; Clark, 2000). The gender perspective evaluates the meanings men and women attach to work and family life and the ways their ideologies contribute to the types and levels of conflict experienced. The broader approaches of the life course perspective (e.g., Becker \& Moen, 1999) and ecological systems theory (e.g., Bronfenbrenner, 1989; Voydanoff, 2005) both recognize the complexities of the intersection of work and family across individuals' and families' life courses (Bianchi \& Milkie, 2010).

Ecological systems theory, as a popular systems theory utilized in work-family conflict research, follows two important propositions (Bronfenbrenner, 1989). The first proposition is that human development occurs "through processes of progressively more complex reciprocal interaction between an active, evolving biopsychological human organism and the persons, objects, and symbols in its immediate environment," which are labeled as proximal processes (Bronfenbrenner, 1994, p. 38). The second proposition is that "the form, power, content, and direction of the proximal processes effecting development vary systematically as a joint function of the characteristics of the developing person; of the environment-both immediate and more remote-in which the processes are taking place; and the nature of the developmental outcomes under 
consideration" (Bronfenbrenner, 1994, p. 38). Proximal processes function to create and maintain development, and they are the key to ecological systems theory (Bronfenbrenner, 1989). Put more succinctly, the characteristics of an individual interact with his/her environment, and systems overlap through inputs, processes, outputs, and feedback loops that occur via an individual's active engagement in the different domains (Hill et al., 2008).

Regarding the structure of the systems in Bronfenbrenner's theory, a microsystem is an immediate face-to-face setting that consists of a pattern of interpersonal relationships, social roles, and activities experienced by an individual (Bronfenbrenner, 1994). A mesosystem is a system of microsystems. An exosystem consists of the linkages and processes occurring between two or more systems, with at least one system that does not contain the individual but that contains events that indirectly influence proximal processes in the immediate environment (Bronfenbrenner, 1994). A macrosystem consists of an overarching pattern of micro-, meso-, and exosystems that is characteristic of a particular culture. A chronosystem comprises consistency or change over time that is characteristic not only of the individual, but of the environment (e.g., changes in family structure, socioeconomic status, employment, or place of residence; Bronfenbrenner, 1994).

While ecological systems theory focuses on the development and characteristics of an individual, sociotechnical systems theory focuses on work factors that are central to I/O psychology. Sociotechnical systems theory is concerned with the synergy among work subsystems; the interaction of subsystems (i.e., personnel, technological, and 
external) occurs with one subsystem not more important than any other. The subsystems each have distinct characteristics that can be attended to in research models. Ecological systems theory is also concerned with interactions, but the focus is on the individual interacting with his/her immediate environment (i.e., microsystems) without distinguishing among different factors that can affect an individual in his/her immediate environment.

In the next chapter, I will be considering perceived control over work hours as a work design variable in the work system; control over work hours is perceived by employees given the environment in which they work. I will provide a rationale for examining the perception of control over work hours in lieu of other control/autonomy variables that have been used in past research. Then I will review past research that has examined control as an antecedent of work-family conflict. 


\section{Chapter 4: Perceived Control over Work Hours}

Control regarding one's time, instead of control over specific tasks at work, has not been given much attention in the work-family literature (Kelly \& Moen, 2007). Yet, it is important to examine different forms of control because, as Thompson and Prottas (2005) stated, "If employees have control over their jobs, it seems likely that they would, in turn, have more control over other aspects of their lives" (p. 104). To date, much of the literature examining control involves professional occupations where a greater number of flexibility options, such as where to work, may be more suitable than they would be for other types of jobs such as low-wage jobs (Grawitch \& Barber, 2010). For example, telecommuting is not appropriate for all types of workers because not all workers (e.g., cashiers) are able to perform their jobs away from their work environment (e.g., grocery stores). It is therefore important to tease apart different aspects of control to determine which are suitable for certain industries.

\section{Workplace Flexibility as a Proxy for Control}

I will briefly discuss what workplace flexibility is before discussing control over work hours specifically. I will do this in order to establish that flexibility and control are similar constructs and that it is appropriate for me to use the workplace flexibility literature to hypothesize that perceived control over hours is an antecedent of workfamily conflict. In fact, Eaton (2003) uses control and autonomy as interchangeable components of flexibility on the job. This will be in addition to the use of autonomy in the job design literature to inform the hypotheses of this dissertation. Workplace flexibility is a broad term that has been conceptualized in numerous ways (Hill et al., 
2008), which necessitates a more careful examination of the literature in order to tease apart results specifically regarding control over when work is done and not where work is done. Hill et al. (2008) defined workplace flexibility as "the ability of workers to make choices influencing when, where, and for how long they engage in work-related tasks" (p. 152).

\section{Defining Control}

Control in the work-family literature. I first examined the work-family literature in which control has been extensively investigated. Generally, Thomas and Ganster (1995) defined control as "the belief that one can exert some influence over the environment, either directly or indirectly, so that the environment becomes more rewarding or less threatening" (p. 7). Control can be framed as a resource provided by the work system to reduce internal and external demands placed on employees, leading to lower work-family conflict. As Kelly and Moen (2007) stated, job control is an often studied variable that pertains to employees' control over how their work is done and is measured using skill discretion and decision-making authority (e.g., Karasek, 1979; Karasek \& Theorell, 1990). That is the reason why autonomy to decide how one performs his/her own work is most often associated with work/family balance (Clark, 2001). On the other hand, Kelly and Moen (2007) described schedule control as an ability to determine when and where one works. It is a complementary dimension of job control given that schedule control focuses on the "time and timing of work" whereas job control does not (Kelly \& Moen, 2007). 
Control as a job design variable. I also considered the job design literature important to examine in terms of autonomy because more job design research needs to be incorporated into work-family research as most jobs are designed without consideration of employees' family needs and with the expectation that employees arrange their lives around work (Kossek, 2005). Also, autonomy is one of the most widely researched work characteristics (Johns, 2006; Morgeson \& Humphrey, 2006). It has held a central position in most models of work organization and occupational health (Bond, Flaxman, \& Bunce, 2008), including the job characteristics model (Hackman \& Oldham, 1976), sociotechnical systems theory (Emery \& Trist, 1960), action theory (Frese \& Zapf, 1994), and the demands-control model (Karasek, 1979). Originally regarded as the amount of freedom and independence an individual has to carry out his/her work assignments (Hackman \& Oldham, 1975), recent research has expanded the conceptualization of autonomy to include the extent to which a job allows freedom, independence, and discretion to schedule work, choose the methods to perform tasks, and make decisions (Morgeson \& Humphrey, 2006). Examining autonomy as a one-dimensional construct may obscure important information given that autonomy has multiple facets with unique predictive qualities (Breaugh, 1985; Humphrey, Nahrgang, \& Morgeon, 2007; Morgeon \& Humphrey, 2006). More specifically, autonomy has been conceptualized as: (a) work scheduling autonomy, which is an individual's freedom to control the scheduling and timing of work; (b) decision-making autonomy, which is an individual's freedom to make decisions at work; and (c) work methods autonomy, which is an individual's freedom to control which methods and procedures to use (Jackson, Wall, Martin, \& Davids, 1993). 
Examining perceived control over work hours as a job design construct is advantageous in conjunction with the overarching theory of macroergonomics because Grant et al. (2010) anticipate that job design researchers will need "to pay close attention to context (Johns, 2006) to capture the organizational, occupational, social, environmental, and technological opportunities and constraints that affect how jobs are designed, enacted, and experienced" (p. 442). In fact, the job characteristics model (JCM), which is one of the most widely utilized models in the job design literature that includes only a subset of job characteristics, has been expanded by Parker et al. (2001) to better capture technological and social developments in the workplace (Grant \& Parker, 2009). The elaborated JCM includes not only core task characteristics described by the original JCM, but also physical characteristics (e.g., ergonomics, work conditions, physical demands, and equipment use) and knowledge characteristics (e.g., problemsolving, job complexity, information processing, and specialization; Morgeson \& Campion, 2003; Morgeson \& Humphrey, 2006).

Job design research is valuable to the work-family literature because employees' ability to integrate work and family is impacted by the job itself and not just personal and environmental factors (Perlow, 2001). For example, employees would be better able to deal with conflicting work and nonwork demands if they had autonomy and discretion in determining when, where, and how their jobs get done (Bailyn, 1993; Clark, 2001;

Thompson \& Prottas, 2005). A combination of elements, which includes work design, family-supportive benefits and human resources incentives, are necessary for organizations to include in their strategy to reduce employees' work-family conflict (Batt 
\& Valcour, 2003). Yet, work-family research has not fully utilized job design as a key approach to minimize work-family conflict (Thompson \& Prottas, 2005). Given this gap in the work-family literature, research integrating macroergonomic principles, which include job design variables like employee control and the idea that subsystems are not stand-alone aspects of the system because changing one impacts all the others, would improve the research area. We can move closer to finding the different elements needed (e.g., supervisor support) to buffer the relationship between employee control and workfamily conflict.

\section{Precise Measurement of Control}

The current study is focusing on only when one works, measured using items that refer to the perception of control an employee has to decide when to take breaks and when to schedule work hours, which can vary considerably for grocery store workers because new schedules are created every week or month (Richman, Johnson, \& Buxbaum, 2006). It is important to focus on one specific aspect of control because, as Shockley and Allen (2007) stated, "Precise definition and measurement [of both work-tofamily and family-to-work conflict and flexible work arrangements] are essential to better understanding these complex relationships" (p. 490). Byron (2005) also emphasized the importance of examining "more finely-grained variables that may more fully capture employees' likelihood of experiencing work-family conflict”' (p. 194).

Precise measurement of control is also necessary because, as Hill et al. (2008) pointed out, few organizational situations allow employees to have total control over defining their work environments. Constraints related to the nature of the job, availability 
of technology, and the needs of the organization prevent total employee flexibility. Since the utilization of flexible work options is more advantageous in some occupations than others, flexibility should be considered on a continuum and not a dichotomy of flexible or not flexible (Hill et al., 2008). Examining perceived control over work hours is important in this particular study because much of the work in a grocery store must be done in the store and not while off-site. Also, most of the positions held by grocery store workers are customer-service oriented, and workers need to be available to customers during store hours, which are long. Examining perceived control over work hours alone will also allow for the full impact of the variable to be established on work-family conflict without being confounded by other types of control that may not have any effects because they are not available to the participants.

\section{Perceived Control over Work Hours Relates to Work-family Conflict}

Kelly and Moen (2007) presented a conceptual model that postulates perceived schedule control predicts enacted schedule control, which relates to work-family conflict, with work-family conflict then directly predicting work, health, and well-being outcomes. This specific model has yet to be empirically tested, and only a few studies have empirically tested variations of control over work hours relating to work-family conflict. I will first examine those studies and then, given that most research concerning job autonomy does not pertain specifically to control over work hours (Kelly \& Moen, 2007),

I will use the flexibility literature in order to hypothesize that perceived control over work hours is related to work-family conflict. 
Control over time. Clark (2001) labeled discretion in one's work schedule as temporal flexibility, and measured it with five items concerning the flexibility employees have for both when and where they work. Even with the label "temporal flexibility," Clark (2001) did not assess only the timing of one's work, but also the location (i.e., home) where work is done. When temporal flexibility was entered into the same regression equation as "operational flexibility," which is the autonomy an employee has to decide how s/he completes his/her work, operational flexibility explained most of the variance in work/family balance. Yet Clark (2001) believed there are "additional work and family characteristics that determine when flexibility is functional," and they need to be studied further in order to establish the conditions in which temporal flexibility is valuable (p. 362).

Geurts, Beckers, Taris, Kompier, and Smulders (2009) separated worktime control into two variables: leave control and flextime. Leave control was defined as employee control over when to take days off and vacation time. Flextime was defined as employee control over when to start and stop working days. They found that leave control was negatively related to work-family interference, whereas flextime was not. The issue with this study is that work-family interference was measured using one item (i.e., "Do you let pass or neglect family activities because of your job?") related to workto-family conflict.

Flexibility. In her meta-analysis, Byron (2005) found the relationship between schedule flexibility (i.e., giving employees control over their schedule) and work-tofamily conflict had an effect size of -.30 and the relationship between schedule flexibility 
and family-to-work conflict had an effect size of -.17. Yet, schedule flexibility was not formally defined and there was no differentiation between when or where work takes place. Also, several other recent meta-analyses have shown that work flexibility is associated with reduced work-family conflict (Allen \& Shockley, 2009; Mesmer-Magnus \& Viswesvaran, 2006). Jones et al. (2008) found that perceived workplace flexibility and not actual use of workplace flexibility was associated with work-family fit. Hill, Erickson, Holmes, and Ferris (2010) found that perceived schedule flexibility, measuring employee perception of the amount of control employees have over when they work (i.e., scheduling hours, time of day, etc.), was a stronger predictor of work-family conflict than work-at-home (i.e., a formal arrangement defined as working from home a majority of the time).

Golden and Wiens-Tuers (2006) found that workers who were forced to work overtime, which is a lack of control over work hours, experienced work-to-family conflict at twice the rate as workers who worked overtime voluntarily. Kelloway and Gottlieb (1998) examined the effects alternative work arrangements have on women's well-being and found that flexible schedules, part-time work, and job sharing reduced stress, increased employees' sense of competence at home, and improved morale only when their workload was reduced and they had a greater sense of control over their time. From this study, it is apparent that control over work schedules is a resource only when employees perceive the demands they were experiencing to be minimized as a result of increased control. When individuals are able to go to medical appointments or be at home with their children after school as a result of being able to work schedules they have 
helped create, the demand of having to be at work during specific times determined by supervisors is lessened. Also, there is less room for work-family conflict to manifest itself if employees are meeting the demands of both the work domain and the home domain by using control over work hours as a resource to counter those demands. Therefore, it is hypothesized that perceived control over work hours is related to work-to-family and family-to-work conflict.

Hypothesis 1a: Perceived control over work hours and work-to-family conflict will exhibit a negative, direct relationship.

Hypothesis $1 b$ : Perceived control over work hours and family-to-work conflict will exhibit a negative, direct relationship.

I will move on from this discussion that contends perceived control over work hours is an antecedent of work-family conflict to a discussion that considers work-family conflict as a safety hazard that can influence safety performance. I will first discuss the conceptualization of safety performance. Next I will explain the importance of considering a systems approach in safety research. Then I will examine antecedents of safety performance in general and build the argument for why work-family conflict negatively impacts safety compliance and safety participation. With the work-family conflict - safety performance relationships established, I will return to perceived control over work hours as a distal antecedent of safety performance, with work-family conflict acting as a mediator between perceived control over work hours and safety performance. I will then discuss the important role supervisors play in workplace safety that will lead 
to a discussion of supervisor instrumental support as an important buffer of stressor-strain relationships. 


\section{Chapter 5: Safety Performance}

The term safety performance has not been consistently used in the literature, which is problematic when comparing results across studies (Christian, Bradley, Wallace, \& Burke, 2009). Safety performance can refer to a metric for employees' safety-related behaviors (Griffin \& Neal, 2000), as I use it in this dissertation. Researchers have also used the term to refer to an organizational metric for safety outcomes that are tangible events or results like accidents and injuries (Christian et al., 2009). Safety performance is important in the psychological safety literature because safety performance is a measurable criterion that is more proximally related to psychological factors than accidents or injuries (Christian et al., 2009). An additional benefit of safety performance over objective safety outcomes is that researchers can predict safety performance behaviors with greater accuracy because objective safety outcomes often have a low base rate and skewed distributions (Christian et al., 2009; Zohar, 2000). Likewise, individuals may underreport their subjective accident and injury data because of the social desirability bias (Christian et al., 2009). Therefore, it is important to distinguish between safety-related behaviors and the outcomes of those behaviors because antecedents may affect each differently (Christian et al., 2009).

The present study is based on Cullen and Hammer's (2007) model, with workfamily conflict being an antecedent of decreased safety performance, to determine which aspects of the system need to be changed in order to reduce the negative effects of workfamily conflict on safety behavior. This chapter begins with an explanation of the conceptualization of safety performance using Borman and Motowidlo's (1993) two- 
component framework. I will continue with an explanation as to why a systems perspective is important in safety research. A summary of empirical research that has investigated the antecedents of safety performance will follow as a way to indicate that there is a lack of research examining nonwork influences on safety, such as work-family conflict. I will then argue that work-family conflict is a predictor of safety performance and a mediator of the perceived control over work hours - safety performance relationships.

\section{Conceptualization of Safety Performance}

Safety performance is comprised of two components: safety compliance and safety participation (Griffin \& Neal, 2000). Griffin and Neal (2000) presented this framework for safety performance, which they derived from Borman and Motowidlo's (1993) two-component structure of job performance that includes task performance and contextual performance. Borman and Motowidlo's (1993) conceptualization of job performance looks beyond the traditional evaluation of work in terms of proficiency where an individual performs tasks listed in a job description in order to produce or sell a certain number of widgets (Griffin, Neal, \& Parker, 2007). Griffin and Neal (2000) utilized the same conceptualization to demonstrate that safety performance includes behaviors that are not only prescribed safety behaviors but that performance also includes behaviors that support a safe environment in addition to direct safety behaviors that create a safe environment.

Specifically, safety compliance is defined as "the core safety activities that need to be carried out by individuals to maintain workplace safety" (Griffin \& Neal, 2000, p. 
349). Examples include wearing personal protective equipment (PPE), following proper safety rules and procedures for a given task, and adhering to prescribed safety regulations. Using Borman and Motowidlo’s (1997) definition of job performance, Griffin and Neal (2000) defined safety compliance as being analogous to task performance. Task performance is described as the effectiveness of employees in performing activities that contribute to the technical core of an organization by either: (a) directly implementing a part of the technological process (i.e., transforming raw materials into goods or services) or (b) indirectly planning, coordinating, supervising, or staffing the organization so it functions efficiently and effectively; replenishing essential materials or services; or distributing finished products (Borman \& Motowidlo, 1997; Motowidlo, Borman, \& Schmit, 1997).

Safety participation is defined as "behaviors [that] may not directly contribute to workplace safety, but they do help to develop an environment that supports safety" (Griffin \& Neal, 2000, p. 349). Examples of safety participation include attending safety meetings, voluntarily performing safety activities, promoting the safety program in the workplace, communicating with coworkers when they witness noncompliance with safety procedures, and putting effort into improving workplace safety. Safety participation is analogous to contextual performance (Griffin \& Neal, 2000). Contextual performance is described as discretionary behaviors that support the technical core of an organization by maintaining the broader psychological, social, and organizational environment (Borman \& Motowidlo, 1997). More specifically, contextual performance includes "activities that promote the viability of the social and organizational network and enhance the 
psychological climate in which the technical core is embedded" (Motowidlo et al., 1997, p. 76).

Together, safety compliance and safety participation comprise the overall domain of safety performance, in the same way that task performance and contextual performance comprise the overall domain of job performance. Safety compliance and safety participation are regulated by an individual based on the number of resources available while on the job. A task becomes more difficult and challenging as the demands of that task increase. Employees must then exert more effort and allocate a greater number of resources to perform the task, leaving fewer resources for other things. As Griffin, Neal, and Neale (2000) stated, since contextual performance is the discretionary component of performance, it is sacrificed for task performance as demands increase because available resources are dedicated to task performance first.

For those reasons, organizations have usually focused on safety compliance when trying to influence the safety performance of their employees. Safety compliance is required of employees as it entails abiding by the rules and regulations set forth by the organization and taking precautions against safety hazards (Griffin \& Neal, 2000). Yet safety participation is especially important in this study because I am examining the safety performance of grocery store workers. Burke, Sarpy, Tesluk, and Smith-Crowe (2002) referred to Borman and Motowidlo's (1993) observation that service-oriented occupations may treat contextual performance as task performance because contextual behaviors are routine in "helping" occupations. Similarly, in grocery stores where there are fewer safety hazards when compared to other industries traditionally studied in the 
safety literature, there may be fewer mandatory safety rules to follow. This would place the importance of having a safe work environment on safety participation.

Also, both safety compliance and safety participation are being examined in the current study because even with research being conducted to improve safety compliance, safety concerns are still an issue for organizations, and more concentration needs to be given to safety participation as a means of improving safety behavior (Clarke, 2006a). It is important to consider safety participation in conjunction with safety compliance because, as Clarke (2006b) concedes, employees' participation in safety programs that are designed to improve the physical environment, work design, and communication both directly and indirectly affects accident risk. From that statement we see the importance of the social subsystem's interaction (i.e., safety participation) with the technological subsystem (i.e., safety compliance) in affecting safety.

\section{A Systems Approach to Safety}

Griffin et al. (2007) pointed out that Borman and Motowidlo’s (1993) distinction between task and contextual performance follows a distinction between a task context (i.e., technical subsystem) and a social context (i.e., social subsystem) in the work environment (Griffin et al., 2007), which is fundamental to sociotechnical systems theory (Trist, 1981). There is increasing interest in the role of social-organizational factors in safety performance (Hofmann, Morgeson, \& Gerras, 2003) because technology has greatly developed while human reliability has remained a concern in organizational safety (Mearns, Whitaker, \& Flin, 2001). It is important to remember that one of the most important components of a work system is the individual working; one individual's 
behavior impacts other individuals, groups, teams, and the entire organization (Griffin et al., 2007). Therefore, while technology continues to progress, research needs to focus more on the social side by examining such things as organizational culture and human reliability to complement the technological side of sociotechnical systems (Mearns et al., 2001). In relation to the hierarchy of controls, a way to manage work-related safety hazards (Colligan \& Cohen, 2004), only focusing on the technical side of the work environment has been expressed by numerous researchers as an insufficient way to avoid safety hazards (Ford \& Tetrick, 2008; Paul \& Maiti, 2008).

In their study of coal mines, Paul and Maiti (2008) included supervisor support as a social subsystem variable in their model examining the impact of personal and sociotechnical variables on work injuries. They found that supervisor support had an indirect effect on work injuries through its impact on job stress, a personal variable. Other research has shown that supervisory safety practices have positive effects on reducing workplace accidents and increasing safety perceptions (Zohar, 2002b; Zohar \& Luria, 2004). For example, Torp and Grogaard (2009) examined managers and their employees working in motor vehicle repair garages in Norway and found that both management support, as it was related to health and safety, and general social support led to a higher level of compliance with health and safety routines by employees.

\section{Antecedents of Safety Performance}

There has been a large amount of research that has concentrated on the antecedents of workplace safety, and much of that research has focused primarily on personnel selection, training, and ergonomic factors as the key antecedents of safety 
(Probst \& Brubaker, 2001). For example, past research has examined antecedents focused on the individual as a way to determine what types of corrective action or punishment are necessary to change employees' safety behavior and attitudes (Lee, 1994, as cited in Harvey, Bolam, Gregory, \& Erdos, 2001). This is in response to the fact that causes of accidents have traditionally been attributed to human error (Kondo, 1996). For example, Hofmann, Jacobs, and Landy (1995) stated that investigating the rationale individuals have for performing unsafe behaviors, some of which can lead to accidents, will be more successful than trying to simply predict accidents.

While some researchers believe workers are responsible for accidents, others believe environmental factors are to blame. Still other researchers (e.g., DeJoy, 1994, 1996; Perrow, 1984) assert that accidents are the result of "an interacting system of social and technical forces" and "that employees just happen to find themselves at the end of a series of interrelated events" (Paul \& Maiti, 2008, p. 738). Similarly, Griffin and Neal (2000) listed both individual (i.e., personality, ability, and experience) and environmental features (i.e., climate, leadership, work design, and group norms) as antecedents to change employees' safety performance. I follow the perspective that safety outcomes are influenced by system factors, and the social and technical factors of a system interact with the individual (Brown, Willis, \& Prussia, 2000).

Contextual/Situational factors. Past research has certainly shown that accidents are affected by individual behavior. While we do not want to automatically blame the worker for the occurrence of accidents, a disproportionate number of safety interventions implemented at the individual level indicate the implicit idea that safety problems occur 
as a result of individuals (Hofmann \& Stetzer, 1996). There are contextual influences, however, that go beyond the individual level affecting behavior in the workplace (House, Rousseau, \& Thomas-Hunt, 1995).

Extenuating circumstances such as work-family conflict and a lack of supervisor support cause stress that may interfere with even the most safety conscious employees and cause them to act in ways that do not represent their attitudes (Glasscock, Rasmussen, Carstensen, \& Hansen, 2006). More generally, stress can affect different areas of human functioning, including performance, perceptions, thinking processes, mood states, and physiological and biochemical functions (Cooper \& Payne, 1978; Murphy, DuBois, \& Hurrell, 1986; Murphy \& Hurrell, 1986; Selye, 1976). Job stressors are defined as potentially threatening or demanding events in the environment that require an adaptive response (Ivancevich \& Matteson, 1980). Murphy et al. (1986) discussed using job redesign and organizational change as possible strategies to reduce workers' stress, which would indirectly affect accident risk. The macroergonomics approach utilizes job design and its interaction with the workers as a way to improve the performance and effectiveness of an organization (Hendrick, 2002a). Control over work hours, as previously discussed, is a job design construct that impacts work-family conflict as a stressor.

In support of Murphy et al.'s (1986) model, early studies have found that workers who suffer from stress are more involved in safety incidents (Murphy et al., 1986). For example, Alkov (1981) found pilots and crew members who were exposed to stressful life changes to be involved in a higher number of aircraft accidents than personnel who 
were not exposed to such events. Glasscock et al. (2006) found that when farmers experienced high levels of stress, their attention and concentration were reduced and it was not as easy for them to avoid safety risks in their work environment. Stress is a general term that can be caused by many factors, which is why safety directors and risk managers are exploring specific psychosocial and organizational factors that may be stressful in order to improve safety (Huang, Chen, \& Grosch, 2010).

\section{Work-family Conflict and Safety Performance}

Other researchers agree that it is crucial to investigate specific work-related stressors like work-family conflict instead of only examining overall job stress in relation to workplace safety behaviors (Hammer et al., 2007; Hemingway \& Smith, 1999; Probst, 2002). This is in line with the matching/specificity hypothesis that speaks to the importance of examining specific types of stressors and moderators in order to predict strain (Cohen \& Wills, 1985). The matching/specificity hypothesis will be discussed further when I explain hypotheses regarding the moderating effect of supervisor instrumental support on both perceived control over work hours and work-family conflict. In particular, more attention needs to be paid to family/nonwork pressures that can be carried into the work environment and distract workers. Work-family conflict causes stress, and employees who experience stress are less able to concentrate on effectively performing their jobs because of limited resources (Hammer et al., 2007).

Given that Cullen and Hammer's (2007) is the only published study examining work-family conflict in relation to safety performance, the job performance literature will be reviewed in order to hypothesize the work-family conflict - safety performance 
relationship. Allen et al. (2000) reviewed outcomes related to work-family conflict and found four articles examining the relationship between work-family conflict and job performance. While two studies found a significant, negative relationship (Aryee, 1992;

Frone et al., 1997), the other two studies found a non-significant relationship (Greenhaus, Bedian, \& Mossholder, 1992; Netermeyer, Boles, \& McMurrian, 1996). After their review, Shaffer and Joplin (2001) found that family-to-work conflict was associated with decreased job performance, which aligns with Cullen and Hammer's (2007) finding that family-to-work conflict is associated with decreased safety performance.

Work-to-family conflict and safety performance. It is being argued that workto-family conflict relates to safety compliance and safety participation, with safety performance as a work domain outcome. Amstad, Meier, Fasel, Elfering, and Semmer (2011) conducted a meta-analysis examining outcomes of work-family conflict and found that matching-domain outcomes more strongly relate to each type of interrole conflict than cross-domain outcomes. In other words, work-to-family conflict is more strongly associated with work-related outcomes, while still being associated with family-related outcomes, but to a lesser extent. In support of this hypothesis, a review by Allen et al. (2000) concerning the outcomes of work-to-family conflict found inconsistent results but overall trends. For such psychological variables as job satisfaction $(r=-.24)$, organizational commitment $(r=-.23)$, and turnover intentions $(r=.29)$, employees may be disenchanted with their jobs, which are seen as interfering with their personal lives and creating resentment toward their work. Therefore, work-to-family conflict negatively affects those types of psychological variables in which negative feelings are more likely 
to be carried outside of the work environment. Kossek and Ozeki (1998) found similar results in that the correlation between family-to-work conflict and job satisfaction $(r=-$ .18) was weaker than the correlation between work-to-family conflict and job satisfaction $(r=-.27)$. The inconsistency occurs when one sees that behavioral outcomes like job performance $(r=-.12)$ and absenteeism $(r=-.02)$, which occur in the work environment, are less likely to be affected by work-to-family conflict. More important to this study and specific to safety, Chen, Rosecrance, and Hammer (2006) found a link between work-tofamily conflict and the frequencies of injuries in construction workers (as cited in Hammer et al., 2007).

Role conflict and role ambiguity were significantly related to work injuries in a sample of nurses in Canada (Hemingway \& Smith, 1999). Hofmann and Stetzer (1996) examined perceptions of role overload and found a significant association with safety performance. Having to move between different environments (e.g., work and home) can cause individuals to experience role overload, which can cause them to overlook certain environmental features while focusing too much on others (Davis, 1958; Reason, 1990; Weick, 1990). Any aspect of the work environment that diverts an individual's attention from task activities will place additional and conflicting demands on the individual's attention, thereby increasing the time needed to perform tasks and eventually reduce the quantity or quality of task performance (Baron, 1986). More specific to the present study, work-family conflict is a demand that can compromise personal resources by being a distraction, inducing stress, and causing fatigue, which then impacts safety performance. 
Therefore, it is hypothesized that work-to-family conflict will directly relate to employee safety performance.

Hypothesis 2a: Work-to-family conflict and safety compliance will exhibit a negative, direct relationship.

Hypothesis $2 b$ : Work-to-family conflict and safety participation will exhibit a negative, direct relationship.

Family-to-work conflict and safety performance. Regarding the family domain interfering with the work domain, Cullen and Hammer (2007) found that healthcare workers who experienced more family-to-work conflict had lower levels of safety compliance and safety participation. There is also parallel research to support the relationship between family-to-work conflict and safety compliance and participation. I will begin by examining past research that has found significant relationships between family-to-work conflict and job performance. Griffin and Neal (2000) based their conceptualization of safety performance on Borman and Motowidlo's (1993) reconceptualization of job performance with the reasoning that work behaviors are similar whether one is referring to safety performance or job performance. I am therefore assuming that these two types of performance may share antecedents. Kossek and Ozeki (1998) found that overall, family-to-work conflict, but not work-to-family conflict, related negatively to job performance. Amstad et al. (2011) found that family-to-work conflict was correlated to work-related performance $(r=-.20)$ more so than work-tofamily conflict ( $r=-.11)$. Employees who report experiencing higher levels of family-towork conflict have stronger feelings of being stressed at work, have diminished levels of 
concentration, and have poor job performance (Adams \& Jex, 1999; Kelloway, Gottlieb, \& Barham, 1999; Parasuraman \& Simmers, 2001). Frone et al. (1997) found that greater family overload, greater family time commitment, and higher family distress led to family-to-work conflict, which then led to lower job performance.

The physical and psychological effects that family-to-work conflict can have on individuals may be what contribute to negative safety outcomes. When employees ruminate about family matters, they lose energy as a personal resource that could be used during work (Peeters, Montgomery, Bakker, \& Schaufeli, 2005), and less energy results in exhaustion, poorer accomplishment at work, and diminished vigor (Ten Brummelhuis, Bakker, \& Euwema, 2010). Family-to-work conflict has also been shown to cause employees to be distracted at work (Campbell, Campbell, \& Kennard, 1994; Chapman, Ingersoll-Dayton, \& Neal, 1994; Kinnunen \& Mauno, 1998). Experiencing diminished levels of concentration, being easily distracted, and feeling exhausted are all mechanisms through which family-to-work conflict can negatively affect safety performance. Therefore, family-to-work conflict is hypothesized to be an antecedent of safety compliance and safety participation.

Hypothesis 3a: Family-to-work conflict and safety compliance will exhibit a negative, direct relationship.

Hypothesis $3 b$ : Family-to-work conflict and safety participation will exhibit a negative, direct relationship.

\section{Work-family Conflict Mediates the Relationship between Control and Safety}


A number of studies have investigated the relationship between job autonomy and a variety of safety outcomes. It has been demonstrated that higher levels of job autonomy lead to fewer injuries and accidents (Parker et al., 2001). More specifically, job autonomy leads to decreases in lost time due to injuries (Shannon, Mayr, \& Haines, 1997) and lower accident rates at an organizational level (Betcherman, McMullen, Leckie, \& Caron, 1994). It has also been demonstrated that higher levels of job autonomy lead to an increase in attitudinal and behavioral safety outcomes such as employees actively caring for safety (Geller, Roberts, \& Gilmore, 1996) and employees effectively responding to safety critical situations (Wright, 1993). Parker et al. (2001) investigated the relationship between job autonomy and safe working, which is analogous to safety compliance, and found a significant positive relationship. Control over work hours reduces the stress of work-family conflict and allows employees to feel they are capable of taking care of their family/personal issues when necessary (Kelloway \& Gottlieb, 1998), and reduced levels of stress lead to fewer distractions and less exhaustion that can take away focus on safety performance. Therefore, work-family conflict is hypothesized to mediate the relationship between control over work hours and safety performance.

Hypothesis 4a: Work-to-family conflict will mediate the relationship between perceived control over work hours and safety compliance and safety participation.

Hypothesis 4b: Family-to-work conflict will mediate the relationship between perceived control over work hours and safety compliance and safety participation.

In the next chapter, I will be examining supervisor instrumental support as an organizational variable that not only accommodates employees' need for family- 
supportive supervisor behaviors, but that is considered an essential feature of the work environment for the perception of control over work hours. Arguments for the necessity of having supervisor instrumental support as a moderating variable in the macroergonomics model of work-family conflict and employee safety will conclude the next chapter. 


\section{Chapter 6: Supervisor Support}

Eby et al. (2005) identified a gap in the work-family literature as being a lack of research on support. Spouse support has been the most common type of support examined in relation to work-family conflict (Eby et al., 2005), although supervisory support and organizational support have been receiving more attention recently (e.g., Allen, 2001; Carlson \& Perrewe, 1999; Clark, 2001; Thompson, Beauvais, \& Lyness, 1999). Supervisors who interact with employees on a fairly regular basis can help alleviate the negative effects of work-family conflict on safety performance by being supportive of employees who need to negotiate both the work and family domains.

This chapter will begin with a discussion of supervisor support by first exploring general support literature. Next I will describe family-supportive supervisor behaviors (FSSB) as a particular type of support for employees. A discussion of the ways supervisors can impact both employees' perceived control over work hours and workfamily conflict will follow.

\section{Family-supportive Supervisor Behaviors (FSSB)}

It has been stated that front-line supervisors are largely responsible for the wellbeing of American families (Rodgers \& Rodgers, 1989). Galinsky and Hughes (1987) found that working parents felt having their supervisors trained to be more accommodating during family crises was one of the most advantageous ways to improve the quality of their family lives, second only to increased pay. Past research has shown that supervisor support reduces employee stress, decreases role conflict, and improves family functioning (Burke, 1988; Galinsky \& Stein, 1990; Greenhaus, Bedeian, \& 
Mossholder, 1987). Supervisors' supportive behaviors, specifically family-supportive supervisor behaviors (FSSB), are being examined as a moderator of the relationship between work-family conflict and safety outcomes in that the negative work-family conflict and safety performance relationships will be weaker at higher levels of supervisor support. As past research shows, supervisors who accommodate employees' family issues can alleviate employee stress that can lead to decreased safety performance.

General support literature. General social support is defined as an interpersonal transaction that may involve information exchange (i.e., communicating what resources are available), instrumental assistance (i.e., providing aid and programs), and emotional expression of concern (i.e., acknowledging employees' nonwork needs; House, 1981). This is similar to Wethington and Kessler's (1986) typology of support that includes supervisors transferring aid, advice, and affect to their employees. Nelson and Quick (1991) offered a comparable framework involving instrumental support, informational support, emotional support, and appraisal support (i.e., encouragement and feedback).

Social support can have direct, moderator, meditational, and suppressor effects on the stressor-strain relationship (Carlson \& Perrewe, 1999; Parasuraman et al., 1992; Viswesvaran, Sanchez, \& Fisher, 1999). Regarding the direct effect, supervisor support has been shown to reduce employees' work-family conflict (Anderson, Coffey, \& Byerly, 2002; Frone et al., 1997; Frye \& Breaugh, 2004; Goff, Mount, \& Jamison, 1990; Lapierre \& Allen, 2006; Thomas \& Ganster, 1995; Thompson et al., 1999; Thompson \& Prottas, 2005). The moderating effect occurs when the relationship between a stressor and strain is stronger for individuals who experience low levels of support (Viswesvaran et al., 
1999). Empirical support is mixed for the moderating effect of social support with some researchers finding moderating effects (e.g., Abdul-Halim, 1982) and others not finding such effects (Ganster, Fusilier, \& Mayes, 1986). Researchers have also found reverse buffering effects (e.g., Kickul \& Posig, 2001), which occur when high levels of support exacerbate instead of alleviate the effects of stressors on strains (Viswesvaran et al., 1999). Overall in their meta-analysis, Viswesvaran et al. (1999) found evidence supporting the moderating effects of general social support.

\section{Conceptualization of family-supportive supervisor behaviors (FSSB).}

Hammer et al. (2007) indicated that the most commonly used measures of supervisor support contain self-report questions that deal with items regarding employees' perceptions of how their supervisors value their contributions (e.g., Ostroff, Kinicky, \& Clark, 2002), how their supervisors care for them (e.g., Kinnunen \& Natti, 1994), how understanding and accommodating their supervisors are (e.g., House, 1981), and the degree to which career support is received from their supervisors (e.g., Greenhaus, Parasuraman, \& Wormley, 1990). Prior measures of supervisor support are also contaminated with general measures of organizational support/culture (Allen, 2001; Hammer et al., 2009). Hammer et al. (2009) have dissociated the two concepts of supervisor support and organizational support with the development of the FSSB scale.

It is necessary to differentiate between supervisor support and organizational support because situations arise where direct supervisors disagree with the organization as a whole as to what are appropriate levels of flexibility and sensitivity to be provided to employees who experience conflicting work and family demands (Flye, Agars, \& Kottke, 
2003; Warren \& Johnson, 1995). Working in an organizational culture that is supportive of work-family issues is different from having a supervisor who is supportive of workfamily issues. The reason the two are different is that supervisors carry out enacted practices and not the recorded policies and procedures determined by top management at the organizational level (Zohar, 2003), which gives supervisors more leeway in deciding what they can do to help their employees in ways their employees need to be helped. It can also go the other way in that a supervisor is encouraged by a family-supportive organizational culture to exhibit behaviors that are supportive of employees' work-family demands, but the supervisor must decide whether or not to follow that standard (Hammer et al., 2007). Therefore, employees may feel their supervisors are supportive of their family needs while at the same time feeling their organization is not, and vice versa (Allen, 2001). This is important since direct supervisors are more proximal to employees than top management and have a greater influence over how things are implemented in the work environment.

A family supportive supervisor is defined as a supervisor who empathizes with his/her employees' desires to find balance between work and family responsibilities (Thomas \& Ganster, 1995). Hammer et al. (2009) showed that FSSB is distinct from general supervisor support measures; supervisors can support employees while they do their jobs, but they do not necessarily have to be supportive of employees' family needs. In Kossek, Pichler, Bodner, and Hammer's (2011) meta-analysis, supervisor support measures that are specific to the family role have been found to have stronger relationships with work-family outcomes. The FSSB scale is composed of specific 
supervisor behaviors that are supportive of employees' family roles rather than using general measures of emotional support, which has been an issue with past research involving supervisor support and work-family outcomes (Kossek, et al., 2011; Hammer et al., 2007; Hammer et al., 2009). Supervisor emotional support includes such perceptions as employees feeling comfortable communicating with their supervisor when they need support, feeling that they are being cared for, and feeling that their emotions are being considered (Hammer et al., 2007). Although emotional support is an important aspect of supervisor support, it is not all-encompassing. The FSSB scale is comprised of numerous behaviors supervisors must exhibit in order to be more supportive of their employees' work-family demands (Hammer et al., 2009).

FSSB is defined as enacted behaviors exhibited by supervisors that are perceived to be supportive of employees' work and family demands (Hammer et al., 2007). The FSSB measure consists of four dimensions: (a) emotional support (listening and showing employees that they care about their work-family demands), (b) instrumental support (responding to employees' work and family needs in the form of day-to-day management transactions), (c) role-modeling behaviors (demonstrating ways to synthesize work and family by modeling behaviors in the work environment), and (d) creative work-family management (management-initiated restructuring of work to facilitate employee effectiveness on and off the job; Hammer et al., 2007; Hammer et al., 2009; Hammer et al., 2011). When Hammer et al. (2007) described a theoretical model with which to clarify the multidimensional FSSB construct, they only knew of one measure that existed to evaluate actual behavioral supervisor support (i.e., Shinn, Wong, Simko, \& Ortiz- 
Torres, 1989). Additionally, that one measure only assesses one dimension (i.e., instrumental support) of family-supportive supervision. With the creation of FSSB, Hammer et al. (2009) have operationalized what supervisors need to do, behaviorally, in order to help their employees manage work and family.

As described earlier, emotional support is the most commonly studied form of supervisor support and is examined often as a combined measure of support in conjunction with instrumental support (Fenlason \& Beehr, 1994). Emotional support regarding work-family responsibilities, also known as interactional support (Winfield \& Rushing, 2005) and sensitivity (Hopkins, 2005; Warren \& Johnson, 1995) in the workfamily literature, should include: (a) supervisors expressing concern for the way family issues are impacted by work responsibilities; (b) being conscious of their employees' personal life commitments; (c) making employees feel at ease when opening up about personal issues; and (d) demonstrating compassion, respect, sympathy, and understanding for family responsibilities (Hammer et al., 2009). Instrumental support, unlike emotional support, is related to behavioral aspects of supervisor support that include: (a) accommodating work-family responsibilities through adjusting schedules to increase employees' flexibility when needed, (b) helping with tasks, and (c) interpreting policies and practices properly (Hammer et al., 2007; Hammer et al., 2009). Instrumental support is the only FSSB factor that will be examined in this study because instrumental support pertains to supervisors assisting their employees with issues regarding work hours. Also, as will be discussed, it is important to determine the separate effects of different types of support. 


\section{Supervisor Support Buffers the Effects of Work-family Conflict on Safety Performance}

Before discussing the support hypotheses specifically, I will point out an issue pertaining to past research. Researchers have combined different types of supports like supervisor support, coworker support, and organizational support into such variables as “work support.” For example, Mesmer-Magnus and Viswesvaran’s (2005) meta-analysis, which examined the overlap between work-to-family and family-to-work conflict, found that work-to-family conflict was negatively correlated with a supportive work environment $(r=-.16)$. That is lower than expected based on past research (e.g., Flye et al., 2003). They suggested that the low correlation may have been a product of grouping the variables (i.e., supervisor support, coworker support, perceived work-family culture, and work-family policies) and that examining each variable separately may produce different results. Also, studies show that supervisors are more influential in supporting their employees when they have family issues than organizational-level support because supervisors engage in ongoing interactions with their employees (Zohar, 2002b), placing them in the best position to make an impact.

It is not only important to distinguish who gives support, but also which type of support is given. Fenlason and Beehr (1994) contended that measures of supervisor support need to be operationalized more specifically, without combining different types like emotional and instrumental support into one measure, in order to determine how support acts on stressor-strain relationships. Also, Cohen and Syme (1985) found that support has buffering effects when the support measure has items that assess the 
availability of resources to help individuals deal with stressful situations. This follows the matching/specificity hypothesis put forth by Cohen and Wills (1985), which states "if the right kind of support from the right source of support is matched to the kind of stressors faced, then specific strains will be reduced" (Viswesvaran et al., 1999, p. 318).

The instrumental factor of FSSB examines the access individuals have to resources provided by their supervisors concerning such things as scheduling and coverage when they may be absent. While research concerning social support has found that different types of support can act as a buffer against negative workplace outcomes (Ganster et al., 1986; Greenhaus \& Parasuraman, 1986; Kessler, Price, \& Wortman, 1985; Viswesvaran et al., 1999), Parasuraman et al. (1992) did not find that work support (i.e., supervisors and coworkers) had a buffering effect on the relationship between workfamily conflict and well-being. Their measure of support was a composite of emotional and informational support without instrumental support being included. Parasuraman et al. (1992) posited that a buffering effect was not found because instrumental support is necessary to reduce negative pressures from the work and family domains. Therefore, this study is examining not only supervisor instrumental support as a buffer, which has been shown in numerous studies to be an important resource in alleviating the harmful effects of stressors in both the work and family domains (Goff et al., 1990; Parasuraman et al., 1992; Thomas \& Ganster, 1995), but specifically supervisor instrumental support geared toward employees' family/personal needs in order to determine if this targeted support is necessary to weaken the work-family conflict and safety performance relationships. 
When supervisors offer their employees instrumental support that pertains to work-family issues, employees are receiving tangible resources to combat the demands of work-family conflict that would otherwise negatively affect safety performance. For example, a supervisor may inform an employee of a particular type of child care option offered by the company. Such support allows the employee to worry less about paying for child care and to focus more on safety performance.

Hypothesis 5a: Supervisor instrumental support will moderate the relationship between work-to-family conflict and safety performance. More specifically, the negative association between work-to-family conflict and safety compliance and safety participation will be weaker for individuals who perceive higher instrumental support from their supervisors than for individuals who perceive lower levels of instrumental support from their supervisors.

Hypothesis 5b: Supervisor instrumental support will moderate the relationship between family-to-work conflict and safety performance. More specifically, the negative association between family-to-work conflict and safety compliance and safety participation will be weaker for individuals who perceive higher instrumental support from their supervisors than for individuals who perceive lower levels of instrumental support from their supervisors.

\section{Support Moderates the Relationship between Work Hour Control and Work-family}

\section{Conflict}

As Perlow (2001) explained, "Work-time standards and norms depend on the underlying relationships among employees and between employees and their managers" 
(p. 110). Those relationships are embedded within a larger context that includes the organization itself and society as a whole. Therefore, in order for employees to implement any amount of control over their work hours, other factors within the context, besides the individual, must be taken into consideration.

Researchers discuss the fact that employees need to have the support of their supervisors in order to successfully utilize flexibility practices, which include employees gaining more control over work hours (e.g., Allen, 2001; Anderson et al., 2002; Clark, 2001; Kelly \& Moen, 2007; Thompson et al., 1999). This has lead to supervisor support being examined extensively as a direct or indirect antecedent of control over how, when, and where work is done. This study seeks to demonstrate the importance of control and support as interacting variables in the work system where supervisor instrumental support, as a moderator, is necessary in order for employees' perception of control over their work hours to have an effect on reducing their work-family conflict. Supervisors are important in this study because the direct supervisors in grocery stores are in charge of scheduling all employees and making sure there are enough people to work any given shift.

Giving employees control over their work hours will have a limited effect if supervisors do not encourage employees to take advantage of such policies or if supervisors judge employee performance on "face time" and not output (Clark, 2001; Kossek, 2005). Supportive supervisors increase their employees' perception that they have more control over work and family (Thomas \& Ganster, 1995), which leads to lower levels of work-family conflict. Clark (2001) found that employees' work-family conflict 
was reduced with family sensitive supervision because employees had an increased sense of community and control over the job.

Mesmer-Magnus and Viswesvaran, in their 2006 meta-analysis examining the ways in which family-friendly work environments affect work-family conflict, found a small negative correlation between flexibility and global measures of work-family conflict $(r=-.12)$, but almost no correlation between flexibility and either work-to-family conflict $(r=-.01)$ or family-to-work conflict $(r=.04)$. Flexibility was described generally as being formal or informal and as pertaining to the timing and/or location of work. They suggested that the weak relationships were due to the presence of a negative work-family culture in organizations that punished employees who used flexible work arrangements, thereby reducing the positive effects of flexible arrangements on work-family conflict. In line with Mesmer-Magnus and Viswesvaran's (2006) suggestion, Shockley and Allen (2007) examined the moderating role of family-supportive organizational perceptions on the relationships between flextime and flexplace availability and both work-to-family and family-to-work conflict. They found no significant interactions, showing no support for the influence of family-supportive organizational perceptions affecting employee control, as Mesmer-Magnus and Viswesvaran (2006) presumed. Yet, supervisor support may have more of an influence on employee control than family-supportive organizational perceptions because of the proximity of supervisors to their employees.

Support is being examined as supervisor instrumental behavior in order to determine the effect that specific source (i.e., supervisor) and type (i.e., instrumental) of support have on the perceived control over work hours and work-family conflict 
relationships. The instrumental component of FSSB is geared specifically toward helping employees gain control over their work hours, among other things, which I believe will have a strong impact on employees' perception of control over work hours. Perceived control over work hours is being examined as control over only when work is done in order to avoid the combined effects of when, where, and how work is done and to match the instrumental support given by supervisors.

The perceived control the participants had over their work hours was automatically limited in this study because no overtime was offered in the grocery stores examined. Other hurdles that are faced by grocery store workers in general include schedules varying depending on the managers creating them, schedule requests not receiving much consideration, and the difficulty of having an entire weekend off or two days in a row off (Hammer et al., 2007). The inherent restrictions on grocery store employees' control over work hours would necessitate the support of supervisors. Therefore, it is hypothesized that supervisor instrumental support will moderate the relationship between perceived control over work hours and work-to-family and familyto-work conflict.

Hypothesis 6a: The relationship between perceived control over work hours and work-to-family conflict will be moderated by supervisor instrumental support. More specifically, the negative association between perceived control over work hours and work-to-family conflict will be stronger for individuals who perceive higher instrumental support from their supervisors than for individuals who perceive lower levels of instrumental support from their supervisors. 
Hypothesis 6b: The relationship between perceived control over work hours and family-to-work conflict will be moderated by supervisor instrumental support. More specifically, the negative association between perceived control over work hours and family-to-work conflict will be stronger for individuals who perceive higher instrumental support from their supervisors than for individuals who perceive lower levels of instrumental support from their supervisors.

I will now turn to a discussion of organizational context because, with macroergonomics' emphasis on context, it is important to know about the important aspects of the work environment and key characteristics of the workers examined in this dissertation. 


\section{Chapter 7: Organizational Context}

\section{Characteristics of Grocery Stores and the Workers}

Grocery store workers are being studied in this dissertation because of numerous characteristics they possess, which will be discussed, that lead to both work-family issues and safety concerns. The grocery store industry is one of the largest industries in the United States and provided 2.5 million wage-and-salary jobs in 2008. (BLS, 2010a; CareerOneStop, 2010). The current study was conducted in supermarkets, which make up over two thirds of the grocery store establishments in the United States (BLS, 2010a). The nature of the grocery store industry today is that most of the jobs are found in $20 \%$ of the largest stores, which means there are fewer administrative offices and managementlevel employees than if there were more stores (BLS, 2010a).

Cashiers comprise $34 \%$ of the grocery store workforce, which is the largest occupation in grocery stores, while stock clerks and order fillers comprise $17 \%$, the second largest occupation, for a total of $51 \%$ (BLS, 2010a). The nature of the work is repetitive; cashiers scan items into the cash register for purchase. There is also a great deal of customer interaction, especially for cashiers, which results in the need for employees to always be cordial and positive when interacting with customers. Stock clerks and order fillers place merchandise on shelves and arrange displays to sell products. This can be physically demanding for those workers, especially those who do things like stocking heavy items on the floor or accepting deliveries in the backroom.

Safety. According to the BLS (2010a), grocery stores fall under the purview of the retail sector, and are further categorized into the food and beverage subsector. In 
2008, there were 5.7 total recordable cases of workplace injuries and illnesses per 100 full-time workers in the food and beverage subsector (BLS, 2010a). Injuries occur when cashiers experience repetitive motion injuries or cumulative trauma and when employees stock or transport goods. Compare 5.7 to the 5.1 total recordable cases per 100 full-time workers that occurred in the specialty trade contractors subsector in the construction industry in 2008 (BLS, 2010a). Specialty trade contractors had 570 deaths in 2008, the highest number of fatalities in the construction industry, which is considered the most dangerous industry. This shows that the number of total recordable cases in grocery stores is comparable to the number of cases in a very dangerous occupation and should not be taken lightly.

Also concerning safety in grocery stores is the fact that young workers suffer a higher rate of work-related injuries than older workers (IWH, 2006a; Schulte, Stephenson, Okun, Palassis, \& Biddle, 2005). This is important considering that $29 \%$ of the grocery store workforce is made up of first-time job seekers aged 16 to 24 years (BLS, 2010a). Specifically, 50\% of accidents involving workers aged 15 to 24 occur within the first 6 months of their employment (Beharie, 2005; Breslin \& Smith, 2005; Loughlin \& Barling, 2001; IWH, 2006b).

Scheduling and earnings. There is typically a lack of autonomy in scheduling because there are very specific tasks that need to be accomplished during certain shifts, such as attending to customers during operating hours and assuring all the shelves are stocked with the proper merchandise. This often precludes employees from being allowed to make personal phone calls, which creates a boundary between work and nonwork. It is 
also the case that not all employees have the choice to have fixed shifts in grocery stores because there are busier seasons than others, like during holidays, and employees need to be called in when others are out sick or have personal days off (BLS, 2010a). Schedule change requests made by employees several weeks in advance are usually not approved and employees are only permitted to switch shifts with coworkers if there is an emergency. By directly interacting with and interviewing the grocery stores employees participating in this study, I learned that these scheduling issues can be quite pervasive.

The hours of operation and days open are greater than most work establishments, so employees are needed to work not only day shifts, but also early mornings, late nights, weekends, and holidays (BLS, 2010a). This does not, however, lead to more hours worked per employee. While the average workweek consists of 33.6 hours for workers in all industries, grocery store employees work an average of 29.4 hours per week (BLS, 2010a). Thirty percent of grocery store workers are employed part-time, with a majority of those part-time employees working as cashiers or counter service workers (BLS, 2010a). Therefore, most employees working in retail grocery stores are paid modestly because they work as cashiers, floor employees, and backroom employees. While fulltime employees generally earn benefits (e.g., sick leave, paid vacations, and health and life insurance), part-time employees typically do not unless they belong to a union. In 2008, nonsupervisory employees earned $\$ 340$ per week while the average weekly earnings in the private sector was $\$ 608$ per week (BLS, 2010a). Supervisors differ in that most of them are employed full-time, earn higher pay, and often work more than 40 hours per week (BLS, 2010a). The longer hours are necessary to oversee staff and conduct 
trainings during all shifts and to also assist their workers during unexpectedly busy times (BLS, 2010a).

Stress/Strain. A grocery store, while clean and climate-controlled, can be hectic and stressful (BLS, 2010a). Cranwell-Ward (1987) categorized organizations in the retail industry as dealing with high levels of technology, being service-oriented, and undergoing structural job changes, which lead to stressful working environments (as cited in Broadbridge, 1999). Broadbridge (1999) qualitatively found that stressors experienced by retail managers, including long working hours, work overload, time pressures and deadlines, and staff shortages, were likely to lead to more family-to-work conflict than work-to-family conflict. Regarding retail workers in general, high levels of role stress are a result of conflicting demands between low levels of flexibility on the job and extensive customer service requirements (Wetzels, de Ruyter, \& Bloemer, 2000).

There is a relatively high turnover rate in grocery stores, which leaves positions open for first-time job seekers, people with limited job skills, and people seeking parttime or alternative work schedules (BLS, 2010a). Given the large number of these types of workers and the fact that little or no work experience is necessary for many of the positions in grocery stores, the average weekly earnings are considerably lower in grocery stores than in all other industries, as discussed previously. Research has shown that low-wage service workers experience higher levels of job-family role strain because their occupations have certain inherent job characteristics (e.g., rotating schedules, nonday shifts) that create strain, making it difficult for individuals to juggle work and family roles (Swanberg, 2005). 


\section{Characteristics of Low-wage Workers}

Kelly and Moen (2007) admitted that control over work hours is most likely to "flourish" in white-collar occupations, but this does not preclude a wide variety of industries that provide direct services to the public, such as retail stores, health care organizations, and unionized government agencies, from having systems that allow employees to set, change, and coordinate their work hours (Corporate Voices for Working Families, 2006; Henly, Schaefer, \& Waxman, 2006; Trade Union Congress, 2007). It is important to conduct studies that investigate the outcomes of schedule control in a variety of occupations not considered white-collar (Kelly \& Moen, 2007), including grocery stores given some of the issues the workers face, as will be discussed next.

According to the Families and Work Institute (2006), only 39\% of low-wage employees are offered any paid sick days for personal illnesses compared to $79 \%$ of higher-wage employees, and only $51 \%$ of low-wage employees have paid vacation days compared to $90 \%$ of higher-wage employees. Regarding child care, only $24 \%$ of lowwage parents are given paid time off to care for a sick child rather than having to use paid vacation days compared to 54\% of higher-wage parents (Families and Work Institute, 2006). Given that low-wage workers have fewer options to take time off, they may need to pay others for help with child care or other responsibilities they are not able to take care of, which can be difficult with their low wages (Workplace Flexibility, 2010). Seventeen percent of employees earning less than $\$ 15$ per hour had access to long-term disability insurance compared to $48 \%$ of higher-wage employees. Many low-wage employees care for multiple children in single-parent homes or in homes where both 
parents work (Acs \& Loprest, 2007). They also care for elderly relatives or other family members who have significant health conditions (National Alliance for Caregiving and AARP, 2004).

Work schedules often change on a weekly or monthly basis and are created by supervisors without employee input, so while some may label such change "flexible," it does not address the needs of the workers (Richman et al., 2006). As Richman et al. (2006) stated, scheduling choice, predictable scheduling, and/or greater advance notice of scheduling would greatly benefit low-wage workers. They specifically mention technological systems that would allow supervisors to match employees' scheduling preferences with business demands. Over one third of low-wage and hourly workers who work part-time would prefer to work full-time (Swanberg, 2008), and even those who work full-time do not always work all their hours because employers try to reduce labor costs when there are variations in consumer demands (Lambert, 2007; Lambert \& Henley, 2007). Although many low-wage workers are more likely to work nonstandard hours and mandatory and unscheduled overtime than other workers (Richman et al., 2006), the participants in this study were not allowed to work overtime hours. Only one third of low-wage workers are able to choose when they take their breaks during their shifts (Bond \& Galinsky, 2006). This lack of control can be an issue for employees who have personal needs, such as nursing mothers, or parents who need to call their children when they arrive home from school (Workplace Flexibility, 2010). 


\section{Chapter 8: Method}

The present study utilizes data that were collected as part of a larger work and family study conducted by Dr. Leslie Hammer of Portland State University and Dr. Ellen Kossek of Michigan State University that was partially supported by the Work, Family and Health Network. The Work, Family and Health Network is funded by a cooperative agreement through the National Institutes of Health and the Centers for Disease Control and Prevention. This entire work and family study was completed during a three-year time span. I contributed to this larger study during data collection and data cleaning. I traveled to the Midwest and verbally administered surveys to participants. Once all the data were collected I continued my involvement in the study during the data cleaning process to prepare the data for use in publications.

\section{Procedure}

Twelve stores in a Midwestern United States grocery store chain were visited by researchers to collect data. The survey consisted of 196 items and took between 35 to 50 minutes to complete. Every employee was recruited by a researcher, who was trained in interview techniques, to participate during company time in a "work stress research project conducted by university researchers." Informed consent was read verbally to participants and then both the participants and the researcher signed two copies of the consent, one for the participants to keep for their records. All participants were told they could stop the survey at any time or did not have to answer any question they did not feel comfortable answering. To ensure anonymity and confidentiality, randomly assigned numeric identifiers, rather than names, were recorded on the surveys and it was 
emphasized to participants that their employer was in no way part of the study. The survey was individually administered verbally during face-to-face interviews.

Researchers helped to interpret survey questions when needed. A $\$ 25$ gift card was given to each employee as incentive to participate. Break rooms or managers' offices were typically used to administer the survey in order to assure privacy and quiet. The process of verbally administering the survey led to almost no missing data. The original paper surveys are stored in locked file cabinets, following human subjects protection guidelines, and the archival datasets are stored on a secure computer network.

\section{Participants}

The majority of employees in the present study work in the front end of the store as cashiers and the remaining employees work in different departments located throughout the store, including bakery/deli, dairy/frozen, produce, and stockroom. These types of associate-level grocery store jobs consist of a low level of task variety involving repetitive activities like scanning, bagging, and stocking, and a low level of autonomy. This is in contrast to their supervisors, who experience more task variety and higher levels of autonomy.

Tables 1 and 2 contain all demographic information; means, standard deviations, and ranges of all continuous variables are given and frequencies of all categorical variables are given. Data were collected from 30-90 employees per store in 12 stores. The sample includes a total of 360 employees. A total of 590 employees were invited to participate in the survey, and 360 employees (61\% response rate) completed the survey. The employees ranged in age from 18 to 80 years, with an average age of 38 years $(S D=$ 
15.25). The employees included 97 (27\%) males and $262(73 \%)$ females. Three hundred and thirty employees were White (92\%), 14 (4\%) were Black or African American, 2 (.5\%) were American Indian or Alaskan native, 1 (.5\%) was Asian, $2(.5 \%)$ were Native Hawaiian or other Pacific Islander, and 9 (2.5\%) reported being an unspecified race. Regarding family roles, 196 (55\%) employees were married or living as married, 38 (11\%) employees were either divorced or separated, $16(4 \%)$ employees were widowed, and $108(30 \%)$ employees were never married. One hundred forty-six (41\%) employees had at least one child living at home and 208 (59\%) employees had no children. Of those employees with children living at home, 61 (17\%) had only one child and 85 (24\%) had more than two children. Fifty-eight (16\%) employees were providing care for an adult, with a majority of those employees (62\%) caring for one parent. Employees had been working for this particular company for an average of 7 years $(S D=5.96)$. The average number of hours worked per week was $31(S D=8.55)$.

\section{Measures}

Table 3 contains a list of all the items for each scale used in this dissertation. Table 4 shows the mean, standard deviation, and range of each scale.

Work-family conflict. Netermeyer et al. (1996) developed and validated two scales: work-to-family conflict and family-to-work conflict. A confirmatory factor analysis was used to determine that work-to-family conflict and family-to-work conflict load as two separate factors of the overall construct of work-family conflict. They are two conceptually different constructs and should be measured separately (Netermeyer et al., 1996). Work-to-family conflict occurs when the demands, time allocated to, and strain 
created by work interferes with the performance of family responsibilities. Family-towork conflict occurs when the demands, time allocated to, and strain created by family interferes with the performance of work duties. Each measure consists of five items rated on a 5-point scale ranging from strongly disagree (1) to strongly agree (5). Higher scores on both scales indicate higher experienced levels of work-to-family and family-to-work conflict. Netermeyer et al. (1996) examined reliability in three different samples: elementary and high school teachers and administrators (WFC: $\alpha=.88$, FWC: $\alpha=.86$ ), small business owners (WFC: $\alpha=.89$, FWC: $\alpha=.83$ ), and real estate salespeople (WFC: $\alpha=.88$, FWC: $\alpha=.89$ ).

Netermeyer et al. (1996) provided evidence of construct validity by examining correlations between their work-to-family and family-to-work scales and variables predicted to be positively and negatively associated with work-to-family and family-towork conflict. Across three samples, 22 out of 26 correlations were significant pertaining to: (a) the positive association between work-to-family and family-to-work conflict and role conflict, role ambiguity, job burnout, job tension, intention to leave an organization, and search for another job and (b) the negative association between work-to-family and family-to-work conflict and organizational commitment and job satisfaction. Netermeyer et al. (1996) also predicted work-to-family and family-to-work conflict to be negatively associated with life satisfaction, relationship satisfaction, and relationship agreement, and found 15 out of 16 correlations across three samples to be significant. All positive correlations between work-to-family and family-to-work conflict and physical symptomology and depression were significant. 
A total of 10 items was used in the present study; five items measured work-tofamily conflict and five items measured family-to-work conflict. An example item for work-to-family conflict is, "The amount of time my job takes up makes it difficult to fulfill my family responsibilities." An example item for family-to-work conflict is, "The demands of my family or spouse/partner interfere with work-related activities." The coefficient alpha reliability for participants in the current study for work-to-family conflict was .87 and for family-to-work conflict was .85 .

Safety performance. Neal, Griffin, and Hart (2000) measured the two components of safety performance using two separate measures. Safety compliance measures an individual's level of compliance with safety procedures, and Neal et al. (2000) found an alpha of .94 when measuring safety compliance with four items. Safety participation measures the extent to which employees participate in safety-related activities at work, with four items having an alpha of .89 in Neal et al.'s (2000) study. Although there is a strong body of work examining safety performance, there is a lack of validity information pertaining to safety compliance and safety participation as conceptualized by Griffin and Neal (DeArmond, Smith, Wilson, Chen, \& Cigularov, 2011).

In the present study four items were used to measure safety compliance and four items were used to measures safety participation. A 5-point Likert scale was used to rate each item in the two scales, with 1 representing "strongly disagree" and 5 representing "strongly agree." Higher safety compliance scores indicate that employees perform their work in a safe manner. Higher safety participation scores indicate that employees are 
willing to participate in safety-related activities. Sample items for safety compliance include, "I ensure the highest levels of safety when I carry out my job," and "I carry out my work in a safe manner." Sample items for safety participation include, "I voluntarily carry out tasks or activities that help to improve my workplace safety," and "I help my co-workers when they are working under risky or hazardous conditions." The coefficient alpha reliability provided by the current study was .89 for safety compliance and .74 for safety participation.

Supervisor instrumental support. FSSB is a construct conceptualized by Hammer et al. (2007) and the measure was developed and validated by Hammer et al. (2009). The multidimensional measure of FSSB consists of 14 items rated on a scale from 1 (strongly disagree) to 5 (strongly agree). Higher scores indicate that employees perceive their supervisors to be engaging in more supportive behaviors. The overall FSSB measure was found by Hammer et al. (2009) to have an alpha of .94. It is composed of four subordinate dimensions. Emotional support $(\alpha=.90)$ measures the degree to which employees perceive their supervisors care for or consider their feelings, and that employees feel comfortable communicating with their supervisors. Role modeling ( $\alpha=.86)$ measures the extent to which employees' observe their supervisors behaviorally demonstrating ways to integrate work and family. Instrumental support $(\alpha=$ .73) measures the degree to which employees perceive their supervisors as responsive to their work and family needs in the form of day-to-day management transactions. Creative work-family management ( $\alpha=.90)$ measures the extent to which employees perceive that their supervisors initiate the restructuring of work to facilitate their effectiveness while at 
work and while at home. My hypothesized model includes only the instrumental support dimension, but additional analyses were run using the overall measure of FSSB and the other three dimensions, so they are described here.

Hammer et al. (2009) provided evidence of convergent validity by correlating the scale score of the overall measure of FSSB with scores on Shinn et al.'s (1989) measure of supervisor support behaviors $(r=.68)$ and Yoon and Lim's (1999) measure of general supervisor support behaviors $(r=.74)$. The four dimensions of FSSB correlated with Yoon and Lim's (1999) measure: emotional support $(r=.68)$, instrumental support ( $r=$ $.67)$, role modeling $(r=.61)$, and creative work-family management $(r=.64)$. The four dimensions also correlated with Shinn et al.'s (1989) measure: emotional support ( $r=$ $.64)$, instrumental support $(r=.56)$, role modeling $(r=.55)$, and creative work-family management $(r=.59)$. The large correlations imply a strong conceptual overlap in overall FSSB and the four dimensions, which provides evidence of convergent validity.

Hammer et al. (2009) provided evidence of criterion-related validity by using FSSB scores as predictors of six important work-family and job outcomes in multilevel regression models, with the number of hours worked and the number of children living at home included as control variables. FSSB was significantly related to five of the six outcomes: (a) significantly and negatively related to work-to-family conflict $(\beta=-.31$, $\left.\mathrm{CI}_{95}=-.44,-.19\right)$ and turnover intentions $\left(\beta=-.46, \mathrm{CI}_{95}=-.62,-.30\right)$ and $(\mathrm{b})$ significantly and positively related to work-to-family positive spillover $\left(\beta=.10, \mathrm{CI}_{95}=.01, .19\right)$, family-to-work positive spillover $\left(\beta=.19, \mathrm{CI}_{95}=.10, .28\right)$, and job satisfaction $(\beta=.42$, 
$\left.\mathrm{CI}_{95}=.33, .51\right)$. FSSB was not significantly related to family-to-work conflict $(\beta=-.01$, $\left.\mathrm{CI}_{95}=-.10, .07\right)$

For instrumental support, the respondents rated three items. An example item is, "I can rely on my supervisor to make sure my work responsibilities are handled when I have unanticipated nonwork demands." Cronbach's alpha from the present study for the instrumental component of the FSSB scale was .73. Emotional support was measured using four items, with an example item being, "My supervisor makes me feel comfortable talking to him or her about my conflicts between work and nonwork.” The alpha reliability of emotional support in the present study is .90 . The role modeling dimension includes three items with an alpha of .86 in the present study. An example item includes, "My supervisor demonstrates effective behaviors in how to juggle work and nonwork balance." Creative work-family management is composed of four items, which includes the item, "My supervisor is creative in reallocating job duties to help my department work better as a team." Cronbach's alpha reliability from the present study for creative work-family management is .90 .

Perceived control over work hours. Four items developed by Bond, Galinsky, and Hill (2004) for the Sloan Foundation Work Survey entitled, When work works: A project on workplace effectiveness and workplace flexibility, were used to assess employees' perceived control over work hours. The respondents rated each item on a Likert scale ranging from 1 to 4 . A rating of 1 represents "none," 2 represents "a little," 3 represents "some," and 4 represents "a lot." The items were preceded by the statement, "How much control do you have...." Sample items include, “...over which shifts you 
work?" and "...over the scheduling of your work hours?" The coefficient alpha reliability for the four items from the present study was .62 .

Control variables. Control variables are extraneous variables that are not associated with hypotheses being examined (Spector \& Brannick, 2011). In order to explain the reasoning for including seven control variables in this study, I will refer to the relevant literature for not only safety performance but also work-family conflict. The seven control variables that will be discussed are age, gender, marital status, parental status, elder care status, job tenure, and hours worked per week. Age, job tenure, and hours worked per week are continuous variables that did not need to be dummy coded. Gender, marital status, parental status, and elder care status are categorical variables that were dummy coded for use in the analyses. For gender, male was coded as 0 and female was coded as 1. Marital status was treated as a dichotomous variable with divorced or separated, widowed, and never married combined and coded as 0 and married or living as married combined and coded as 1 . Parental status was coded as 0 for those employees without children living at home and 1 for those employees with children living at home. Regarding elder care status, employees not caring for elderly adults were coded as 0 and employees caring for elderly adults were coded as 1 .

In the model, work-to-family conflict and family-to-work conflict, as mediators, are endogenous variables just like safety compliance and safety participation. In a SEM model, when one variable is controlled for in relation to one endogenous variable, it must be used as a control variable for all endogenous variables. Therefore, while arguments for 
the use of certain control variables are not made with regard to safety performance, the seven control variables discussed were regressed on all endogenous variables.

Safety performance. Age is an individual attribute that has been established as an important contributor to safety performance. In an examination of construction workers, one of the most studied groups of workers in safety research, Sawacha, Naoym, and Fong (1999) found that age is strongly related to safety performance. In particular, individuals between the ages of 16 to 20 experienced the highest number of accidents. The number of experienced accidents tends to decline after the age of 28 , reaching a low in the midforties. Age is usually linked to experience so that the older an individual is, the more experience s/he possesses, and the more aware of safety requirements for the job (Sawacha et al., 1999). This will also account for job tenure being included as a control variable in this study as it affects safety performance. Similarly, Siu, Phillips, and Leung (2003) studied construction workers in Hong Kong and found a curvilinear relationship between age and occupational injuries. There is an increase in the frequency of injuries as one ages and then that frequency declines after middle-age.

Age is also related to risk taking, and risk taking has been found to be related to safety performance (Christian et al., 2009). Risk taking involves individuals who engage in unsafe behaviors because they are excited by risk or because they underestimate the likelihood of accidents (Christian et al., 2009). Nicholson, Soane, Fenton-O'Creevy, and Willman (2005) found that risk taking is inversely related to age so that risk taking decreased with age. Therefore, age is an important variable to account for in regard to safety performance. 
In addition to age, gender is included as a control variable for safety performance because it has also been found to influence the number of accidents and injuries (safety outcomes) experienced on the job (IWH, 2006a; Liao, Arvey, Butler, \& Nutting, 2001; Loughlin \& Frone, 2004; Schulte et al., 2005). For example, Liao et al. (2001) found that female firefighters experienced a greater number of injuries than male firefighters, even after controlling for age, tenure, race, personality, and secular differences. This gender difference may be attributable to a higher rate of reporting injuries, especially minor injuries, by female workers (Liao et al., 2001). Alternatively, men experienced $93 \%$ of fatal work injuries in 2009 in the United States compared to the 7\% of fatal work injuries women experienced (BLS, 2011). The men's share of fatal work injuries is disproportionate relative to their hours worked per week, with men working $56 \%$ of the total hours worked per week in 2009. This may be attributed to the fact that the highest number of fatal injuries occurs in the construction industry, which is male-dominated (BLS, 2011). Either way, there is a gender difference regarding the safety concern of injuries, and so gender needs to be controlled in relation to safety performance.

The number of hours worked per week has also been found to be an important determinant of safety performance. The mechanism through which the number of hours worked per week can impact safety performance is the fatigue that can accompany a greater number of hours worked, which leads to attentional failures (Lockley et al., 2004). Working a greater number of hours also increases one's exposure to hazards on the job (Caruso et al., 2006). Numerous studies have found that an increased number of work hours can lead to safety issues like motor vehicle crashes (Barger et al., 2005) and 
medical errors (Landrigan et al., 2004). Inness, Turner, Barling, and Stride (2010) identified hours worked per week as a control variable and found it to be significantly related to safety participation in their analysis. Therefore, hours worked per week will be included as a control variable for safety performance in this study.

Work-family conflict. Seven control variables were identified that might affect participants' work and family experiences: age, gender, marital status, parental status, elder care status, job tenure, and hours worked per week (Hammer et al., 2005; Major et al., 2002). Age, gender, and marital status all impact the number of responsibilities people have in their lives, such as household or caregiving responsibilities, which contribute to work-family conflict (Barnett \& Hyde, 2001; Halpern, 2005). Pertaining specifically to age, older individuals, who tend to have stable careers, place a greater emphasis on work and family balance (Gordon \& Whelan, 1998). Regarding gender, past reviews have shown that men are performing more child care tasks and tasks at home than before, especially when their wives are employed (Barnett \& Rivers, 1996). Yet, women are still performing more care activities than men, including child care, elder care, and home care (Halpern, 2005). Specifically, even though men are performing more child care tasks and other tasks at home than at any time before, $85 \%$ of women, compared to $67 \%$ of men, spend time performing household tasks like cleaning and cooking (Halpern, 2005). Marital status, specifically regarding whether someone has a significant other, is important when examining work-family conflict because having support at home can decrease work-family conflict (Hammer, Allen, \& Grigsby, 1997). Having a significant other can also increase work-family conflict if there are more 
responsibilities, such as when one is part of a dual-earner couple (Hammer et al., 1997). Overall, age, gender, and marital status are important characteristics to control for when examining work-family conflict.

Family demands such as parental status and elder care status and work demands like number of hours worked per week affect work-family conflict because they affect the amount of resources people have to deal with both work and family issues (Kelly \& Moen 2007). A number of trends that are increasing in the United States, including more employed parents who care for children under the age of 18 , an increase in the number of dual earner parents, and $15 \%$ of the workforce being "sandwich generation" employees who care for aging parents and financially dependent children or grandchildren, correspond to an increase in workers experiencing work-family conflict (Kossek, 2006). It is important to control for parental status and elder care status when examining the mediators in this study given that both contribute to employees' work-family conflict. Number of hours worked per week has also been found to relate to work-family conflict in that longer work hours take time away from employees' personal lives, which can create work-to-family conflict (Major et al., 2002). Similarly, greater time spent at home will leave less time to work, which may create family-to-work conflict if employees are expected to work a certain number of hours (Parasuraman, Pruohit, Godshalk, \& Beutell, 1996). Therefore, parental status, elder care status, and number of hours worked per week will be controlled when examining work-family conflict.

Job tenure is also an important control variable with regard to work-family conflict. Employees who have higher job tenure are believed to have greater flexibility, 
which may reduce work-family conflict. For example, lower tenure employees may be required to work nights or weekends while higher tenure employees are not, which can increase work-family conflict (Lambert, Hogan, \& Barton, 2004). Also, it has been reported that employees who have shorter tenure experience higher levels of work-family conflict (Grandey \& Cropanzano, 1999). Yet, Greenhaus, Parasuraman, Granrose, Rabinowitz, and Beutell (1989) found that older workers and those with higher tenure experienced higher work-family conflict. Regardless, job tenure has been shown to have an effect on work-family conflict and is controlled for in the present study.

Store effects. Data were collected from 12 different grocery stores in one grocery store chain. An analysis of variance (ANOVA) was run for each mediator and outcome variable to determine if there were store differences. The first ANOVA showed that safety compliance varied across employees in the 12 different stores, $F(11,339)=1.86, p$ $=.04$. The second ANOVA showed that safety participation also varied across different employees in the 12 different stores, $F(11,339)=2.79, p=.00$. Neither work-to-family conflict, $F(11,339)=.70, p=.74$, or family-to-work conflict, $F(11,339)=.33, p=.98$, varied across employees in the 12 different stores. Yet, as discussed previously, when one endogenous variable is controlled for in a moderated mediation model, all endogenous variables are controlled for in the model. Therefore, the 12 stores were dummy coded and used as control variables in this study. 


\section{Chapter 9: Results}

\section{Analytic Approach}

Descriptive statistics. Table 5 presents the means, standard deviations, and internal consistency reliabilities of variables used in the current study. Correlations of study variables are also provided in Table 5 to show the interrelatedness of the measures. There are numerous significant correlations among the study variables. Control over work hours was inversely related to work-to-family conflict $(r=-.25, p<0.01)$ and directly related to supervisor instrumental support $(r=.27, p<0.01)$. Work-to-family conflict was positively correlated with family-to-work conflict $(r=.40, p<0.01)$ and negatively correlated with supervisor instrumental support $(r=-.26, p<0.01)$. Family-towork conflict was inversely related to both safety compliance $(r=-.16, p<0.01)$ and safety participation $(r=-.11, p<0.05)$. Safety compliance was positively related to safety participation $(r=.54, p<0.01)$. These correlations were in the expected directions.

In line with recommendations in the literature (Edwards \& Lambert, 2007; Muller, Judd, \& Yzerbyt, 2005; Preacher, Rucker, \& Hayes, 2007), structural equation modeling (SEM) techniques were used to analyze the moderated mediation model. Moderated mediation is also known as a conditional indirect effect because the strength of an indirect effect varies across the levels of another variable (Preacher et al., 2007). It is best to test moderated mediation using SEM because all paths can be estimated simultaneously (Preacher et al., 2007). There are several kinds of moderated mediation, with this study examining a first- and second-stage moderation, where a fourth variable moderates both paths of the indirect effect. 
SEM offers several strengths over conventional ordinary least-squares (OLS) regression. First, maximum likelihood estimation procedures used in SEM accommodate missing data better than most other procedures (Arbuckle, 1996). Second, bootstrapping can be used in SEM, which is steadily becoming the preferred method of testing indirect effects (MacKinnon, Lockwood, \& Williams, 2004) and can handle the analysis of nonnormal data that violate the basic assumption of OLS regression (West, Finch, \& Curran, 1995; Yung \& Bentler, 1996). Bootstrapping will be discussed in more detail during the discussion of the hypotheses regarding mediating relationships.

As previously mentioned, several authors have explained methods for examining moderated mediation (e.g., Edwards \& Lambert, 2007; Muller et al., 2005; Preacher et al., 2007). The basic form of the over-identified model I examined was the same across all analyses. An over-identified model has a greater number of observations than free parameters, which leads to a number of degrees of freedom greater than zero (Kline, 2011). The entire model was tested using Amos 7.0 (Arbuckle, 2006). The indirect association between perceived control over work hours and safety performance through work-to-family conflict was examined by constraining the paths to and from family-towork conflict to zero. The indirect association between perceived control over work hours and safety performance through family-to-work conflict was examined by constraining the paths to and from work-to-family conflict to zero. The hypothesized indirect associations are represented through combined effects of two paths, illustrated in Figure 3 , in the moderated mediation model. The hypothesized effects of the moderator (i.e., supervisor instrumental support) are denoted with the subscript $\mathrm{M}$ in Figure 3. I 
centered the predictor and moderator variables by subtracting the mean of each variable before calculating the cross products (Aiken \& West, 1991).

Five cases were found to have missing data. Given the small number of cases with missing data, they were excluded from the SEM analyses through listwise-deletion (Kline, 2011). Therefore, the sample size was reduced to 355 to examine only complete records. Confidence intervals for the hypothesized indirect effects were calculated using bias-corrected bootstrap procedures with 2000 resamples from the original data (MacKinnon et al., 2004). MacKinnon et al. (2004) recommended reporting biascorrected bootstrap procedures over percentile-based bootstrap procedures because the confidence intervals in the latter method are often too wide and therefore are not as stringent as the former method, which produces more accurate confidence intervals. Effect sizes for each individual relationship in the model are provided by estimates of the standardized path coefficients.

For the confirmatory factor analysis (CFA) evaluations and model comparisons, I applied the comparative fit index (CFI) and the root-mean-square error of approximation (RMSEA) because they are frequently reported (Coovert \& Craiger, 2000; Lang, Bliese, Lang, \& Alder, 2011). Regarding CFI, values above .95 are considered an excellent fit (Hu \& Bentler, 1999). Values below .05 are considered an excellent fit for RMSEA (MacCallum, Browne, \& Sugawara, 1996), with values at .08 or below considered reasonable (Vandenberg \& Lance, 2000).

\section{Preliminary Analyses}


The first step of conducting SEM analyses is to examine the measurement model. Therefore, I first conducted CFAs to confirm a two-factor structure of the work-family conflict measure and of the safety performance measure. A comparison of the one-factor and two-factor models for both work-family conflict and safety performance is shown in Table 6. A CFA with work-to-family conflict and family-to-work conflict as distinct factors demonstrated adequate fit to the data, $\chi^{2}(34, N=355)=140.00, p<.001, \mathrm{CFI}=$ .99, RMSEA $=.09$. A CFA with work-to-family conflict and family-to-work conflict as one factor demonstrated worse fit to the data than the two-factor model, $\chi^{2}(35, N=355)$ $=671.06, p<.001, \mathrm{CFI}=.93, \mathrm{RMSEA}=.23 . \mathrm{A}$ chi-square difference test was applied and it was determined that the improvement in fit with two factors instead of one factor was statistically significant, $\chi^{2}{ }_{D}(1, N=355)=531.06, p=<.0001$. This finding is in line with the significant correlation of work-to-family conflict and family-to-work conflict ( $r$ $=.40, p<0.001)$, which is a moderate correlation demonstrating a connection between the two factors, but not a large correlation that would suggest a one-factor model.

A CFA with safety compliance and safety participation as distinct factors demonstrated adequate fit to the data, $\chi^{2}(19, N=355)=68.17, p<.001, \mathrm{CFI}=.99$, RMSEA $=.09$. A CFA with safety compliance and safety participation as one factor demonstrated worse fit to the data than the two-factor model, $\chi^{2}(20, N=355)=229.20$, $p<.001, \mathrm{CFI}=.98, \mathrm{RMSEA}=.17$. A chi-square difference test was also applied to the safety performance CFAs and it was determined that the improvement in fit with two factors instead of one factor was statistically significant, $\chi^{2}{ }_{D}(1, N=355)=161.03, p<$ .001. Again, this finding demonstrates support for the significant correlation between 
safety compliance and safety participation $(r=.54, p<0.001)$, which is a moderate

correlation that indicates two factors, but not a large correlation that would suggest a onefactor model.

\section{Hypothesis Testing}

A summary of the hypotheses can be found in Table 7. The hypothesized model is depicted in Figure 4. The path coefficients for the final model are shown in Table 8 and in Figure 5.

Hypotheses 1a and 1b. Hypothesis 1 concerned whether perceived control over work hours would have a negative direct effect on both work-to-family conflict (Hypothesis 1a) and family-to-work conflict (Hypothesis 1b). As hypothesized, control over work hours was negatively associated with work-to-family conflict (Path A: $\beta=-$ $\left..26 ; \mathrm{CI}_{95}=-.35,-.17 ; p<.01\right)$. When there was a higher level of perceived control over work hours, less work-to-family conflict was experienced. The relationship between perceived control over work hours and family-to-work conflict was in the hypothesized direction and it was significant (Path $\mathrm{B}: \beta=-.15 ; \mathrm{CI}_{95}=-.25,-.05 ; p=<.05$ ). When employees perceived to have control over their work hours, family did not greatly interfere with work. Hypothesis 1 was supported.

Hypotheses 2a, 2b, 3a and 3b. Hypothesis 2 concerned whether work-to-family conflict had a negative direct effect on safety compliance (Hypothesis 2a) and safety participation (Hypothesis $2 \mathrm{~b}$ ). Hypothesis 3 concerned whether family-to-work conflict had a negative direct effect on safety compliance (Hypothesis 3a) and safety participation (Hypothesis 3b). It was found that work-to-family conflict was not significantly 
associated with safety compliance (Path $\mathrm{C}: \beta=.04 ; \mathrm{CI}_{95}=-.08, .15 ; p=.62$ ). Similarly, work-to-family conflict was not significantly associated with safety participation (Path D: $\left.\beta=.06 ; \mathrm{CI}_{95}=-.06, .17 ; p=.46\right)$. Therefore, Hypothesis 2 was not supported.

Conversely, family-to-work conflict was significantly associated with safety compliance (Path E: $\beta=-.16 ; \mathrm{CI}_{95}=-.28,-.03 ; p<.05$ ). When more family-to-work conflict was experienced, employees did not follow safety rules on the job. The relationship between family-to-work conflict and safety participation was also found to be significant (Path F: $\beta=-.14 ; \mathrm{CI}_{95}=-.25,-.03 ; p<.05$ ). When family responsibilities interfered with work, employees were less willing to participate in safety-related activities. Therefore, Hypothesis 3 was fully supported.

Hypotheses $4 \mathbf{a}$ and $4 \mathrm{~b}$. The traditional analysis used to demonstrate mediating relationships uses a series of regression analyses (Baron \& Kenny, 1986). Recently the application of the Baron and Kenny method (1986) in research has decreased because methodologists have identified potential limitations in its multistep approach (MacKinnon, Lockwood, Hoffman, West, \& Sheets, 2002). Baron and Kenny suggested that to support mediation, the direct effect from the independent variable $(X)$ to the outcome $(Y)$ must be significant in Step 1, and that one cannot proceed with the additional steps unless significance is found. The issue is that with more complex meditational processes, the size of the association between $X$ and $Y$ typically becomes smaller because that relationship is more likely to be "(a) transmitted through additional links in a causal chain, (b) affected by competing causes, and (c) affected by random factors" (Shrout \& Bolger, 2002, p. 429). Such reasoning has led methodologists to 
question the necessity of demonstrating the existence of the direct effect from $X$ to $Y$ (MacKinnon, Krull, \& Lockwood, 2000; Shrout \& Bolger, 2002). In fact, an update to the Baron and Kenny (1986) approach states that Step 1 is no longer essential in confirming mediation (Kenny, Kashy, \& Bolger, 1998).

It is now more common and more highly recommended to perform a single test, which was first proposed by Sobel (1982; MacKinnon et al., 2002). The Sobel test more directly addresses mediation because it is based on formal significance tests of the indirect effect of $a b$ (MacKinnon, Warsi, \& Dwyer, 1995; Preacher \& Hayes, 2004). Not only is the Sobel test very conservative (MacKinnon et al., 1995), but there is an assumption that the indirect effect $a b$ is normally distributed (Edwards \& Lambert, 2007). This is a weak assumption because the distribution of $a b$ is nonnormal even when the variables forming the product $a b$ are normally distributed (Edwards \& Lambert, 2007). Bootstrapping is now gaining popularity as an alternative test to replace the Sobel test of indirect effects (Shrout \& Bolger, 2002). Using bootstrapped confidence intervals prevents power problems that occur when there are nonnormal sampling distributions (MacKinnon et al., 2004).

The bias-corrected standardized indirect effects are reported for all four proposed mediations. The indirect relationship between perceived control over work hours and safety compliance through work-to-family conflict was not significantly different from zero (Path AC: $\left.\beta=.00, \mathrm{CI}_{95}=-.02, .02 ; p=.92\right)$. The indirect relationship between perceived control over work hours and safety compliance through family-to-work conflict was not significantly different from zero (Path BE: $\beta=.01, \mathrm{CI}_{95}=.00, .02 ; p=.23$ ). The 
indirect relationship between perceived control over work hours and safety participation through work-to-family conflict was not significantly different from zero (Path AD: $\beta=$ $\left..01, \mathrm{CI}_{95}=-.01, .03 ; p=.52\right)$. The indirect relationship between perceived control over work hours and safety participation through family-to-work conflict was not significantly different from zero (Path BF: $\beta=.01, \mathrm{CI}_{95}=.00, .03 ; p=.24$ ). Hypotheses $4 \mathrm{a}$ and $4 \mathrm{~b}$ were not supported.

Hypotheses 5a and 5b. Hypothesis 5 concerned whether supervisor instrumental support interacted with work-to-family conflict (Hypothesis 5a) and family-to-work conflict (Hypothesis 5b) in the prediction of safety performance (e.g., safety compliance and safety participation). Supervisor instrumental support did not moderate the relationship between work-to-family conflict and either safety compliance (Path $\mathrm{C}_{\mathrm{M}}$ : $\beta=$ $\left.-.06 ; \mathrm{CI}_{95}=-.16, .06 ; p=.43\right)$ or safety participation $\left(\right.$ Path $\mathrm{D}_{\mathrm{M}}: \beta=-.06 ; \mathrm{CI}_{95}=-.16, .04$ $p=.35)$. It was also found that supervisor instrumental support did not moderate the relationship between family-to-work conflict and either safety compliance (Path $\mathrm{E}_{\mathrm{M}}$ : $\beta=$ $\left..05 ; \mathrm{CI}_{95}=-.08, .18 ; p=.54\right)$ or safety participation $\left(\right.$ Path $\mathrm{F}_{\mathrm{M}}: \beta=.05 ; \mathrm{CI}_{95}=-.06, .17 ; p$ $=.44)$. Hypotheses $5 \mathrm{a}$ and $5 \mathrm{~b}$ were not supported.

Hypotheses 6a and 6b. Hypothesis 6 concerned whether supervisor instrumental support interacted with perceived control over work hours in the prediction of work-tofamily conflict (Hypothesis 6a) and family-to-work conflict (Hypothesis 6b). Supervisor instrumental support did not moderate the relationship between perceived control over work hours and work-to-family conflict (Path $\mathrm{A}_{\mathrm{M}}: \beta=.01 ; \mathrm{CI}_{95}=-.10, .12 ; p=.96$ ). Supervisor instrumental support was not found to moderate the relationship between 
perceived control over work hours and family-to-work conflict (Path $\mathrm{B}_{\mathrm{M}}: \beta=-.07 ; \mathrm{CI}_{95}=$ $-.18, .05 ; p=.36)$. Hypothesis 6 was not supported.

\section{Additional Analyses}

In a moderated mediation model, it is necessary to regress the outcome variables on the moderator variable in order to estimate the indirect paths of the mediating relationships. This generates path coefficients for the direct relationships between the moderator and the outcomes. The direct relationship between supervisor instrumental support and safety compliance had been found to be significant (Path $\mathrm{G}: \beta=.17$ CI $_{95}=$ $.07, .27 ; p<.01)$. The direct relationship between supervisor instrumental support and safety participation had also been found to be significant (Path $\mathrm{H}: \beta=.21 ; \mathrm{CI}_{95}=.11, .31$; $p<.01)$. Therefore, while supervisor instrumental support did not act as a moderator in the model, support was directly associated with safety compliance and safety participation so that higher levels of supervisor instrumental support were associated with more safety compliance and safety participation in the workplace. Regarding the influence of a supervisor's instrumental support on work-to-family and family-to-work conflict, the direct relationship between supervisor instrumental support and work-tofamily conflict had been found to be significant (Path I: $\beta=-.14 ; \mathrm{CI}_{95}=-.23,-.03 ; p<$ $.05)$. The direct relationship between instrumental supervisor support and family-to-work conflict had not been found to be significant (Path $\mathrm{J}: \beta=-.01 ; \mathrm{CI}_{95}=-.14, .13 ; p=.98$ ). Therefore, higher levels of supervisor instrumental support were associated with lower levels of work-to-family conflict but not family-to-work conflict. 
Chi-square difference tests were conducted to determine if the hypothesized model fit the data better than competing models with either the perceived control over work hours - safety compliance relationship added or the perceived control over work hours - safety participation relationship added. The chi-square statistics for the hypothesized model showed the model had adequate fit to the data, $\chi^{2}(2, N=355)=$ $4.48, p=.11, \mathrm{CFI}=.99, \mathrm{RMSEA}=.06$. The model with the direct relationship between perceived control over work hours and safety compliance added did not show adequate fit to the data, $\chi^{2}(1, N=355)=6.11, p<.05, \mathrm{CFI}=.99$, RMSEA $=.12$. The model with the direct relationship between perceived control over work hours and safety participation demonstrated adequate fit with the data, $\chi^{2}(1, N=355)=4.85, p=.05, \mathrm{CFI}=.99$, RMSEA $=.10$. Regarding the hypothesized model and the model with the direct effect between perceived control over work hours and safety compliance, the chi-square difference test demonstrated that the competing model did not significantly fit the data better, $\chi^{2}(1, N=355)=1.63, p=.20$. A chi-square test also demonstrated that the competing model with the added relationship between perceived control over work hours and safety participation did not significantly fit the data better than the hypothesized model, $\chi^{2}(1, N=355)=.37, p=.54$. Therefore, it was not justified to examine the direct effects between perceived control over work hours and safety compliance and participation.

Post hoc analyses were also conducted to determine the effect of the overall FSSB measure in the model and the effects of the separate dimensions in addition to the instrumental support dimension included in the hypothesized model (see Table 9). The 
overall construct of FSSB and its separate dimensions demonstrated similar patterns in all hypothesized relationships and in additional relationships examined. The moderating or mediating relationships are not shown in the table because they were all non-significant. The three exceptions include: (a) the relationship between family-to-work conflict and safety participation in the model examining creative work-family management, (b) the relationship between creative work-family management and safety participation, and (c) the relationships between both emotional support and role modeling behaviors and workto-family conflict. The relationship between family-to-work conflict and safety participation became non-significant when the hypothesized model included creative work-family management in place of instrumental support while the relationship was significant for the other two dimensions of the FSSB measure (i.e., emotional support and role modeling behaviors), as well as for overall FSSB. Of the three inconsistencies between the original findings pertaining to instrumental supervisor support and the post hoc analyses examining each of the dimensions of FSSB and overall FSSB, creative work-family management was involved each time. Creative work-family management may be the most distal dimension of FSSB in that it involves a "dual agenda" where, in addition to employees' work and family needs, higher-level organizational goals (e.g., productivity) that do not necessarily have an immediate or apparent impact on employees' work and family lives are taken into account (Hammer et al., 2007). This dimension may be more important to an organization as it assures that not only are employees' work and family needs being met, but productivity is being considered and positively affected as well. Therefore, creative work-family management may be a 
necessary component of redesigning work to support family demands, which is why safety participation was significantly affected by family-to-work conflict when overall FSSB was in the model, but it is not a sufficient component alone from the perspective of the employees.

The relationship between creative work-family management and safety participation was also not significant, while the relationships between the other dimensions of FSSB and overall FSSB were significantly related to safety participation. The non-significant relationship, however, was just above the .05 level of significance, which some would label as marginally significant, therefore corresponding to the other results regarding different dimensions of FSSB being associated with safety participation. In fact, the effect size and confidence interval of the creative work-family management safety participation relationship almost exactly match the effect size and confidence interval of the emotional support - safety participation relationship, which was found to be significant.

The relationship between support and work-to-family conflict was either significant or non-significant depending on the dimension of FSSB examined. When instrumental support, creative work-family management, or overall FSSB predicted work-to-family conflict, the relationship was significant. When emotional support or role modeling behaviors predicted work-to-family conflict, the relationship was nonsignificant. This is interesting given that FSSB pertains specifically to behaviors exhibited by supervisors to support families, which one would expect to reduce the disruptions work causes to employees' families. This relationship may differ depending 
on the specific dimension of FSSB investigated because instrumental support and creative work-family management produce tangible benefits like schedule changes or cross-training within and between departments, respectively (Hammer et al., 2007). Emotional support and role modeling behaviors involve more abstract resources being offered by supervisors to their employees (e.g., expressing concern for employees' family responsibilities and providing examples of strategies to lead to desirable work-life outcomes, respectively; Hammer et al., 2007). Perhaps tangible resources have a greater impact on work-to-family conflict than abstract resources. Yet, abstract resources necessitate also having tangible resources, which would explain the significant relationship between overall FSSB, which includes all four dimensions, and work-tofamily conflict. Making use of different types of support may also depend on the type of employees receiving the support. More proactive employees, who take initiative in improving current circumstances or creating new ones (Crant, 2000), may be able to utilize different types of resources better than employees who are not willing to work toward their own work-family balance by making abstract resources into more tangible ones for themselves. Future research could examine the ways different employee characteristics influence the impact of FSSB on outcomes such as work-family conflict.

\section{Summary of Results}

Table 10 provides a summary of all results in this study. Half of the direct relationships hypothesized were supported. Perceived control over work hours was found to be significantly associated with work-to-family conflict so that a higher perception of control over work hours was associated with reduced levels of work-to-family conflict 
(Hypothesis 1a supported). The negative relationship between perceived control over work hours and family-to-work conflict was also significant in that employees were experiencing lower levels of family-to-work conflict when they perceived to have some level of control over their work hours (Hypothesis 1b supported). Work-to-family conflict was not significantly associated with either safety compliance (Hypothesis 2a not supported) or safety participation (Hypothesis $2 \mathrm{~b}$ not supported). Conversely, family-towork conflict was significantly associated with safety compliance (Hypothesis 3a supported) and safety participation (Hypothesis $3 \mathrm{~b}$ supported) so that employees followed safety rules and participated in additional safety activities when their family responsibilities did not interfere with work.

Four mediating relationships were hypothesized (Hypotheses 4a and 4b): (a) the indirect relationship between perceived control over work hours and safety compliance through work-to-family conflict, (b) the indirect relationship between perceived control over work hours and safety compliance through family-to-work conflict, (c) the indirect relationship between perceived control over work hours and safety participation through work-to-family conflict, and (d) the indirect relationship between perceived control over work hours and safety participation through family-to-work conflict. The mediating relationships hypothesized were not supported.

Supervisor instrumental support was hypothesized to moderate six relationships (Hypotheses 5a, 5b, 6a, and 6b): (a) the work-to-family conflict and safety compliance relationship, (b) the work-to-family conflict and safety participation relationship, (c) the family-to-work conflict and safety compliance relationship, (d) the family-to-work 
conflict and safety participation relationship, (e) the perceived control over work hours and work-to-family conflict relationship, and (f) the perceived control over work hours and family-to-work conflict relationship. Despite strong past findings regarding the buffering effect of support, none of the six moderating relationships were significant.

Given the lack of significant findings for both the mediating and moderating relationships, I conducted numerous post hoc analyses to determine other possible significant paths in the model examined. Supervisor instrumental support was found to directly affect work-to-family conflict in that a higher level of support reduced work-tofamily conflict. Supervisor instrumental support was also found to directly affect safety compliance and safety participation so that a higher level of support increased safety compliance and participation. While supervisor instrumental support was found to have a direct effect on work-to-family conflict, there was no direct effect between supervisor instrumental support and family-to-work conflict. Post hoc analyses were also conducted to determine if overall FSSB and the other three subdimensions, emotional support, role modeling, and creative work-family management, produced similar results to those found when instrumental support was used to examine the relationships in this study. Overall FSSB and the subdimensions demonstrated similar patterns in all hypothesized relationships and in additional relationships examined. The three exceptions include: (a) the relationship between family-to-work conflict and safety participation in the model examining creative work-family management, (b) the relationship between creative workfamily management and safety participation, and (c) the relationships between both emotional support and role modeling behaviors and work-to-family conflict. 


\section{Chapter 10: Discussion}

Over the past decade, the impact of organizational factors on safety performance and such negative consequences as accidents and injuries has been increasingly investigated in the literature (Burke, Chan-Serafin, Salvador, Smith, \& Sarpy, 2008). Macroergonomics attempts to shift the focus from only one aspect of the work environment (e.g., the individual worker, the equipment used, etc.) to a more comprehensive analysis of what contributes to safety problems and ways to ameliorate those problems. Occupational hazards, from a systems perspective, are conditions or incidents that occur as a result of the convergence of behavioral, organizational, operational, and physical-environmental factors that are specific to tasks, job operations, and sociotechnical systems (Imada, 2002). As Imada (2002) stated, most of the accidents and injuries in today's workplaces occur as a result of operational hazards, which are hazards related to job performance, dynamic operational circumstances, and/or irregular or temporary work conditions or situations for which there are no standard operating procedures or physical standards. Operational hazards include situations that are distracting to employees or that cause exhaustion and loss of focus like work-family conflict. This necessitates a systems approach to occupational safety hazards in which individuals and their external demands are taken into consideration along with promotion of a work system that contains resources to decrease those demands to positively affect safety.

I will now turn to a review of the results in which perceived control over work hours and supervisor instrumental support were proposed as important resources offered 
in the work environment hypothesized to reduce work-family conflict, which would then lead to higher levels of safety performance. I will then provide possible explanations for each of the findings and also examine post hoc analyses that were conducted to determine additional relationships after obtaining certain non-significant results. Based on all the results, I will discuss both the theoretical and practical implications of this study. Then I will review possible limitations of the study and suggest future areas of research that are based on the results. I will end this dissertation with a general conclusion.

\section{Direct Effects}

\section{Perceived control over work hours and work-family conflict. Control is}

important in today's work environment as workers' values have changed in that they both value and expect to have greater control over the planning and pacing of their work (Hendrick, 2002b). Perceived control over work hours was examined in the current study because of the growing desire employees have to gain more control and because control is an important concept in macroergonomics and sociotechnical systems theory. The importance of control in macroergonomics stems from macroergonomics' focus on the needs of the worker, not the job itself, and the worker's ability to determine the most effective ways (e.g., scheduling) to perform his/her job. As a component of the technical subsystem in sociotechnical systems theory, perceived control over work hours is a tool employees can utilize to directly influence their performance in the work domain and in the family domain. Additionally, according to COR theory, giving employees the opportunity to implement some level of control or preference concerning when they work enhances individuals' resources, allowing them to focus on the tasks at hand. 
An employee's perceived control over his/her work hours was negatively associated with work-to-family conflict. Therefore, when one is able to determine his/her own work hours, work issues interfere less with family matters. Freedom of choice regarding work hours is a resource located in the work domain that allows employees to deal with their work demands in a way that suits their needs, leaving less of a chance for work to interfere with their family responsibilities. According to the job design literature, there is uncertainty and also internal and external sources of variance in certain work environments that can cause reduced productivity, lower job satisfaction, and diminished well-being (Morgeson et al., 2010; Wright \& Cordery, 1999). As discussed previously in relation to sociotechnical systems theory, work-family conflict occurs as a result of the incompatibility between internal (i.e., work) and external (i.e., family) sources that can negatively affect work outcomes. Work-to-family conflict causes disruptions and uncertainty in one's life, and by increasing employees' perceived control over their work hours to alleviate the stress of work-to-family conflict brings the solution to the source (i.e., the employees). Wall, Jackson, and Davids (1992) asserted that variance in the environment that cannot be eliminated must be controlled at the source or as close to the source as possible. Therefore, perceived control over work hours reduces work-to-family conflict because employees are able to deal with work issues as they arise, preventing work problems from interfering too much with family matters.

Similarly, one's ability to determine his/her own work hours reduced the interference of family matters with work. This result is consistent with what was hypothesized and to what has been found in past studies. It was hypothesized that higher 
control over work hours gives employees more time to take care of family issues and schedule personal matters when needed because they are able to choose the work schedule that best suits their needs. Perceived control over work hours fits into the technical subsystem, which can be thought of as the aspects of the work environment that involve accomplishing tasks, including providing the tools to accomplish those tasks. Hence, perceived control over work hours is a tool that can be utilized by employees to reduce their family-to-work conflict. This corresponds to Cullen and Hammer's (2007) implication that, "Increased perceptions of control may make workers better equipped to meet their family responsibilities" (p. 275).

Work-family conflict and safety performance. Work-to-family conflict was not significantly associated with either safety compliance or safety participation. In contrast, family-to-work conflict was significantly associated with both safety compliance and safety participation. Distraction-conflict theory explains that any aspect of the work environment that diverts an individual's attention from task activities will place additional and conflicting demands on the individual's attention, thereby increasing the time needed to perform tasks and eventually reducing the quantity or quality of task performance (Baron, 1986). Therefore, a reduction in family-to-work conflict will reduce distractions, such as having to worry about children being home alone after school or having to schedule medical appointments. Reduced distractions will have a positive effect on safety outcomes because employees will have more resources available to focus on the tasks at hand instead of using resources to think about family demands that pull their attention somewhere other than safety issues. These findings replicate Cullen and 
Hammer's (2007) findings that family-to-work conflict, but not work-to-family conflict, is negatively associated with safety compliance and safety participation. In the Cullen and Hammer (2007) study, the standardized path coefficients were reported as -.27 for the family-to-work conflict - safety compliance relationship and -.23 for the family-towork conflict - safety participation relationship, both significant at the .001 level. In the current study, both the standardized and unstandardized path coefficients were -.16 and .14 for the safety compliance and safety participation relationships, respectively. All the family-to-work conflict - safety performance relationships were significant at the .05 level. The replication of these significant findings gives support to macroergonomics' assertion that external forces (i.e., family) can affect the safety of employees.

Given that work-to-family conflict was not associated with safety performance, it may be because work-to-family conflict has an effect in the family domain and safety performance occurs in the work domain. This also makes sense from a macroergonomics perspective because work would become the external force that is interfering with family, and the family domain does not include employee safety performance. However, and as discussed previously, it has been shown that some work and family factors have "simultaneously disruptive effects" within both the work and family domains (Byron, 2005 , p. 190). This is not the case with work-to-family conflict and safety performance, and Cullen and Hammer (2007) postulated that work-to-family conflict was not significantly associated with either safety compliance or safety participation because safety performance is a behavioral outcome and not an affective outcome. Given the results of this study and the Cullen and Hammer (2007) study, organizations can focus on 
ways to reduce employees' family-to-work conflict so that their safety performance improves.

\section{Mediating and Moderating Relationships}

Work-family conflict as a mediator. All of the meditating relationships proposed in this dissertation were not significant. Employees' perception of having control over their work hours was not found to indirectly affect safety compliance through either work-to-family conflict or family-to-work conflict. Also, perceived control over work hours did not indirectly impact safety participation through either work-tofamily conflict or family-to-work conflict. The impact of perceived control over work hours may not have been as great in this study because the participants had a restricted level of control over their work hours. A limiting factor for these employees was the lack of overtime offered in the grocery stores they worked. Regarding grocery stores in general, there are other issues related to scheduling that include new hires receiving better schedules than long-time employees, schedules being unpredictable because of constant changes, schedules varying depending on the managers creating them, the difficulty of having an entire weekend off or two days in a row off, and schedule requests not receiving much consideration (Boushey, Fremstad, Gragg, \& Waller, 2007; Hammer et al., 2007). This lack of complete control may have impacted the full effect perceived control could have in the mediating relationships. As will be discussed, additional analyses showed that perceived control over work hours had a direct effect on both workto-family and family-to-work conflict. 
Perhaps a different type of autonomy may have a significant effect on these mediating relationships, and it would be advantageous to test the model using all three types of autonomy (i.e., work scheduling autonomy, decision-making autonomy, and work methods autonomy; Jackson et al., 1993). For example, work methods autonomy may affect safety performance through work-to-family conflict or family-to-work conflict because employees would perceive having a greater influence over the way they accomplish their tasks, leaving a greater number of resources to handle work and family demands that could affect behaviors leading to accidents and injuries. More specifically, employees would be able to influence specific behaviors rather than just the order in which to complete those behaviors (Humphrey et al., 2007). This can occur in conjunction with the examination of numerous types of supervisor support given that the moderating effects of supervisor instrumental support were not significant in the present model. It may also be that a lack of perceived control over work hours for the participants constituted a "strong situation" (Mischel, 1968) in which there was a smaller chance to detect individual differences because the employees' behavior was constrained by the work situation in the grocery stores.

Supervisor instrumental support as a moderator. All of the moderating relationships proposed in this study were not significant. Supervisor instrumental support was hypothesized as a moderator, but it was not found to moderate either the relationships between work-to-family conflict and safety compliance and participation or the relationships between family-to-work conflict and safety compliance and participation. The non-significant moderating effects are not all that surprising given that 
empirical support is mixed for the moderating effect of social support (Abdul-Halim, 1982; Ganster et al., 1986; Kickul \& Posig, 2001). Yet, Viswesvaran et al. (1999) found evidence supporting the moderating effects of general social support in their metaanalysis. Coworker support would align more with social support than supervisor support because coworkers are peers who employees may be more comfortable asking for help when they have work-family issues. For example, employees could ask each other to cover shifts at the last minute if a family situation occurred unexpectedly instead of calling a supervisor to call out of work. Or coworkers can cover on the floor if someone has to take a quick break to make a phone call regarding a medical appointment or child care arrangements.

Supervisor instrumental support was also hypothesized and found not to moderate either the relationship between perceived control over work hours and work-to-family conflict or the relationship between perceived control over work hours and family-towork conflict. Perhaps the amount of power a direct supervisor has limits the amount of instrumental support they can offer to their employees. In this type of work environment, there is a budget set for the total amount of money paid to employees each pay period (Hammer et al., 2007). Low-level supervisors cannot allow employees to work as many hours as they would like, especially where overtime is concerned, because that would most likely exceed the budget. There also needs to be a certain number of employees on the floor, leaving less room for supervisors to approve a schedule that has too many or too few employees working at one time. With such restrictions put on the supervisors, there is only so much instrumental support that can be offered to accommodate 
scheduling issues. Supervisor instrumental support may interact with other types of autonomy more than perceived control over work hours in grocery stores to reduce workfamily conflict. For example, work methods autonomy may be a more appropriate antecedent because supervisors can help grocery store workers have more opportunities to control the way they do their work rather than when they do their work, given all the limitations concerning budget and staffing numbers.

\section{Post Hoc Analyses}

\section{Supervisor instrumental support and safety performance. Given that} supervisor instrumental support was not found to moderate either the perceived control over work hours - work-family conflict relationships or the work-family conflict - safety performance relationships, I conducted a post hoc examination of the supervisor instrumental support - safety performance relationships. This was done because support, in addition to its moderating effects, has been found to have direct or main effects on strain and well-being (Parasuraman et al., 1992). The FSSB dimension of supervisor instrumental support, which is specific to work and family matters, was found to positively affect both safety compliance and safety participation. In other words, when supervisors respond to their employees' work and family needs in the form of day-to-day management transactions (e.g., explaining work-family policies, assisting with tasks, scheduling), employees adhere to safety rules (i.e., safety compliance) and increase their discretionary safety behavior (i.e., safety participation). Support, which has been an extensively examined construct in the organizational literature, is also an important component of the personnel subsystem in sociotechincal systems theory (Holman et al., 
2002). Supervisors help employees to cope with external demands that may not necessarily be handled by resources in the technical subsystem (Appelbaum, 1997). When supervisors act in a way that helps their employees deal with negative work-family issues or assist with specific actions geared toward resolving employees' work-family matters, work-family demands decrease and employees have more available resources to focus on safety performance. These findings give confirmation to the idea that workfamily issues are influential when it comes to safety performance.

Alternatively, Hofmann and Morgeson (1999) described safety-related behavior using social exchange theory (i.e., Gouldner, 1960; Blau, 1964): Individuals who are given support from their organization may feel obligated to give something in return, even if they do not receive rewards for engaging in that behavior. Supervisors who support their employees in their work-family matters exceed mandatory requirements set forth to protect workers' safety and health (Mearns et al., 2010). Therefore, employees may engage in a greater number of safety behaviors, like following safety rules, which will benefit not only themselves, but their company as well.

These findings regarding the direct association between supervisor instrumental support and safety compliance and participation align with the abundance of research that has found supportive leadership to be an essential determinant of organizational safety (Barling \& Zacharatos, 1999). Supervisors help to motivate employees to safely perform tasks that need to be completed (Neal \& Griffin, 2002). Differences in organizational characteristics regarding management commitment that discriminate between lowaccident and high-accident companies include regular contact and open communication 
links between management and employees (Cohen, Smith, \& Cohen, 1975). Additionally, safer companies promote safety through such actions as praising and recognizing individual employees for positive safety behaviors, and even enlisting employees' families in safety promotions (Cleveland, Cohen, Smith, \& Cohen, 1978; Davis \& Stahl, 1964, as cited in Zohar, 1980; National Safety Council, 1969, as cited in Zohar, 1980). A number of the attributes concerning management commitment found to positively affect safety align with supervisors' supportive behaviors toward employees and their families found in the FSSB measure that have been found in this study to influence safety compliance and participation. It would be advantageous to examine other types of supervisor behaviors that may impact workplace safety in future studies.

For instance, studies involving transformational leadership, a more general construct that does not specifically focus on safety, have found that this style, rather than transactional leadership, leads to better safety records (O’Dea \& Flin, 2000; Williams, Turner, \& Parker, 2000; Zohar, 2002a). Transformational leaders foster closer relationships with their employees, which are demonstrated by a greater concern for the members of their group, individualized consideration of employees' needs and capabilities, and a small power distance that has been shown to lead to incremental effects over that of transactional leadership in reducing negative safety outcomes (Bass, 1990; Yukl, 1998; Zohar, 2002b; Zohar \& Tenne-Gazit, 2008). Transformational leaders also create more opportunities for sharing and clarifying perceptions (Kozlowski \& Doherty, 1989) and have open lines of verbal communication with their employees (Klauss \& Bass, 1982). Together, the characteristics of transformational leaders lead to 
the transmission of more information from which employees can assess what is valued, prioritized, and supported by their supervisors (Zohar \& Tenne-Gazit, 2008).

More specifically, Mullen, Kelloway, and Teed (2011) examined transformational and passive leadership styles, with passive leadership defined as uninvolved leadership (Avolio, 1999; Bass, 1997), that are specific to safety. They hypothesized that the same leader could alternate between displaying transformational and passive leadership styles, which leads to inconsistent leadership. Employees who reported their supervisors to display safety-specific transformational leadership behaviors also reported higher levels of safety compliance and participation (Mullen et al., 2011). Displaying passive leadership behaviors along with transformational leadership behaviors attenuates the positive safety outcomes (i.e., safety compliance and participation) of safety-specific transformational leadership.

\section{Theoretical Implications}

Numerous theoretical implications can be identified from this dissertation. First, macroergonomics involves organizational structures, policies, and processes and utilizes theories that are applicable to I/O psychology. Two of the relevant topics studied within macroergonomics that pertain to this dissertation are design of working times and quality management (Hendrick, 2002a). Although not hypothesized, this dissertation found direct significant relationships between supervisor support and safety performance.

Interdisciplinary approaches to safety research are emerging and important in the pursuit of safer work environments. Macroergonomics and I/O psychology have commonalities 
that lend themselves to a good partnership where researchers can learn from each other and collaborate to advance the study of safety.

Second, Hofmann and Stetzer (1996) discussed the necessity of creating research models that are comprehensive because numerous systems and variables work together to create a safe work environment. Along these lines, safety directors and risk managers are exploring psychosocial and organizational factors in order to improve safety rather than focusing solely on engineering controls (Huang et al., 2010). Although the personnel component of instrumental supervisor support and the technical component of perceived control over work hours did not interact to reduce safety performance in the hypothesized model, both variables were found to have direct relationships with either work-family conflict and/or safety performance.

Third, and also in relation to a systems perspective, this dissertation has taken the occupational and organizational context into consideration. That includes exploring the boundaries of grocery store employees' perceived control over their work hours and the role of their supervisors' support in enacting that control and influencing their safety performance. Little research has examined the link between occupational and organizational context and work design, therefore doing so is a contribution to the literature (Morgeson et al., 2010). For example, Wall and Jackson (1995) contended that inconsistencies found in the job design literature might be because of a failure to incorporate such things as contextual uncertainty into the research. It is important for future research to explore varied contexts to determine what works and what does not in 
different work environments "to yield more veridical theoretical models of work design" (Morgeson et al., 2010, p. 357).

Similarly, and as discussed previously, increases in dual earner families, gender integration in organizations, single parents in the workforce, and employees with numerous family-care responsibilities have changed the nature of work and family roles (Kossek \& Lambert, 2005; Neal \& Hammer, 2007). Being part of a dual-earner couple or being a single parent can create situations outside of work that then affect employees in the work environment, especially for low-wage workers who have fewer financial resources to pay for such things as child care (Acs \& Loprest, 2005). Several constructs used in this study, perceived control over work hours, supervisor instrumental support, and work-family conflict, were found to affect the safety performance of low-wage workers. It is necessary to recognize that more safety research using diverse samples needs to be conducted in order to find the critical constructs that can be utilized in safety programs to create safer work environments.

\section{Practical Implications}

In addition to the theoretical implications of this dissertation, there are numerous practical implications. First, organizations implement rules and regulations through such endeavors as risk management systems and safety initiatives in order to increase workplace safety and to decrease the cost of accidents and injuries (Katz-Navon, Naveh, $\&$ Stern, 2009). At one time researchers believed that issues concerning safety compliance at work were caused by employees' poor attitudes. Therefore, safety interventions have included incentives and feedback as methods to increase compliance 
with safety regulations (Katz-Navon et al., 2009). Now organizations need to focus on the stressors their employees experience as part of their safety programs, and numerous studies, including this dissertation, have found that family-to-work conflict impacts safety compliance and safety participation. For example, by acknowledging that outside forces have an impact on safety performance, organizations can be proactive by implementing safety programs that help employees to relieve some of their family-to-work conflict. Targeting organizational and job design constructs like supervisor support and control over work hours would change the context of the organization to improve all employees' work-family issues, thereby increasing safety performance by reducing distractions in the workplace.

Second, since instrumental supervisor support was found to directly impact safety compliance and safety participation, this necessitates the education of managers, through training, to understand the importance of their support for their employees' work-family issues and to give managers the tools with which to apply that knowledge. Hammer et al. (2011) conducted an intervention focusing on training supervisors to increase the familyspecific support they offered to their employees. It was found that employees experiencing high levels of family-to-work conflict and working in grocery stores where direct supervisors received training exhibited higher levels of physical health and job satisfaction and lower levels of turnover intentions than similar employees working in grocery stores where the direct supervisors did not receive training.

Managers and supervisors at all levels need to be aware of the importance of work-family support because many organizations view new ways of working (e.g., 
flexible schedules) not as opportunities to learn and adapt to the changing workforce and changing technologies, but rather as individual "accommodations" that deviate from a set standard (Lee, MacDermid, \& Buck, 2000). In fact, policies may be adopted for symbolic rather than substantive reasons, which does not create real organizational behavioral or structural changes (Edelman, Uggen, \& Erlanger, 1999; Meyer \& Rowan, 1977; Scott, 1995, as cited in Blair-Loy \& Wharton, 2002). Also, employees may feel that their supervisors view them as not being committed to their jobs or to their organization if they need more support, such as using different flexible work arrangements, which may prevent employees from asking for help because they believe it will lead to negative career consequences (Allen \& Russell, 1999; Crittenden, 2001; Glass, 2004; Hill, Martinson, Ferris, \& Baker, 2004; Fletcher \& Bailyn, 1996; Hochschild, 1997; Perlow, 1997; Weeden, 2005). Therefore, implementing trainings to teach supervisors ways to be more supportive of employees' work-family issues will be beneficial to employees, supervisors, and organizations because it will reduce employees' work-family conflict and increase safety performance.

\section{Potential Limitations}

There are a number of potential limitations that need to be addressed in the present study. First, the study was cross-sectional, which means that although there are theoretically sound reasons to assume for example, that family-to-work conflict predicts safety performance, no solid conclusions regarding causal relationships can be made. Second, the present study may have limited generalizability given that only grocery store workers in one store chain located in the Midwestern U.S. participated. Yet, given the 
lack of research conducted using low-wage workers as participants, the specificity of the participants' occupation may also be viewed as a strength of this study.

Since the sample may be simultaneously considered a strength and a limitation of this study, it is important to consider generalizability more in depth because the sample examined was so specific in terms of type of industry and type of worker. Perceived control over work hours may greatly differ in this sample of grocery store workers, who did not have the option to work overtime if they wanted or needed to, compared to professional employees who may have inherently more control over their work hours because of the nature of their work. It is also possible that supervisor instrumental support affects different workers differently. In more professional occupations workers may need or utilize supervisor support in different ways. For example, consultants who decide when they work and how they work may not require as much supervisor instrumental support if their work schedules fit well with their family/nonwork lives. Conversely, those types of consultants may need their supervisors' instrumental support in that they need their supervisors to ask or acknowledge when there are certain times they need to focus more on their family/nonwork lives. Many professionals are expected to work more than the standard eight-hour days and they may always be on-call or required to answer emails or phone calls at any time. If supervisors can give professional employees a little leeway during certain times, this may be the type of instrumental support they can utilize more so than what low-wage or blue-collar workers, or other workers like nurses in which there is a hierarchy, need in terms of having help to adjust schedules. It may also be that consultants who have that flexibility and work too much so 
that it negatively affects their family/nonwork lives need certain types of supervisor support like role modeling or emotional support in order to better balance their work and family/nonwork lives.

Generalizability may also be an issue in this model if the variables are not stable but more dynamic. Different events or situations at work or at home may occur in people's lives that change their level of work-family conflict. Similarly, events or situations supervisors experience may change the level of support they are willing or able to offer their employees. Varying situations at work may also change employees' perceived control over their work hours. The effects of the relationships may change at different points in time depending on the personal experiences of employees and their supervisors, which may lead to different results in the same sample at different times. Therefore, more research is needed to determine if the results can be generalized to employees in different organizations and in different industries.

Third, the data collected for this study are from the same source (i.e., self-report), which leads to common method variance. Campbell and Fiske (1959) described method variance as the variance attributed to a measurement method and not to study constructs. Spector (1987) stated that a lack of method variance can bias study results when the relationships between constructs are measured using the same method, usually with selfreport data. That bias refers to the inflation of the relationships among study variables when using a single data source (Bishop, Scott, Goldsby, \& Cropanzano, 2005). Future research may use other data sources, such as supervisors' rating of safety performance or safety records, to avoid common method bias. 


\section{Future Directions}

Macroergonomics. Future safety research may incorporate the macroergonomics approach to determine that all aspects of the system are being examined.

Macroergonomics is an approach that allows one to look at the broader picture of the work system to determine ways an individual interacts with his/her work environment and also ways the work environment impacts an individual. It also emphasizes that focusing on one adverse aspect of the system may not be enough to create valuable change if there are other adverse factors still creating demands elsewhere in the system. This will allow for a more comprehensive model that ensures certain aspects of the system are not neglected, which can reduce effectiveness of constructs used to create positive changes. In turn, this will help an organization to find the most advantageous means of solving problems like accidents and injuries without always looking at their employees as the cause of the problems. In the present study, supervisor instrumental support and work-family conflict all directly affected safety performance. Trying to improve only one of those constructs in the work environment still leaves the potential for safety to be negatively affected by other problems not being addressed.

It would also be beneficial to bring more technology-focused variables into I/O psychology given that so many aspects of work are affected by technology and its rapid advancement. Technology is infiltrating all areas of life with the availability of computers, cell phones, and numerous other electronics that keep people in constant contact with each other and keep people informed at any time of the day. As has been discussed throughout this dissertation, the nature of work has been changing drastically 
through the use of technology. While some industries have to deal with these changes more so than others, change will continue, technology will progress, and everyone will eventually need to adapt. Being able to adapt is important because the changing nature of work, the complexity of modern technology, the work organization, and the production system have placed additional demands on the workforce (Shahnavaz, 2002). It is the role of $\mathrm{I} / \mathrm{O}$ psychologists to not only determine the impact of these changes on workers, but to evaluate the willingness of workers to embrace these changes and assist workers as they navigate the changes in the work environment. Specifically concerning this study, macroergonomics offers ways to increase employee control using the technology that is currently infiltrating the work environment and that should be utilized properly. For example, self-scheduling software can be introduced into the work environment as a mechanism to help employees gain more control in determining the hours they work, which then impacts safety performance. Additional studies can examine the impact of scheduling software on employees' work-family conflict and safety outcomes in conjunction with the impact of such software on employee perception of control over work hours. Also, with supervisor instrumental support directly affecting employee safety, computer technology (e.g., computer-based training) can be used to train supervisors to give more instrumental support to their employees.

Work-family conflict. Utilizing a systems approach has occurred in work-family research (e.g., Bronfenbrenner's ecological systems theory), but not using the approach of macroerogonomics. This study asserts that it is important to examine subsystems simultaneously because individuals are affected by more than one aspect of their 
environment. For example, just increasing employees' perception that they have control over their work hours is not sufficient to reduce work-family conflict because only workto-family conflict was affected. Given the lack of significant findings regarding supervisor instrumental support as a buffer, it would be advantageous to examine different types and sources of support to determine what is necessary to help employees gain and utilize control over their work hours. For example, it may be that certain employees need more coworker support in order to switch a shift at the last minute when an emergency suddenly occurs.

Control over work hours is also important to further examine because work or schedule flexibility is a central variable used in work-life research, and work-life policy makers use it as a key strategy to cope with the global economy (Bond et al., 2004; Bond, Galinsky, Kim, \& Brownfield, 2005; Hill \& Civian, 2008). The issue is that research on employer policies to support work-life integration does not effectively differentiate between policy types (e.g., flexible schedules, elder care and child care referrals, tuition assistance, wellness programs, etc.; Kossek, 2005; Ryan \& Kossek, 2008). Researchers also do not examine the way policies are enacted (e.g., whether they are universal; Kossek, 2005). For example, not all flexible arrangements are formal; informal management practices (i.e., supervisor support) allow some employees to exercise control over their schedules without following formal policies (Grzywacz, Carlson, \& Shulkin, 2008). Similarly, Kossek (2005) stated that researchers often overemphasize giving employees access to autonomy through a formal policy. Examining the way jobs are designed to give employees more autonomy and how that influences employees' 
effectiveness in their work and life domains, in addition to examining "the enabling roles of job design and policies in supporting employee preferences for and outcomes of personal job autonomy," would be valuable to consider in future research (Kossek, 2005, p. 109).

Job autonomy. Most of the safety literature examining work hours, work schedules, or shiftwork in relation to safety focuses on effects like fatigue or sleepiness on the outcome of safety. Literature examining control as it relates to safety behavior and accidents has examined employee safety control, defined as an individual's perception of his/her ability or opportunity to manage work conditions to avoid accidents and injuries (Harris, 1998; Huang, Ho, Smith, \& Chen, 2006; Leiter \& Robichaud, 1997; Pasmore \& Friedlander, 1982), with limited research examining job autonomy as it relates to safety. One exception is a study conducted by Parker et al. (2001) in which they examined job autonomy in terms of both work scheduling and work methods using Jackson et al.'s (1993) measure and found there was a direct effect with safety compliance. More research is needed to determine which types of autonomy are applicable to different industries and occupations. Knowing which components of autonomy are important to particular workers allows researchers and practitioners to tailor approaches to improve safety in the work environment. For example, employees in grocery stores may be able to directly reduce stressful work aspects if they have more decision-making autonomy to refund a customer's money for returned merchandise (Parker et al., 2001). Low-wage employees may also be able to reduce negative safety outcomes if they have the freedom to take rest breaks when needed (Frese, 1989). 
Also as an example, if there are conditions of uncertainty or variability (Holman et al., 2002), which occur in the scheduling of grocery store employees' hours, giving employees more control is an effective way to reduce that uncertainty or variability and to put the focus on performance. Wall, Corbett, Martin, Clegg, and Jackson (1990) found that operators working with unreliable machines, which led to repeated operational problems, performed better when they were given more autonomy. Holman et al. (2002) explained that using worker knowledge can enhance productivity by giving employees more control through such techniques as job enrichment, lowering direct supervision, using autonomous work groups, and reducing the specification of work methods. In terms of schedule control, allowing employees some choice over the best hours to work that suit their needs would reduce the uncertainty of what their work hours will be during any given week. This is in accordance with sociotechnical systems theory, which proposes that poor performance or the inability to accomplish tasks or goals is minimized by providing control mechanisms to deal with variances that occur in production and human operators from both internal and external sources, or performance problems as a result of uncertainty in the system (Rousseau, 1977).

\section{Conclusion}

Just as workers need to adapt to technical aspects of work and technology as it progresses, researchers also need to adapt. Adapting includes determining which factors are affecting workers in today's world and integrating those factors into the research. Occupational health psychology (OHP) is an interdisciplinary field that includes psychology, public health, human factors/ergonomics, organizational studies, and allied 
fields such as economics, industrial engineering, and occupational sociology (Society for Occupational Health Psychology, 2005). Aspects of each field involved in OHP can be used in I/O psychology to enhance models that lead to better outcomes in safety, health, and well-being. This dissertation has used principles from human factors/ergonomics to inform my I/O psychology research in order to create a richer model of work-family conflict and safety. 
Table 1

Means, Standard Deviations, and Range of Continuous Demographic Variables

\begin{tabular}{lllll}
\hline Variable & $\mathrm{N}$ & Mean & SD & Range \\
\hline Age in Years & 359 & 38.18 & 15.35 & $18-80$ \\
$\begin{array}{l}\text { Years of position } \\
\text { experience (job tenure) }\end{array}$ & 360 & 6.44 & 5.97 & 15 days -33 years \\
$\begin{array}{l}\text { Hours worked per week } \\
\text { 30u }\end{array}$ & 31.36 & 8.55 & $4-45$ hours \\
\hline
\end{tabular}


Table 2

Frequency of Categorical Demographic Variables

\begin{tabular}{|c|c|c|c|}
\hline Variable & Category & $N$ & Percentage \\
\hline \multirow[t]{2}{*}{ Gender } & Male & 97 & $27 \%$ \\
\hline & Female & 262 & $73 \%$ \\
\hline \multirow[t]{6}{*}{ Race } & White & 330 & $92 \%$ \\
\hline & $\begin{array}{l}\text { Black or African } \\
\text { American }\end{array}$ & 14 & $4 \%$ \\
\hline & $\begin{array}{l}\text { American Indian or } \\
\text { Alaskan native }\end{array}$ & 2 & $.5 \%$ \\
\hline & Asian & 1 & $.5 \%$ \\
\hline & $\begin{array}{l}\text { Native Hawaiian or } \\
\text { other Pacific Islander }\end{array}$ & 2 & $.5 \%$ \\
\hline & Other & 9 & $2.5 \%$ \\
\hline \multirow[t]{5}{*}{ Educational level attained } & Some high school & 10 & $3 \%$ \\
\hline & $\begin{array}{l}\text { High school diploma or } \\
\text { GED }\end{array}$ & 196 & $55 \%$ \\
\hline & $\begin{array}{l}\text { Some college or } \\
\text { associate's degree }\end{array}$ & 119 & $33 \%$ \\
\hline & Bachelor's degree & 28 & $8 \%$ \\
\hline & Graduate degree & 5 & $1 \%$ \\
\hline \multirow[t]{6}{*}{$\begin{array}{l}\text { Total household income in } \\
\text { the past } 12 \text { months }\end{array}$} & Less than $\$ 25,000$ & 132 & $38 \%$ \\
\hline & $\$ 25,000-\$ 40,000$ & 102 & $30 \%$ \\
\hline & $\$ 40,000-\$ 55,000$ & 50 & $14 \%$ \\
\hline & $\$ 55,000-\$ 70,000$ & 31 & $9 \%$ \\
\hline & $\$ 80,000-\$ 85,000$ & 10 & $3 \%$ \\
\hline & Over $\$ 85,000$ & 21 & $6 \%$ \\
\hline
\end{tabular}


Table 2

(Continued)

Variable

Category

$N$

Percentage

Marital status

Married or living as

196

$55 \%$

married

Divorced or

separated, widowed, $162 \quad 45 \%$

or never married

Parental Status

Has children living a

146

$41 \%$

home

Does not have $\quad 208 \quad 59 \%$

children living at

home

Elder care status

Provides elder care $\quad 58$

$16 \%$

Does not provide

elder care

300

$84 \%$ 
Table 3

Measures

CONTROL OVER WORK HOURS, Bond, Galinsky, and Hill (2004)

Please check the box that best indicates how things are with your work schedule. Check only one box per statement. How much control do you have...

\begin{tabular}{|c|c|c|c|c|}
\hline over when you take breaks? & 1 & 2 & 3 & 4 \\
\hline over which shifts you work? & 1 & 2 & 3 & 4 \\
\hline over the scheduling of your work hours? & 1 & 2 & 3 & 4 \\
\hline over your work pace? & 1 & 2 & 3 & 4 \\
\hline
\end{tabular}

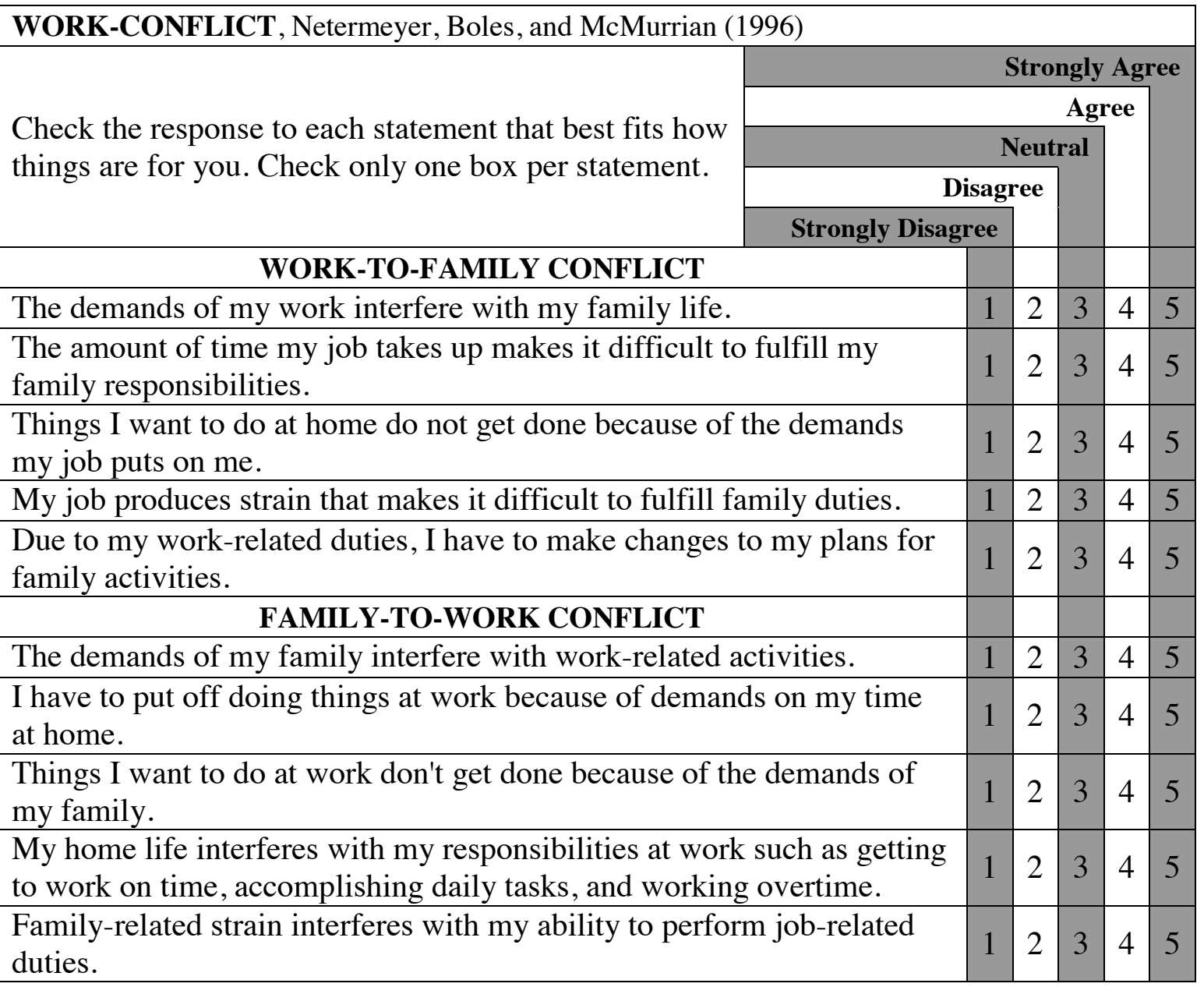


Table 3

(Continued)

FAMILY SUPPORTIVE SUPERVISORY BEHAVIORS, Hammer, Kossek, Yragui, Bodner, \& Hanson (2009)

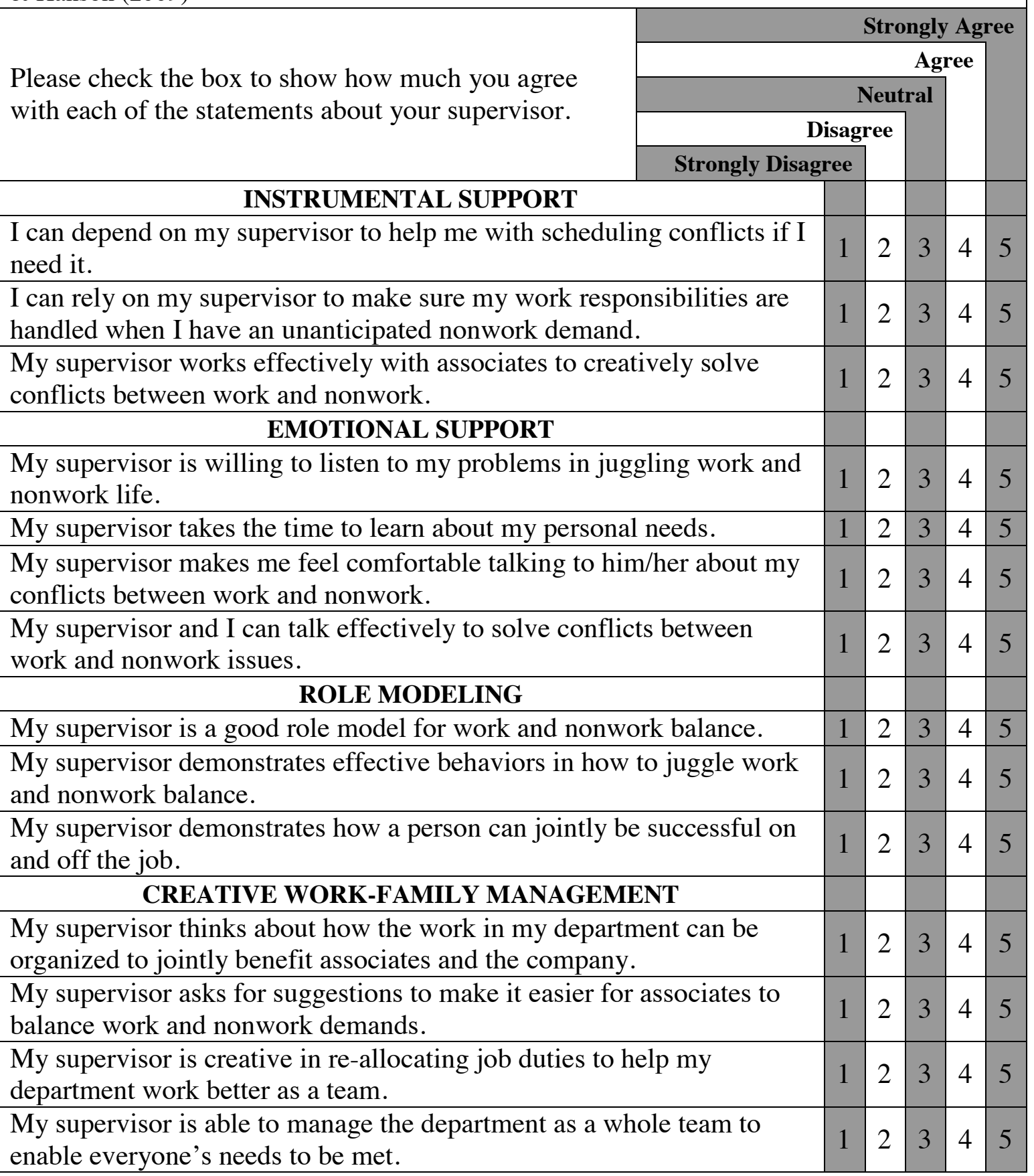


Table 3

(Continued)

SAFETY PERFORMANCE, Neal, Griffin, and Hart (2000)

Please read each statement and fill in the blank or check the box to indicate your response as it relates to your safety and health. Check only one response per question and try to answer all questions.

\begin{tabular}{|c|c|c|c|c|c|}
\hline $\mathbf{S}$ & & & & & \\
\hline SAFETY COMPLIANCE & & & & & \\
\hline I carry out my work in a safe manner. & 1 & 2 & 3 & 4 & 5 \\
\hline I use all the necessary safety equipment to do my job. & 1 & 2 & 3 & 4 & 5 \\
\hline I use the correct safety procedures for carrying out my job. & 1 & 2 & 3 & 4 & 5 \\
\hline I ensure the highest levels of safety when I carry out my job. & 1 & 2 & 3 & 4 & 5 \\
\hline SAFETY PARTICIPATION & & & & & \\
\hline program within the oroanizatio & 1 & 2 & 3 & 4 & 5 \\
\hline I put in extra effort to improve the safety & 1 & 2 & 3 & 4 & 5 \\
\hline $\begin{array}{l}\text { I help my co-workers when they are working under risky or hazardous } \\
\text { conditions. }\end{array}$ & 1 & 2 & 3 & 4 & 5 \\
\hline $\begin{array}{l}\text { I voluntarily carry out tasks or activities that help to improve } \\
\text { workplace safety. }\end{array}$ & 1 & 2 & 3 & 4 & 5 \\
\hline
\end{tabular}


Table 4

Means, Standard Deviations, and Range of Scale Variables

$\begin{array}{llll}N & M & S D & \text { Range }\end{array}$

Instrumental Support

(FSSB)

359

3.61

.75

$1-5$

Perceived Control over

Work Hours

$360 \quad 2.55$

.75

$1-4$

Work-to-family Conflict

358

2.62

.88

$1-5$

Family-to-work Conflict

358

1.92

.56

$1-4.20$

Safety Compliance

359

4.15

.53

$2-5$

Safety Participation

360

3.95

.55

$2-5$ 


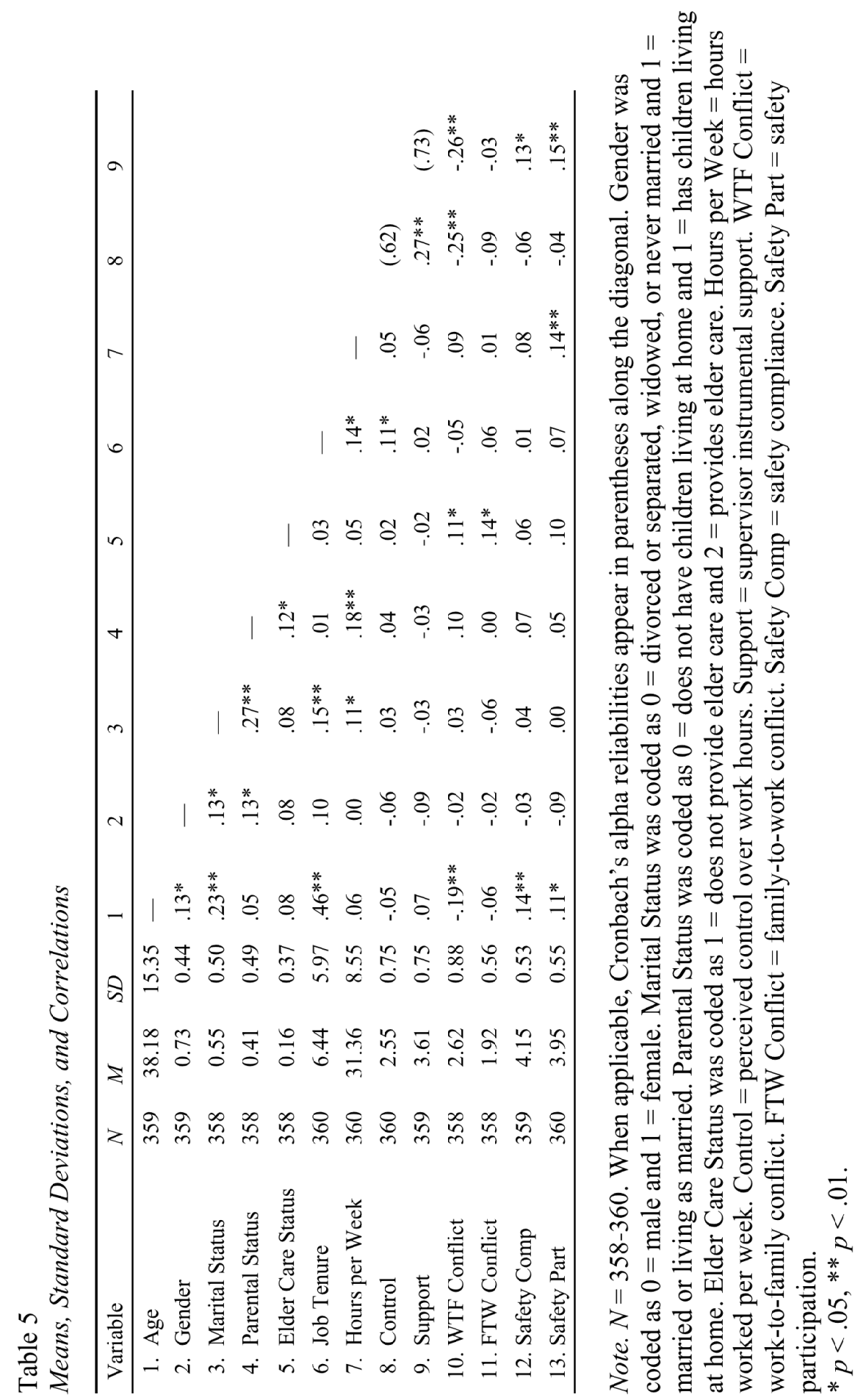




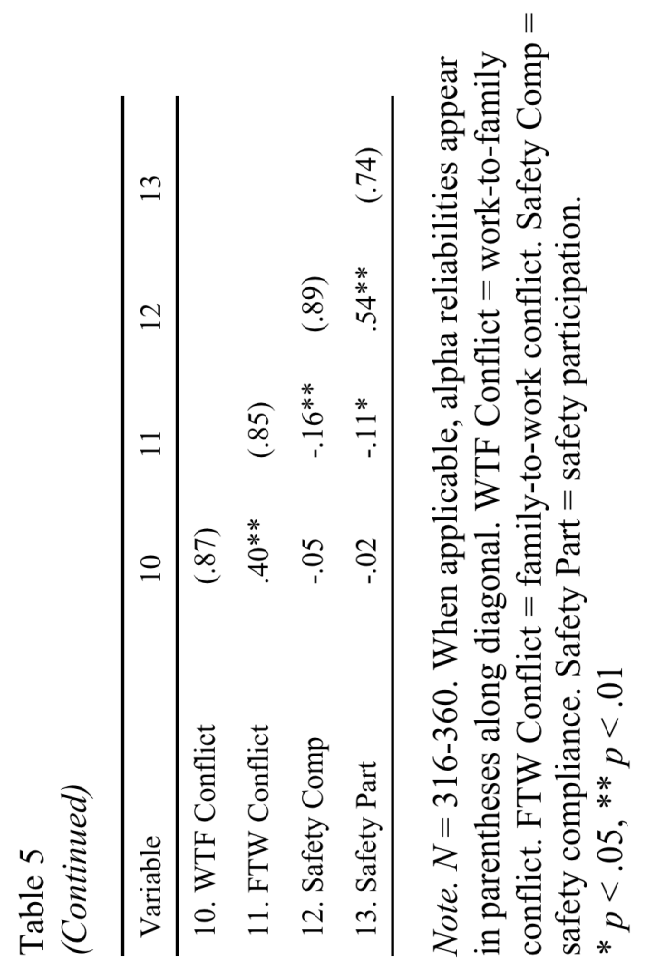


Table 6

Comparison for Alternative Factor Structure Models for Work-family Conflict and Safety Performance

\begin{tabular}{lccccc}
\hline Model & $\chi^{2}$ & $d f$ & $p$ & CFI & RMSEA \\
\hline $\begin{array}{l}\text { WFC and } \\
\text { FWC }\end{array}$ & 140.00 & 34 & $<.001$ & .99 & .09 \\
$\begin{array}{l}\text { Common } \\
\text { factor } \\
\text { model }\end{array}$ & 671.06 & 35 & $<.001$ & .93 & .23 \\
\hline $\begin{array}{l}\text { Safety } \\
\begin{array}{l}\text { Comp and } \\
\text { Safety Part }\end{array}\end{array}$ & 68.17 & 19 & $<.001$ & .99 & .09 \\
$\begin{array}{l}\text { Common } \\
\text { factor } \\
\text { model }\end{array}$ & 229.20 & 20 & $<.001$ & .98 & .17 \\
\hline
\end{tabular}

Note. $N=360$, Model fit: comparative fit index $=$ CFI, root-mean-square error of approximation $=$ RMSEA. $\mathrm{WFC}=$ work-to-family conflict. FWC = family-to-work conflict. 
Table 7

Summary of Hypotheses

\begin{tabular}{|c|c|}
\hline Hypothesis $1 a$ & $\begin{array}{l}\text { Perceived control over work hours and work-to-family conflict will } \\
\text { exhibit a negative, direct relationship. }\end{array}$ \\
\hline Hypothesis $1 b$ & $\begin{array}{l}\text { Perceived control over work hours and family-to-work conflict will } \\
\text { exhibit a negative, direct relationship. }\end{array}$ \\
\hline Hypothesis $2 a$ & $\begin{array}{l}\text { Work-to-family conflict and safety compliance will exhibit a negative, } \\
\text { direct relationship. }\end{array}$ \\
\hline Hypothesis $2 b$ & $\begin{array}{l}\text { Work-to-family conflict and safety participation will exhibit a negative, } \\
\text { direct relationship. }\end{array}$ \\
\hline Hypothesis $3 a$ & $\begin{array}{l}\text { Family-to-work conflict and safety compliance will exhibit a negative, } \\
\text { direct relationship. }\end{array}$ \\
\hline Hypothesis $3 b$ & $\begin{array}{l}\text { Family-to-work conflict and safety participation will exhibit a negative, } \\
\text { direct relationship. }\end{array}$ \\
\hline Hypothesis $4 a$ & $\begin{array}{l}\text { Work-to-family conflict will mediate the relationship between perceived } \\
\text { control over work hours and safety compliance and safety participation. }\end{array}$ \\
\hline Hypothesis $4 b$ & $\begin{array}{l}\text { Family-to-work conflict will mediate the relationship between perceived } \\
\text { control over work hours and safety compliance and safety participation. }\end{array}$ \\
\hline Hypothesis $5 a$ & $\begin{array}{l}\text { Supervisor instrumental support will moderate the relationship between } \\
\text { work-to-family conflict and safety performance. More specifically, the } \\
\text { negative association between work-to-family conflict and safety } \\
\text { compliance and safety participation will be weaker for individuals who } \\
\text { perceive higher instrumental support from their supervisors than for } \\
\text { individuals who perceive lower levels of instrumental support from their } \\
\text { supervisors. }\end{array}$ \\
\hline Hypothesis $5 b$ & $\begin{array}{l}\text { Supervisor instrumental support will moderate the relationship between } \\
\text { family-to-work conflict and safety performance. More specifically, the } \\
\text { negative association between family-to-work conflict and safety } \\
\text { compliance and safety participation will be weaker for individuals who } \\
\text { perceive higher instrumental support from their supervisors than for } \\
\text { individuals who perceive lower levels of instrumental support from their } \\
\text { supervisors. }\end{array}$ \\
\hline Hypothesis $6 a$ & $\begin{array}{l}\text { The relationship between perceived control over work hours and work- } \\
\text { to-family conflict will be moderated by supervisor instrumental support. } \\
\text { More specifically, the negative association between perceived control } \\
\text { over work hours and work-to-family conflict will be stronger for } \\
\text { individuals who perceive higher instrumental support from their } \\
\text { supervisors than for individuals who perceive lower levels of } \\
\text { instrumental support from their supervisors. }\end{array}$ \\
\hline Hypothesis $6 b$ & $\begin{array}{l}\text { The relationship between control over work hours and family-to-work } \\
\text { conflict will be moderated by supervisor instrumental support. More } \\
\text { specifically, the negative association between perceived control over } \\
\text { work hours and family-to-work conflict will be stronger for individuals } \\
\text { who perceive higher instrumental support from their supervisors than for } \\
\text { individuals who perceive lower levels of instrumental support from their } \\
\text { supervisors. }\end{array}$ \\
\hline
\end{tabular}


Table 8

Path Coefficients for Direct Effects, Indirect Effects, and Moderations

\begin{tabular}{|c|c|c|c|c|c|}
\hline Path Label & DV & IV & Coefficient & $\mathrm{CI}_{95}$ & $p$ \\
\hline A & WFC & Control & -.26 & {$[-.35,-.17]$} & $<.01$ \\
\hline B & FWC & Control & -.15 & {$[-.25,-.05]$} & $<.05$ \\
\hline $\mathrm{C}$ & Safety Comp & WFC & .04 & {$[-.08, .15]$} & .62 \\
\hline $\mathrm{D}$ & Safety Part & WFC & .06 & {$[-.06, .17]$} & .46 \\
\hline $\mathrm{E}$ & Safety Comp & FWC & -.16 & {$[-.28,-.03]$} & $<.05$ \\
\hline $\mathrm{F}$ & Safety Part & FWC & -.14 & {$[-.25,-.03]$} & $<.05$ \\
\hline $\mathrm{AC}$ & Safety Comp & $\begin{array}{l}\text { Indirect Effect: } \\
\text { Control through WFC }\end{array}$ & .00 & {$[-.02, .02]$} & .92 \\
\hline $\mathrm{AD}$ & Safety Part & $\begin{array}{l}\text { Indirect Effect: } \\
\text { Control through WFC }\end{array}$ & .01 & {$[-.01, .03]$} & .52 \\
\hline $\mathrm{BE}$ & Safety Comp & $\begin{array}{l}\text { Indirect Effect: } \\
\text { Control through FWC }\end{array}$ & .01 & {$[.00, .02]$} & .23 \\
\hline $\mathrm{BF}$ & Safety Part & $\begin{array}{l}\text { Indirect Effect: } \\
\text { Control through FWC }\end{array}$ & .01 & {$[.00, .03]$} & .24 \\
\hline $\mathrm{C}_{\mathrm{M}}$ & Safety Comp & Support x WFC & -.06 & {$[-.16, .06]$} & .43 \\
\hline $\mathrm{D}_{\mathrm{M}}$ & Safety Part & Support x WFC & -.06 & {$[-.16, .04]$} & .35 \\
\hline$E_{M}$ & Safety Comp & Support x FWC & .05 & {$[-.08, .18]$} & .54 \\
\hline $\mathrm{F}_{\mathrm{M}}$ & Safety Part & Support x FWC & .05 & {$[-.06, .17]$} & .44 \\
\hline$A_{M}$ & WFC & Support x Control & .01 & {$[-.10, .12]$} & .96 \\
\hline $\mathrm{B}_{\mathrm{M}}$ & FWC & Support x Control & -.07 & {$[-.18, .05]$} & .36 \\
\hline G & Safety Comp & Support & .17 & {$[.07, .27]$} & $<.01$ \\
\hline $\mathrm{H}$ & Safety Part & Support & .21 & {$[.11, .31]$} & $<.01$ \\
\hline I & WFC & Support & -.14 & {$[-.23,-.03]$} & $<.05$ \\
\hline $\mathrm{J}$ & FWC & Support & -.01 & {$[-.14, .13]$} & .98 \\
\hline
\end{tabular}

Note. $\mathrm{DV}=$ dependent variable. $\mathrm{IV}=$ independent variable. $\mathrm{CI}=$ confidence interval.

Control $=$ perceived control over work hours. Support $=$ supervisor instrumental support. WTF Conflict $=$ work-to-family conflict. FTW Conflict $=$ family-to-work conflict. Safety Comp $=$ safety compliance. Safety Part $=$ safety participation. 
Table 9

Path Coefficients for Additional FSSB Analyses in Comparison to Supervisor Instrumental Support

\begin{tabular}{|c|c|c|c|c|c|}
\hline DV & IV & $\begin{array}{l}\text { Type of } \\
\text { Support }\end{array}$ & $\beta$ & $\mathrm{CI}_{95}$ & $p$ \\
\hline \multirow[t]{5}{*}{ WTF Conflict } & \multirow[t]{5}{*}{ Control } & Instrumental & -.26 & {$[-.35,-.17]$} & $<.01$ \\
\hline & & Overall FSSB & -.26 & {$[-.35,-.16]$} & $<.01$ \\
\hline & & Emotional & -.28 & {$[-.37,-.19]$} & $<.01$ \\
\hline & & Role Modeling & -.28 & {$[-.37,-.19]$} & $<.01$ \\
\hline & & Creative Mgmt & -.26 & {$[-.35,-.17]$} & $<.01$ \\
\hline \multirow[t]{5}{*}{ FTW Conflict } & \multirow[t]{5}{*}{ Control } & Instrumental & -.15 & {$[-.25,-.05]$} & $<.05$ \\
\hline & & Overall FSSB & -.16 & {$[-.26,-.06]$} & $<.05$ \\
\hline & & Emotional & -.16 & {$[-.26,-.07]$} & $<.01$ \\
\hline & & Role Modeling & -.17 & {$[-.28,-.07]$} & $<.01$ \\
\hline & & Creative Mgmt & -.14 & {$[-.24,-.04]$} & $<.05$ \\
\hline \multirow[t]{5}{*}{ Safety Comp } & \multirow[t]{5}{*}{ WTF Conflict } & Instrumental & .04 & {$[-.08, .15]$} & .62 \\
\hline & & Overall FSSB & .08 & {$[-.04, .18]$} & .29 \\
\hline & & Emotional & .06 & {$[-.07, .16]$} & .47 \\
\hline & & Role Modeling & .06 & {$[-.06, .16]$} & .43 \\
\hline & & Creative Mgmt & .11 & {$[-.02, .20]$} & .15 \\
\hline \multirow[t]{5}{*}{ Safety Part } & \multirow[t]{5}{*}{ WTF Conflict } & Instrumental & .06 & {$[-.06, .17]$} & .46 \\
\hline & & Overall FSSB & .07 & {$[-.05, .18]$} & .37 \\
\hline & & Emotional & .05 & {$[-.08, .16]$} & .55 \\
\hline & & Role Modeling & .07 & {$[-.05, .18]$} & .40 \\
\hline & & Creative Mgmt & .08 & {$[-.04, .19]$} & .29 \\
\hline \multirow{5}{*}{ Safety Comp } & \multirow{5}{*}{ FTW Conflict } & Instrumental & -.16 & {$[-.28,-.03]$} & $<.05$ \\
\hline & & Overall FSSB & -.16 & {$[-.28,-.04]$} & $<.05$ \\
\hline & & Emotional & -.16 & {$[-.28,-.04]$} & $<.05$ \\
\hline & & Role Modeling & -.17 & {$[-.29,-.06]$} & $<.05$ \\
\hline & & Creative Mgmt & -.19 & {$[-.31,-.06]$} & $<.01$ \\
\hline \multirow{5}{*}{ Safety Part } & \multirow{5}{*}{ FTW Conflict } & Instrumental & -.14 & {$[-.25,-.03]$} & $<.05$ \\
\hline & & Overall FSSB & -.14 & {$[-.24,-.03]$} & $<.05$ \\
\hline & & Emotional & -.14 & {$[-.25,-.02]$} & $<.05$ \\
\hline & & Role Modeling & -.16 & {$[-.26,-.05]$} & $<.05$ \\
\hline & & Creative Mgmt & -.12 & {$[-.23, .00]$} & .09 \\
\hline \multirow[t]{5}{*}{ Safety Comp } & \multirow[t]{5}{*}{ Support } & Instrumental & .17 & {$[.07, .27]$} & $<.01$ \\
\hline & & Overall FSSB & .24 & {$[.13, .35]$} & $<.01$ \\
\hline & & Emotional & .17 & {$[.06, .26]$} & $<.01$ \\
\hline & & Role Modeling & .18 & {$[.06, .29]$} & $<.01$ \\
\hline & & Creative Mgmt & .30 & {$[.19, .41]$} & $<.01$ \\
\hline
\end{tabular}


Table 9

(Continued)

\begin{tabular}{lllccc}
\hline DV & IV & Type of & $\boldsymbol{\beta}$ & CI $_{95}$ & $\boldsymbol{p}$ \\
\hline Safety Part & \multirow{2}{*}{ Support } & Instrumental & .21 & {$[.11, .31]$} & $<.01$ \\
& & Overall FSSB & .22 & {$[.10, .32]$} & $<.01$ \\
& & Emotional & .14 & {$[.04, .25]$} & $<.05$ \\
& & Role Modeling & .19 & {$[.07, .29]$} & $<.01$ \\
& & Creative Mgmt & .15 & {$[.02, .26]$} & .06 \\
\hline WTF Conflict & Support & Instrumental & -.14 & {$[-.23,-.03]$} & $<.05$ \\
& & Overall FSSB & -.13 & {$[-.23,-.04]$} & $<.05$ \\
& & Emotional & -.09 & {$[-.17, .01]$} & .13 \\
& & Role Modeling & -.08 & {$[-.17, .01]$} & .17 \\
& & Creative Mgmt &.- .19 & {$[-.28,-.10]$} & $<.01$ \\
\hline FTW Conflict & Support & Instrumental & -.01 & {$[-.14, .13]$} & .98 \\
& & Overall FSSB & .01 & {$[-.11, .13]$} & .90 \\
& & Emotional & .05 & {$[-.06, .17]$} & .45 \\
& & Role Modeling & .06 & {$[-.05, .17]$} & .35 \\
& & Creative Mgmt & .04 & {$[-.07, .14]$} & .54 \\
\hline
\end{tabular}

Note $. \mathrm{DV}=$ dependent variable. $\mathrm{IV}=$ independent variable. $\mathrm{CI}=$ confidence interval. Control $=$ perceived control over work hours. WTF Conflict $=$ work-to-family conflict. FTW Conflict = family-to-work conflict. Safety Comp $=$ safety compliance. Safety Part $=$ safety participation. Instrumental $=$ supervisor instrumental support. Emotional = supervisor emotional support. Creative Mgmt = supervisor creative work-family management. 
Table 10

Summary Table of Findings

\begin{tabular}{|c|c|c|c|c|}
\hline \multirow{2}{*}{$\begin{array}{l}\text { Predictors \& } \\
\text { Interactions }\end{array}$} & \multicolumn{4}{|c|}{ Dependent Variables } \\
\hline & WFC & FWC & Safety Comp & Safety Part \\
\hline Control & $\begin{array}{c}\text { H1a } \\
\text { Supported (-) }\end{array}$ & $\begin{array}{c}\text { H1b } \\
\text { Supported (-) }\end{array}$ & --- & --- \\
\hline WFC & --- & -- & $\begin{array}{c}\mathrm{H} 2 \mathrm{a} \\
\text { Not supported }\end{array}$ & $\begin{array}{c}\mathrm{H} 2 \mathrm{~b} \\
\text { Not supported }\end{array}$ \\
\hline FWC & --- & --- & $\begin{array}{c}\text { H3a } \\
\text { Supported (-) }\end{array}$ & $\begin{array}{c}\text { H3b } \\
\text { Supported (-) }\end{array}$ \\
\hline $\begin{array}{l}\text { Control } \rightarrow \\
\text { WFC }\end{array}$ & --- & --- & $\begin{array}{c}\mathrm{H} 4 \mathrm{a} \\
\text { Not supported }\end{array}$ & $\begin{array}{c}\mathrm{H} 4 \mathrm{a} \\
\text { Not supported }\end{array}$ \\
\hline Control $\rightarrow$ & --- & --- & $\mathrm{H} 4 \mathrm{~b}$ & $\mathrm{H} 4 \mathrm{~b}$ \\
\hline $\begin{array}{l}\text { FWC } \\
\text { Support x WFC }\end{array}$ & --- & --- & $\begin{array}{c}\text { Not supported } \\
\text { H5a }\end{array}$ & $\begin{array}{l}\text { Not supported } \\
\text { H5b }\end{array}$ \\
\hline Support x FWC & --- & --- & $\begin{array}{l}\text { Not supported } \\
\text { H5a } \\
\text { Not supported }\end{array}$ & $\begin{array}{l}\text { Not supported } \\
\text { H5b } \\
\text { Not supported }\end{array}$ \\
\hline $\begin{array}{l}\text { Support x } \\
\text { Control }\end{array}$ & $\begin{array}{c}\text { H6a } \\
\text { Not supported }\end{array}$ & $\begin{array}{c}\text { H6b } \\
\text { Not supported }\end{array}$ & --- & --- \\
\hline Support & Post hoc (-) & Not found & Post hoc (+) & Post hoc (+) \\
\hline $\begin{array}{l}\text { Note. Control } \\
\text { support. WTF } \\
\text { family-to-worl } \\
\text { safety particip }\end{array}$ & $\begin{array}{l}\text { ntrol over we } \\
\text { flict = work- } \\
\text { nflict. Safety }\end{array}$ & $\begin{array}{l}\text { hours. Sup } \\
\text {-family con } \\
\text { omp = safet }\end{array}$ & $\begin{array}{l}\mathrm{t}=\text { superviso } \\
\mathrm{t} . \text { FTW Confl } \\
\text { ompliance. S }\end{array}$ & $\begin{array}{l}\text { instrumental } \\
t= \\
\text { ety Part = }\end{array}$ \\
\hline
\end{tabular}




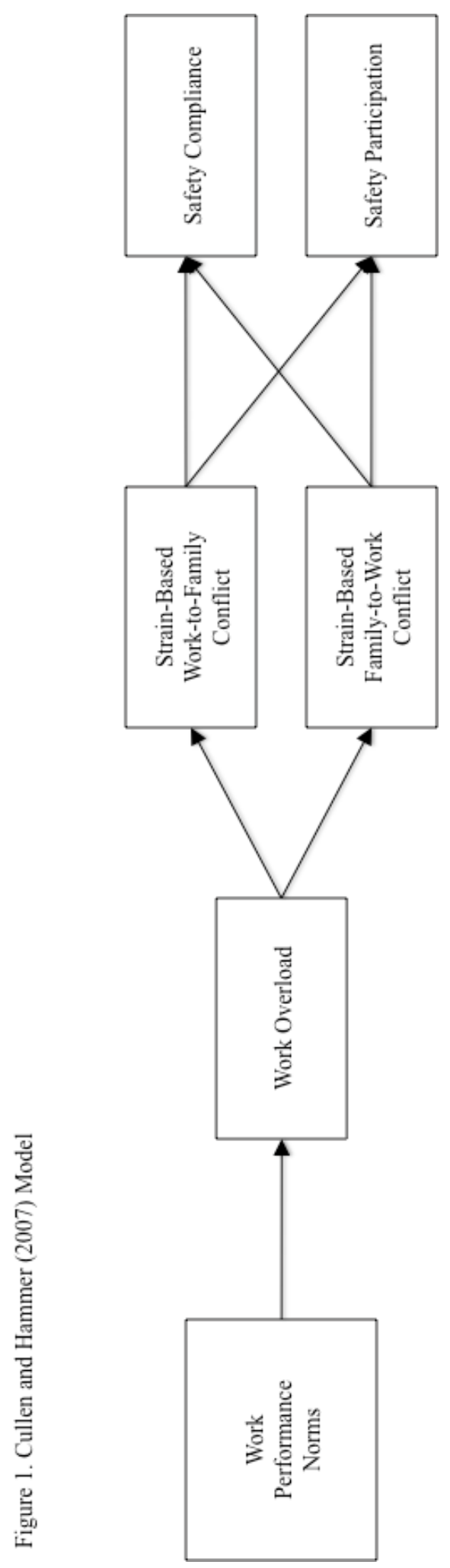




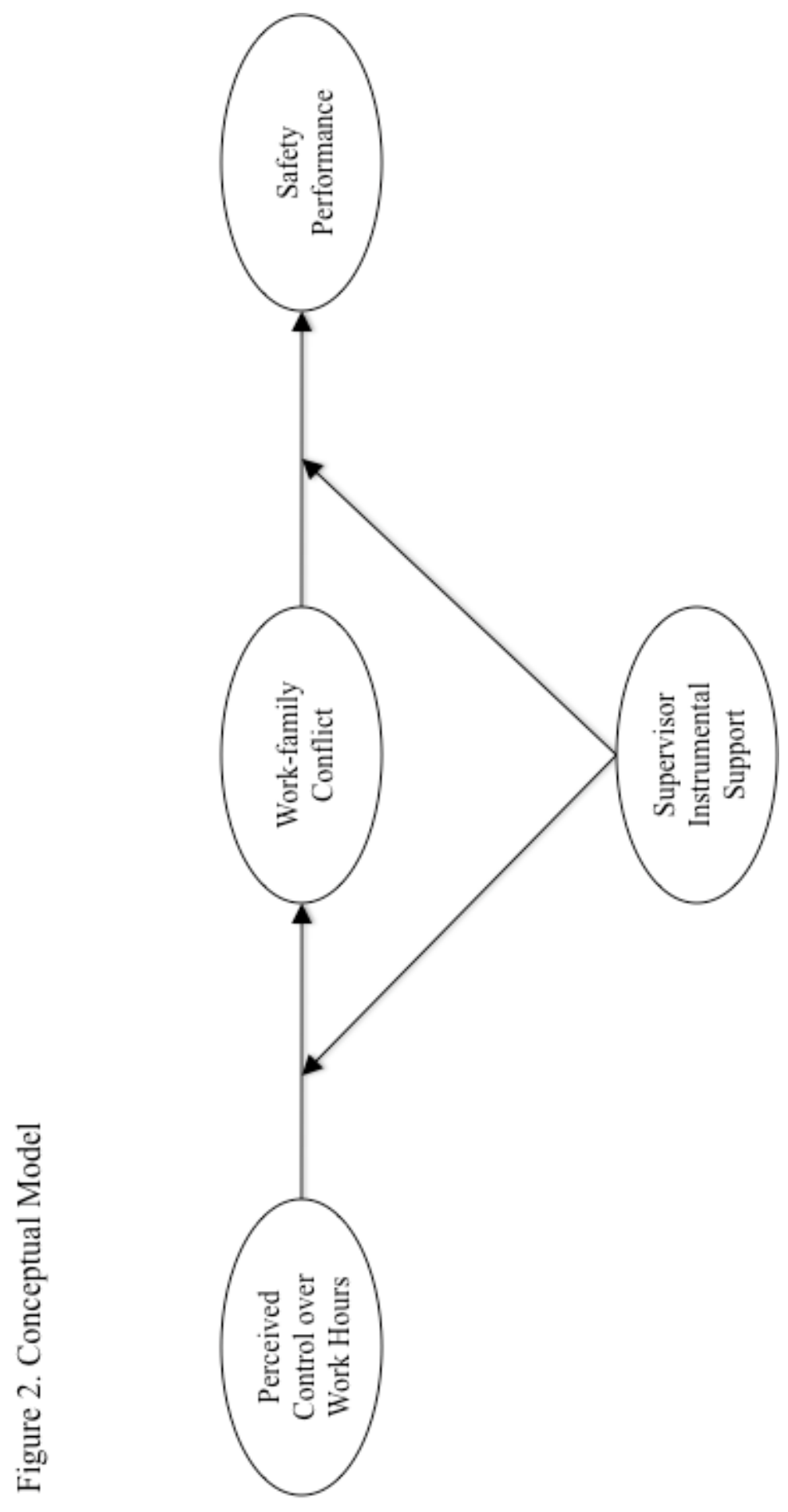


Figure 3. Structural Equation Model

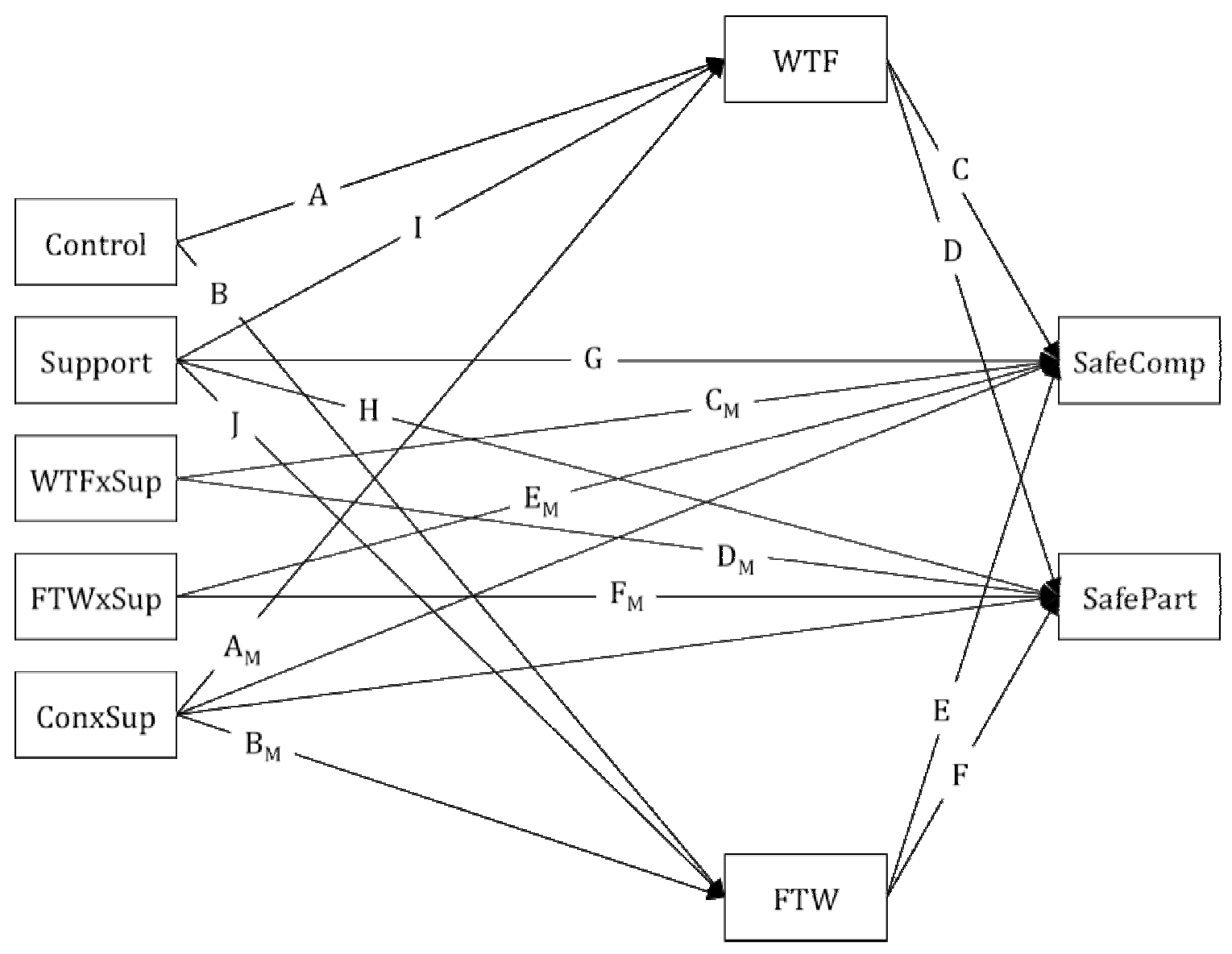




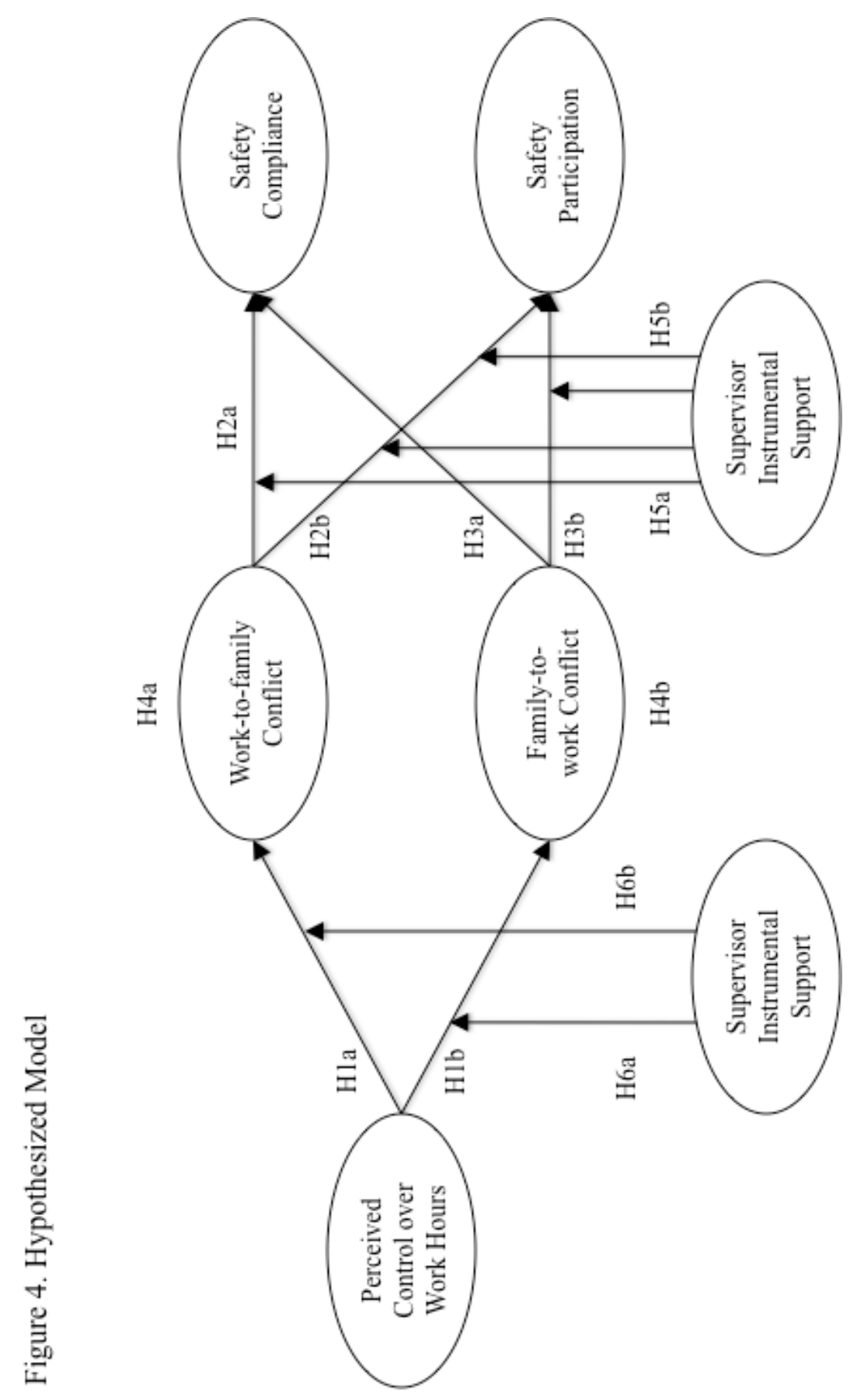




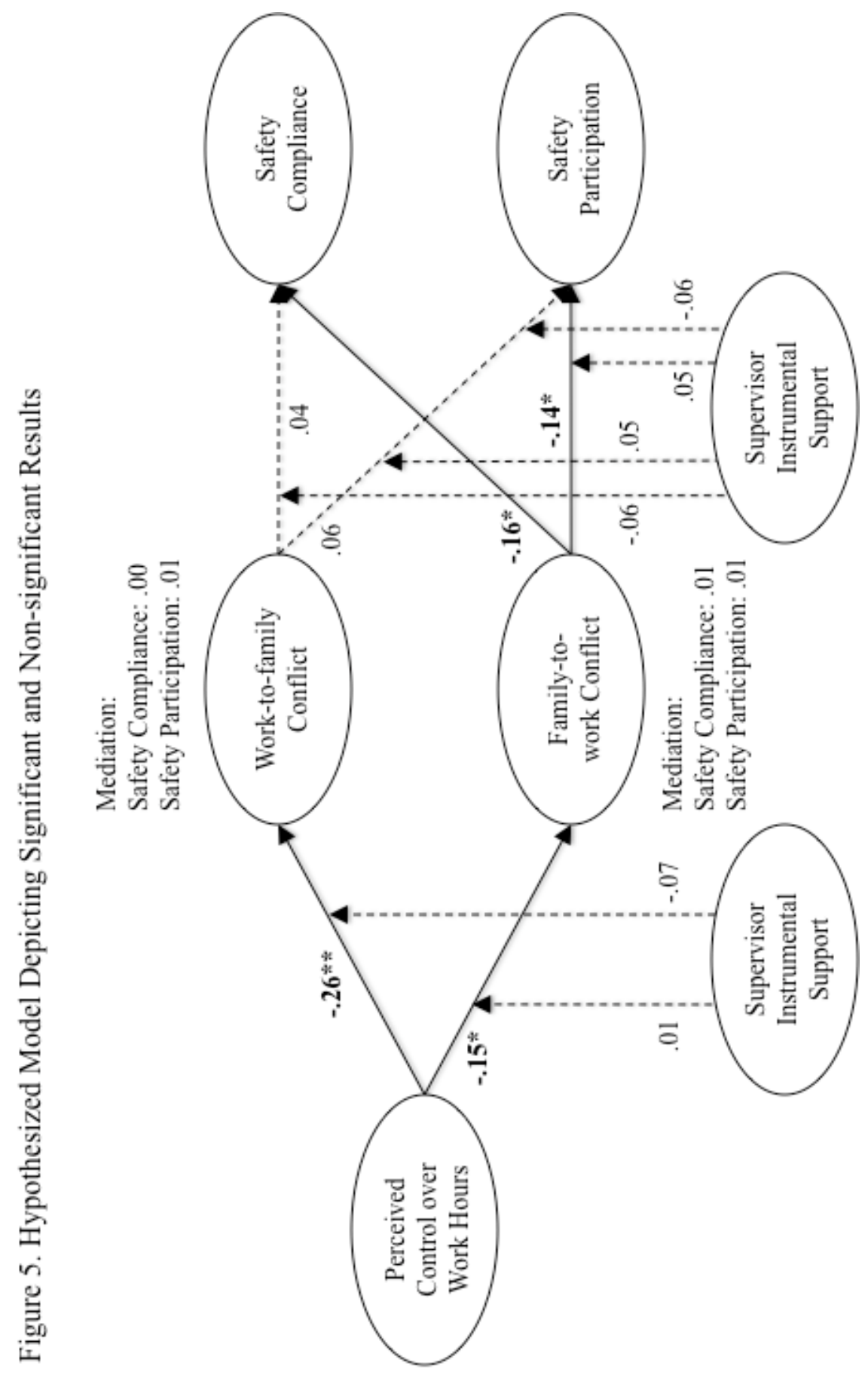




\section{References}

Abdul-Halim, A. A. (1982). Social support and managerial affective responses to job stress. Journal of Occupational Behavior, 3, 281-295.

Acs, G., \& Loprest, P. (2005). Who are low-income working families? Washington, DC: Urban Institute.

Acs, G., \& Loprest, P. (2007). TANF caseload composition and leavers synthesis report. Report to the Administration on Children and Families. Washington, DC: Urban Institute.

Acs, G., \& Nichols, A. (2007). Low-income workers and their employers: Characteristics and challenges. Washington, DC: Urban Institute.

Adams, G. A., \& Jex, S. M. (1999). Relationships between time management, control, work-family conflict, and strain. Journal of Occupational Health Psychology, 4, 72-77.

Aiken, L. S., \& West, S. G. (1991). Multiple regression: Testing and interpreting interactions. Thousand Oaks, CA: Sage.

Alkov, R. A. (1981). Psychosocial stress, health, and human error. Professional Safety, August, 12-14.

Allen, T. D. (2001). Family-supportive work environments: The role of organizational perceptions. Journal of Vocational Behavior, 58, 414-435.

Allen, T. D., Herst, D. E. L., Bruck, C. S., \& Sutton, M. (2000). Consequences associated with work-to-family conflict: A review and agenda for future research. Journal of Occupational Health Psychology, 5, 278-308. 
Allen, T. D., \& Russell, J. E. A. (1999). Parental leave of absence: Some not so family friendly implications. Journal of Applied Social Psychology, 29, 166-191.

Allen, T. D., \& Shockley, K. M. (2009). Flexible work arrangements: Help or hype? In D. R. Crane \& E. J. Hill (Eds.), Handbook of families and work: Interdisciplinary perspectives. Lanham, MD: University Press of America.

Amstad, F. T., Meier, L. L., Fasel, U., Elfering, A., \& Semmer, N. K. (2011). A metaanalysis of work-family conflict and various outcomes with a special emphasis on cross-domain versus matching-domain relations. Journal of Occupational Health Psychology, 16, 151-169.

Anderson, S. E., Coffey, B. S., \& Byerly, R. T. (2002). Formal organizational initiatives and informal workplace practices: Links to work-family conflict and job-related outcomes. Journal of Management, 28, 787-810.

Appelbaum, S. H. (1997). Socio-technical systems theory: An intervention strategy for organizational development. Management Decision, 35, 452-463.

Ashforth, B. E., Kreiner, G. E., \& Fugate, M. (2000). All in a day's work: Boundaries and micro role transitions. Academy of Management Review, 25, 472-491.

Arbuckle, J. L. (1996). Full information estimation in the presence of incomplete data. In G. A. Marcoulides \& R. E. Schumacker (Eds.), Advanced structural equation modeling: Issues and techniques (pp. 243-277). Mahwah, NJ: Lawrence Erlbaum Associates.

Arbuckle, J. L. (2006). Amos (Version 7.0) [Computer Program]. Chicago: SPSS. 
Aryee, S. (1992). Antecedents and outcomes of work-family conflict among married professional women: Evidence from Singapore. Human Relations, 45, 813-837.

Bailyn, L. (1993). Breaking the mold: Women, men, and time in the new corporate world. New York: Free Press.

Bakker, A. B., Demerouti, E., \& Dollard, M. F. (2008). How job demands affect partners' experience of exhaustion: Integrating work-family conflict and crossover theory. Journal of Applied Psychology, 93, 901-911.

Bakker, A. B., Demerouti, E., \& Euwema, M. C. (2005). Job resources buffer the impact of job demands on burnout. Journal of Occupational Health Psychology, 10, 170180.

Barling, J., Loughlin, C., \& Kelloway, E. K. (2002). Development and test of a model linking safety-specific transformational leadership and occupational safety. Journal of Applied Psychology, 87, 488-496.

Barling, J., MacEwen, K. E., Kelloway, E. K., \& Higginbottom, S. F. (1994). Predictors and outcomes of elder-care based interrole conflict. Psychology and Aging, 9, 391-397.

Barling, J., \& Zacharatos, A. (1999). High performance safety systems: Ten management practices to create safe organizations. Paper presented at the Academy of Management meeting, Chicago, IL.

Barger, L. K., Cade, B. E., Ayas, N. T., Cronin, J. W., Rosner, B., Speizer, F. E., \& Czeisler, C. A. (2005). Extended work shifts and the risk of motor vehicle crashes among interns. New England Journal of Medicine, 352, 125-134. 
Barnatt, C. (1997). Challenging reality. Chichester, NY: John Wiley \& Sons.

Barnett, R. C., \& Hyde, J. S. (2001). Women, men, work, and family: An expansionist theory. American Psychologist, 56, 781-796.

Barnett, R. C., \& Rivers, C. (1996). She works/he works: How two-income families are happier, healthier, and better-off. San Francisco: Harper.

Baron, R. S. (1986). Distraction-conflict theory: Progress and problems. In L. Berkowitz (Ed.), Advances in experimental social psychology (Vol. 19, pp. 1-40). New York: Academic Press.

Baron, R., \& Greenberg, J. (1990). Behavior in organizations. Boston: Allyn \& Bacon. Baron, R. M., \& Kenny, D. A. (1986). The moderator-mediator distinction in social psychological research: Conceptual, strategic, and statistical considerations. Journal of Personality and Social Psychology, 51, 1173-1182.

Batt, R., \& Valcour, P. M. (2003). Human resources practices as predictors of work family outcomes and employee turnover. Industrial Relations, 42, 189-220.

Bass, B. M. (1990). Bass and Stogdill's handbook of leadership. New York: Free Press.

Becker, P. E., \& Moen, P. (1999). Scaling back: Dual-earner couples' work-family strategies. Journal of Marriage and Family, 61, 995-1007.

Bedeian, A. G., Burke, B. G., \& Moffett, R. G. (1988). Outcomes of work-family conflict among married male and female professionals. Journal of Management, $14,475-491$.

Beharie, N. (2005). New kid on the block. OH\&S Canada, 19, 30-38.

Betcherman, G., McMullen, K., Leckie, N., \& Caron, C. (1994). The Canadian 
workplace in transition. Kingston, Ontario, Canada: IRC Press.

Beus, J. M., Payne, S. C., Bergman, M. E., \& Arthur, W., Jr. (2010). Safety climate and injuries: An examination of theoretical and empirical relationships. Journal of Applied Psychology, 95, 713-727.

Bianchi, S. M., \& Milkie, M. A. (2010). Work and family research in the first decade of the $21^{\text {st }}$ Century. Journal of Marriage and Family, 72, 705-725.

Billings, R. S., Klimoski, R. J., \& Breaugh, J. A. (1977). The impact of a change in technology on job characteristics: A quasi-experiment. Administrative Science Quarterly, 22, 318-339.

Bishop, J. W., Scott, K. D., Goldsby, M. G., \& Cropanzano, R. (2005). A construct validity study of commitment and perceived support variables: A multifoci approach across different team environments. Group \& Organization Management, 30, 153-180.

Blair-Loy, M. (2003). Competing devotions: Career and family among women executives. Cambridge, MA: Harvard University Press.

Blair-Loy, M., \& Wharton, A. S. (2002). Employees' use of work-family policies and the workplace social context. Social Forces, 80, 813-845.

Blau, P. (1964). Exchange and power in social life. New York: Wiley.

Bluestone, B., \& Rose, S. (1998). Public policy brief: The unmeasured labor force: The Growth in work hours. Blithewood, Annandale-on-Hudson, NY: The Jerome Levy Economics Institute of Bard College, Bard Publications Office, No. 39.

Bond, F. W., Flaxman, P. E., \& Bunce, D. (2008). The influence of psychological 
flexibility on work redesign: Mediated moderation of a work reorganization intervention. Journal of Applied Psychology, 93, 645-654.

Bond, J. T., \& Galinsky, E. (2006). What workplace flexibility is available to entry-level, hourly employees? New York, NY: Families and Work Institute.

Bond, J.T., Galinsky, E., \& Hill, J. (2004). When work works: A project on workplace effectiveness and workplace flexibility. New York, NY: Families and Work Institute.

Bond, J. T., Galinsky, E., Kim, S. S., \& Brownfield, E. (2005). National study of employers. New York, NY: Families and Work Institute.

Bond, J. T., Galinsky, E., \& Swanberg, J. E. (1998). The 1997 National Study of the Changing Workforce. New York: Families and Work Institute.

Borman, W. C., \& Motowidlo, S. J. (1993). Expanding the criterion domain to include elements of contextual performance. In N. Schmitt, \& W. C. Borman (Eds.), Personnel selection in organizations (pp. 71-98). San Francisco: Jossey-Bass.

Borman, W. C., \& Motowidlo, S. J. (1997). Task performance and contextual performance: The meaning for personnel selection research. Human Performance, 10, 99-109.

Boushey, H., Fremstad, S., Gragg, R., \& Waller, M. (2007, March). Understanding low wage work in the United States. The Mobility Agenda: New Ideas for Better Jobs, $1-22$.

Bradley, G. (2002). Information and communication technology (ICT) and changes in 
work life: Macroergonomic considerations. In H. W. Hendrick \& B. M. Kleiner (Eds.), Macroergonomics: Theory, methods, and applications (pp. 173-198). Mahwah, NJ: Lawrence Erlbaum Associates.

Brass, D. J. (1985). Technology and the structuring of jobs: Employee satisfaction, performance, and influence. Organizational Behavior and Human Decision Processes, 35, 216-240.

Breaugh, J. A. (1985). The measurement of work autonomy. Human Relations, 38(6), 551-570.

Breslin, C., \& Smith, P. (2005). Age-related differences in work injuries: A multivariate, population-based study. American Journal of Industrial Medicine, $48,50-56$.

Broadbridge, A. (1999). Retail managers: Stress and the work-family relationship. International Journal of Retail \& Distribution Management, 27(9), 374-382.

Bronfenbrenner, U. (1989). Ecological systems theory. Annals of Child Development, 6, 187-249.

Bronfenbrenner, U. (1994). Ecological models of human development. In International encyclopedia of education, Vol. 3, $2^{\text {nd }}$ Ed. (pp. 37-43). Oxford: Elsevier.

Brown, K. A., Willis, P. G., \& Prussia, G. E. (2000). Predicting safe employee behavior in the steel industry: Development and test of a sociotechnical model. Journal of Operations Management, 18, 445-465. 
Bureau of the Census. (1998). Census brief: Increase in at-home workers reverses earlier trend. Washington, DC: U.S. Department of Commerce, Economics and Statistics Administration, Bureau of the Census, Report No. CENBR/98-2.

Bureau of Labor Statistics. (2010a). Injuries, illnesses, and fatalities: Industries at a glance. Retrieved November 5, 2010. http://www.bls.gov/iag/tgs/iag_ index_naics.htm

Bureau of Labor Statistics. (2010b). Occupational injuries and illnesses: Industry data. Retrieved November 5, 2010. http://data.bls.gov/PDQ/servlet/Survey OutputServlet?data_tool=latest_numbers\&series_id=IIU00000000061100

Bureau of Labor Statistics. (2010c). Occupational injuries and illnesses: Industry data. Retrieved November 5, 2010. http://data.bls.gov/PDQ/servlet/Survey OutputServlet?data_tool=latest_numbers\& series_id=IIU00000000063100 Bureau of Labor Statistics. (2011). Census of Fatal Occupational Injuries Charts, 19922009. Retrieved July 24, 2011. http://www.bls.gov/iif/oshcfoi1.htm

Burke, R. J. (1988). Some antecedents and consequences of work-family conflict. Journal of Social Behavior and Personality, 3, 287-302.

Burke, M. J., Chan-Serafin, S., Salvador, R., Smith, A., \& Sarpy, S. A. (2008). The role of national culture and organizational climate in safety training effectiveness. European Journal of Work and Organizational Psychology, 17, 133-152.

Burke, M. J., Sarpy, S. A., Tesluk, P. E., \& Smith-Crowe, K. (2002). General safety performance: A test of a grounded theoretical model. Personnel Psychology, 55, 429-457. 
Byron, K. (2005). A meta-analytic review of work-family conflict and its antecedents. Journal of Vocational Behavior, 67, 169-198.

Campbell, D. J., Campbell, K. M., \& Kennard, D. (1994). The effects of family responsibilities on the work commitment and job performance of non-professional women. Journal of Occupational and Organizational Psychology, 67, 283-214.

Campbell, D. T., \& Fiske, D. W. (1959). Convergent and discriminant validation by the multitrait-multimethod matrix. Psychological Bulletin, 56, 81-105.

CareerOneStop. (2010). Industry Profile: Supermarkets and other grocery stores. Retrieved November 5, 2010. http://www.careerinfonet.org/industry/Ind_ Search_Report.aspx $?$ ind $=445110 \&$ sector $=44 \&$ stc $=\&$ stfips $=00 \&$ rptLevel $=4 \&$ node $\mathrm{id}=10 \& \mathrm{id}=8 \& \mathrm{x}=24 \& \mathrm{y}=12$

Carlson, D. S., \& Perrewe, P. L. (1999). The role of social support in the stressor strain relationship: An examination of work-family conflict. Journal of Management, 25, 513-540.

Caruso, C. C., Bushnell, T., Eggerth, D., Heitmann, A., Kojola, B., Newman, K., ... Vila, B. (2006). Long working hours, safety, and health: Toward a national research agenda. American Journal of Industrial Medicine, 49, 930-942.

Casillas, A., Robbins, S., McKinniss, T., Postlethwaite, B., \& Oh, I-S. (2009). Using narrow facets of an integrity test to predict safety: A test validation study. International Journal of Selection and Assessment, 17, 119-125.

Chapman, N. J., Ingersoll-Dayton, B., \& Neal, M. B. (1994). Balancing the multiple 
roles of work and caregiving for children, adults, and elders. In C. P. Keita, \& J. J. Hurrell (Eds.), Stress in a changing workplace (pp. 283-300).

Cherns, A. B. (1976). The principles of socio-technical design. Human Relations, 29, 783-792.

Cherns, A. (1987). Principles of socio-technical design revisited. Human Relations, 40, 153-162.

Christensen, K. E., \& Staines, G. L. (1990). Flextime: A viable solution to work/family conflict? Journal of Family Issues, 11, 455-476.

Christian, M. S., Bradley, J. C., Wallace, J. C., \& Burke, M. J. (2009). Workplace safety: A meta-analysis of the roles of person and situation factors. Journal of Applied Psychology, 94, 1103-1127.

Clapp, J. D., \& Beck, J. G. (2009). Understanding the relationship between PTSD and social support: The role of negative network orientation. Behaviour Research and Therapy, 47, 237-244.

Clark, S. C. (2000). Work/family border theory: A new theory of work/family balance. Human Relations, 53, 747-770.

Clark, S. C. (2001). Work cultures and work/family balance. Journal of Vocational Behavior, 58, 348-365.

Clarke, S. (2006a). The relationship between safety climate and safety performance: A meta analytic review. Journal of Occupational Health Psychology, 11, 315-327.

Clarke, S. (2006b). Safety climate in an automobile manufacturing plant. Personnel Review, 35, 413-430. 
Cleveland, R. J., Cohen, H. H., Smith, M. J., \& Cohen, A. (1978). Safety program practices in record-holding plants. Cincinnati, Ohio: National Institute for Occupational Safety and Health.

Cohen, A., \& Margolis, B. (1973). Initial psychological research related to the Occupational Safety and Health Act of 1970. American Psychologist, 28, 600606.

Cohen, A., Smith, M., \& Cohen, H. H. (1975). Safety program practices in high vs. low accident rate companies - An interim report. (U.S. Department of Health, Education and Welfare Publication No. 75-185). Cincinnati, Ohio: National Institute for Occupational Safety and Health.

Cohen, P. N., \& Bianchi, S. M. (1999). Marriage, children, and women's employment: What do we know? Monthly Labor Review, 122, 22-31.

Cohen, S., \& Syme, S. L. (1985). Issues in the study and application of social support. In S. L. Cohen \& S. L. Syme (Eds.), Social support and health (pp. 3-22). New York: Academic Press.

Cohen, S., \& Wills, T. A. (1985). Stress, social support, and the buffering hypothesis. Psychological Bulletin, 98, 310-357.

Colligan, M. J., \& Cohen, A. (2004). The role of training in promoting workplace safety and health. In J. Barling \& M. R. Frone (Eds.), The psychology of workplace safety (pp. 223-248). Washington, DC: American Psychological Association.

Cooke, R. A., \& Rousseau, D. M. (1984). Stress and strain from family roles and 
work-role expectations. Journal of Applied Psychology, 69, 252-260.

Cooper, C. L. (1998). The psychological implications of the changing nature of work. RSA Journal, 1, 71-84.

Cooper, C. L. (1999). Can we live with the changing nature of work? Journal of Managerial Psychology, 14, 569-572.

Cooper, C., \& Kurland, N. B. (2002). Telecommuting, professional isolation and employee development in public and private organizations. Journal of Organizational Behavior, 23, 511-532.

Cooper, C. L., \& Payne, R. (1978). Stress at Work. New York: Wiley.

Coovert, M. D., \& Craiger, J. P. (2000). An expert system for integrating multiple fit indices for structural equations modeling. New Review of Applied Expert Systems, $6,131-140$.

Corporate Voices for Working Families. (2006, October). Workplace flexibility for low wage workers. Washington, DC: Author. Retrieved March 2, 2011, from http://www.cvworkingfamilies.org/issues/publications.shtml

Crittenden, A. (2001). The price of motherhood: Why the most important job in the world is still the least valued. New York: Metropolitan Books.

CRS (1999). CRS report for Congress: Temporary workers as members of the contingent labor force. Washington, DC: The Library of Congress, Congressional Research Service, Order Code No. RL30072.

Cullen, J. C., \& Hammer, L. B. (2007). Developing and testing a theoretical model 
linking work-family conflict to employee safety. Journal of Occupational Health Psychology, 12, 266-278.

Daniels, R. J. (2007). Workplace cognitive failure as a mediator between work-family conflict and safety performance. Unpublished master's thesis. Portland State University, Portland, OR.

Davis, D. R. (1958). Human errors and transport accidents. Ergonomics, 2, 24-33.

Davis, L. E. (1982). Organization design. In G. Salvendy (Ed.), Handbook of industrial engineering (pp. 2.1.1-2.1.29). New York: Wiley.

de Lange, A. H., Taris, T. W., Kompier, M. A., Houtman, I. L. D., \& Bonger, P. M. (2003). "The very best of the millennium": Longitudinal research and the demand-control-(support) model. Journal of Occupational Health Psychology, 8, 282-305.

DeArmond, S., Smith, A. E., Wilson, C. L., Chen, P. Y., \& Cigularov, K. P. (2011). Individual safety performance in the construction industry: Development and validation of two short scales. Accident Analysis and Prevention, 43, 948-954.

DeJoy, D. M. (1994). Managing safety in the workplace: An attribution theory analysis and model. Journal of Safety Research, 25, 3-17.

Demerouti, E., Bakker, A. B., Nachreiner, F., \& Schaufeli, W. B. (2001). The job demands-resources model of burnout. Journal of Applied Psychology, 86, 499512.

Duxbury, L. E., \& Higgins, C. A. (1991). Gender differences in work-family conflict. Journal of Applied Psychology, 76, 60-74. 
Eaton, S. C. (2003). If you can use them: Flexibility policies, organizational commitment, and perceived performance. Industrial Relations, 42, 145-167,

Eby, L. T., Casper, W. J., Lockwood, A., Bordeaux, C., \& Brinley, A. (2005). Work and family research in IO/OB: Content analysis and review of the literature (19802002). Journal of Vocational Behavior, 66, 124-197.

Edelman, L. B., Uggen, C., Erlanger, H. S. (1999). The endogeneity of legal regulation: Grievance procedures as rational myth. American Journal of Sociology, 105, 406454.

Edwards, J. R., \& Lambert, L. S. (2007). Methods for integrating moderation and mediation: A general analytical framework using moderated path analysis. Psychological Methods, 12, 1-22.

Emery, F. (1964). Report of the Hunfoss Project. London: Tavistock Document Series.

Emery, F. E., \& Trist, E. L. (1960). Socio-technical systems. In C. H. Churchman \& M. Verhulst (Eds.), Management science, models and techniques (Vol. 2, pp. 83-97). New York: Peragmon.

Emery, R. E., \& Trist, E. L. (1965). The causal texture of organizational environments. Human Relations, 18, 21-32.

Families and Work Institute. (2006). What do we know about entry-level, hourly employees? Research Brief No. 1, Retrieved March 4, 2011 from http://familiesandwork.org/eproducts/brief1.pdf 
Fenlason, K., \& Beehr, T. (1994). Balancing work and family responsibilities: Flextime and child care in the federal government. Public Administration Review, 56, 174179.

Fletcher, J., \& Bailyn, L. (1996). Challenging the last boundary: Reconnecting work and family. In M. B. Arthur \& D. M. Rousseau (Eds.), The boundaryless career: A new employment principle for a new organizational era (pp. 256-267). New York: Oxford University Press.

Flye, L., Agars, M., \& Kottke, J. (2003). Organizational approaches to work-family conflict: Testing an integrative model. Paper presented at the annual Society of Industrial Organizational Psychology, Orlando, FL, April.

Ford, M. T., \& Tetrick, L. E. (2008). Safety motivation and human resource management in North America. The International Journal of Human Resource Management, $19,1472-1485$.

Fox, M. L., \& Dwyer, D. J. (1999). An investigation of the effects of time and involvement in the relationship between stressors and work-family conflict. Journal of Occupational Health and Psychology, 4, 164-174.

Frese, M. (1989). Theoretical models of control and health. In S. L. Sauter, J. J. Hurrell, \& C. L. Cooper (Eds.), Job control and worker health (pp. 108-128). New York: Wiley.

Frese, M., \& Zapf, D. (1994). Action as the core of work psychology: A German approach. In H. C. Triandis, M. D. Dunnette, \& J. M. Hough (Eds.), Handbook of 
industrial and organizational psychology. Palo Alto, CA: Consulting Psychologists.

Fried, Y., Grant, A. M., Levi, A. S., Hadani, M., \& Slowik, L. H. (2007). Job design in temporal context: A career dynamics perspective. Journal of Organizational Behavior, 28, 911-927.

Friedlander, F., \& Brown, L. D. (1974). Organization development. Annual Review of Psychology, 25, 313-341.

Frone, M. R., Russell, M., \& Cooper, M. L. (1992). Antecedents and outcomes of workfamily conflict: Testing a model of the work-family interface. Journal of Applied Psychology, 77, 65-78.

Frone, M. R., Russell, M., \& Cooper, M. L. (1993). Relationship of work-family conflict, gender, and alcohol expectancies to alcohol use/abuse. Journal of Organizational Behavior, 14, 545-558.

Frone, M. R., Yardley, J. K., \& Markel, K. S. (1997). Developing and testing an integrative model of the work-family interface. Journal of Vocational Behavior, $50,145-167$.

Frye, N. K., \& Breaugh, J. A. (2004). Family-friendly policies, supervisor support, workfamily conflict, family-work conflict, and satisfaction: A test of a conceptual model. Journal of Business and Psychology, 19, 197-220.

Galinsky, E., \& Hughes, D. (1987, August). The Fortune magazine child care study. Paper presented at the annual conference of the American Psychological Association, New York. 
Galinsky, E., \& Stein, P. J. (1990). The impact of human resource policies on employees: Balancing work/family life. Journal of Family Issues, 8, 368-383.

Ganster, D. C., Fusilier, M. R., \& Mayes, B. T. (1986). Role of social support in the experience of stress at work. Journal of Applied Psychology, 71, 102-110.

Geller, E. S., Roberts, D. S., \& Gilmore, M. R. (1996). Predicting propensity to actively care for occupational safety. Journal of Safety Research, 27, 1-8.

Geurts, S. A. E., Beckers, D. G. J., Taris, T. W., Kompier, M. A. J., \& Smulders, P. G. W. (2009). Worktime demands and work-family interference: Does worktime control buffer the adverse effects of high demands? Journal of Business Ethics, $84,229-241$.

Glass, J. (2004). Blessing or curse? Work-family policies and mother's wage growth over time. Work and Occupations, 31, 367-394.

Glasscock, D. J., Rasmussen, K., Carstensen, O., \& Hansen, O. H. (2006). Psychosocial factors and safety behaviour as predictors of accidental work injuries in farming. Work \& Stress, 20, 173-189.

Goff, S. J., Mount, K., \& Jamison, R. L. (1990). Employer supported child care, work/family conflict, and absenteeism: A field study. Personnel Psychology, 43, 793-809.

Golden, T. D., Veiga, J. F., \& Simsek, Z. (2006). Telecommuting's differential impact on work-family conflict: Is there no place like home? Journal of Applied Psychology, $91,1340-1350$.

Golden, L., \& Wiens-Tuers, B. (2006). To your happiness? Extra hours of labor supply 
and worker well-being. The Journal of Socio-Economics, 35, 382-397.

Good, L. K., Sisler, G. F., Gentry, J. W . (1988). Antecedents of turnover intentions among retail management personnel. Journal of Retailing, 64, 295-314.

Gordon, J., \& Whelan, K. (1998). Successful professional women in midlife: How organizations can more effectively understand and respond to the challenges. Academy of Management Executive, 12, 8-27.

Gouldner, A. W. (1960). The norm of reciprocity. American Sociological Review, 25, 165-167.

Grandey, A. A., \& Cropanzano, R. (1999). The conservation of resources model applied to work-family conflict and strain. Journal of Vocational Behavior, 54, 350-370.

Grant, A. M., Fried, Y., \& Juillerat, T. (2010). Work matters: Job design in classic and contemporary perspectives. In S. Zedeck (Ed.), APA Handbook of industrial and organizational psychology, (Vol. 1,pp. 417-453). Washington, DC: American Psychological Association.

Grant, A. M., \& Parker, S. K. (2009). Redesigning work design theories: The rise of relational and proactive perspectives. The Academy of Management Annals, 3, $317-375$.

Grawitch, M. J., \& Barber, L. K. (2010). Work flexibility or nonwork support? Theoretical and empirical distinctions for work-life initiatives. Consulting Psychology Journal: Practice and Research, 62, 169-188. 
Greenhaus, J. H., Bedeian, A. G., \& Mossholder, K. W. (1987). Work experiences, job performance, and feelings of personal and family well-being. Journal of Vocational Behavior, 31, 200-215.

Greenhaus, J. H., \& Beutell, N. J. (1985). Sources of conflict between work and family roles. Academy of Management Review, 10, 76-88.

Greenhaus, J. H., Collins, K. M., Singh, R., \& Parasuraman, S. (1997). Work and family influences on departure from public accounting. Journal of Vocational Behavior, $50,249-270$.

Greenhaus, J. H., \& Parasuraman, S. (1986). A work-nonwork interactive perspective of stress and its consequences. Journal of Organizational Behavior Management, 8, 37-60.

Greenhaus, J. H., Parasuraman, S., Granrose, C. S., Rabinowitz, S., and Beutell, N. J. (1989). Sources of work-family conflict among two-career couples. Journal of Vocational Behavior, 34, 133-153.

Greenhaus, J. H., Parasuraman, S., \& Wormley, W. M. (1990). Effects of race on organizational experiences, job performance evaluations, and career outcomes. Academy of Management Journal, 33, 64-86.

Griffin, M. A., \& Neal, A. (2000). Perceptions of safety at work: A framework for linking safety climate to safety performance, knowledge, and motivation. Journal of Occupational Health Psychology, 5, 347-358. 
Griffin, M. A., Neal, A., \& Neale, M. (2000). The contribution of task performance and contextual performance to effectiveness: Investigating the role of situational constraints. Applied Psychology: An International Review, 49, 517-533.

Griffin, M. A., Neal, A., \& Parker, S. K. (2007). A new model of work role performance: Positive behavior in uncertain and interdependent contexts. Academy of Management Journal, 50, 327-347.

Grzywacz, J. G., Carlson, D. S., \& Shulkin, S. (2008). Schedule flexibility and stress: Linking formal flexible arrangements and perceived flexibility to employee health. Community, Work \& Family, 11, 199-214.

Hackman, J. R., \& Oldham, G. R. (1975). Development of the Job Diagnostic Survey. Journal of Applied Psychology, 60, 159-170.

Hackman, J. R., \& Oldham, G. R. (1976). Motivation through the design of work: Test of a theory. Organizational Behavior and Human Performance, 16, 250-279.

Halpern, D. F. (2005). How time-flexible work policies can reduce stress, improve health, and save money. Stress and Health, 21, 157-168.

Hammer, L. B., Allen, E., \& Grigsby, T. D. (1997). Work-family conflict in dual-earner couples: Within-individual and crossover effects of work and family. Journal of Vocational Behavior, 50, 185-203.

Hammer, L. B., Bauer, T. N., \& Grandey, A. (2003). Effects of spouses' and own workfamily conflict on withdrawal behaviors. Journal of Business and Psychology, 17, 419-436. 
Hammer, L. B., Cullen, J. C., Neal, M. B., Sinclair, R. R., \& Shafiro, M. V. (2005). The longitudinal effects of work-family conflict and positive spillover on depressive symptoms among dual-earner couples. Journal of Occupational Health Psychology, 2, 138-154.

Hammer, L. B., Kossek, E. E., Anger, W. K., Bodner, T., \& Zimmerman, K. L. (2011). Clarifying work-family intervention processes: The roles of work-family conflict and family-supportive supervisor behaviors. Journal of Applied Psychology, 96, $134-150$.

Hammer, L. B., Kossek, E. E., Yragui, N. L., Bodner, T. E., \& Hanson, G. C. (2009). Development and validation of a multidimensional measure of family supportive supervisor behaviors (FSSB). Journal of Management, 35, 837-856.

Hammer, L. B., Kossek, E. E., Zimmerman, K., \& Daniels, R. (2007). Clarifying the construct of family-supportive supervisory behaviors (FSSB): A multilevel perspective. Research in Occupational Stress and Well-Being, 6, 171-211.

Hammer, L. B., Neal, M. B., Newsom, J. T., Brockwood, K. J., \& Colton, C. L. (2005). A longitudinal study of the effects of dual-earner couples' utilization of familyfriendly workplace supports on work and family outcomes. Journal of Applied Psychology, 90, 799-810.

Harris, T. C. (1998). Predicting workplace safety outcomes through subordinate and supervisor involvement in safety issues. Unpublished Doctoral Dissertation. University of Connecticut, Storrs.

Harvey, J., Bolam, H., Gregory, D., \& Erdos, G. (2001). The effectiveness of training 
to change safety culture and attitudes within a highly regulated environment. Personnel Review, 30, 615-636.

Hemingway, M. A., \& Smith, C. S. (1999). Organizational climate and occupational stressors as predictors of withdrawal behaviors and injuries in nurses. Journal of Occupational and Organizational Psychology, 72, 285-300.

Hendrick, H. W. (1997). Organizational design and macroergonomics. In G. Salvendy (Ed.), Handbook of human factors and ergonomics (2nd ed.) (pp. 594-636). New York: Wiley.

Hendrick, H. W. (2002a). An overview of macroergonomics. In H. W. Hendrick \& B. M. Kleiner (Eds.), Macroergonomics: Theory, methods, and applications (pp. 123). Mahwah, NJ: Lawrence Erlbaum Associates.

Hendrick, H. W. (2002b). Macroergonomics methods: Assessing work system structure. In H. W. Hendrick \& B. M. Kleiner (Eds.), Macroergonomics: Theory, methods, and applications (pp. 45-66). Mahwah, NJ: Lawrence Erlbaum Associates.

Hendrick, H. W., \& Kleiner, B. M. (2001). Macroergonomics: An introduction to work system design. Santa Monica, CA: Human Factors and Ergonomics Society.

Henly, J. R., Shaefer, H. L., \& Waxman, E. (2006). Nonstandard work schedules: Employer- and employee-driven flexibility in retail jobs. Social Service Review, $80,609-634$.

Hill, E. J., \& Civian, J. T. (2008). Editors' introduction: Investigating workplace 
flexibility using a multi-organization database: A collaboration of academics and practioners. Community, Work \& Family, 11, 131-132.

Hill, E. J., Gryzwacz, J. G., Allen, S., Blanchard, V. L., Matz-Costa, C., Shulkin, S., et al. (2008). Defining and conceptualizing workplace flexibility. Community, Work \& Family, 11, 149-163.

Hill, E. J., Erickson, J. J., Holmes, E. K., \& Ferris, M. (2010). Workplace flexibility, work hours, and work-life conflict: Finding an extra day or two. Journal of Family Psychology, 24, 349-358.

Hill, E. J. Martinson, V. K., Ferris, M., \& Baker, R. Z. (2004). Beyond the mommy track: The influence of new-concept part-time work for professional women on work and family. Journal of Family and Economic Issues, 25, 121-136.

Hobfoll, S. E. (1989). The ecology of stress. Washington, DC: Hemisphere.

Hobfoll, S. E. (1989). Conservation of resources: A new attempt at conceptualizing stress. American Psychologist, 44, 513-524.

Hobfoll, S. E. (1998). Stress, culture, and community. New York: Plenum.

Hobfoll, S. E., \& Shirom, A. (2001). Conservation of resources: Applications to stress and management in the workplace. In R. T. Golembiewski (Ed.), Handbook of organizational behavior (pp. 57-80). New York: Marcel Dekker.

Hochschild, A. R. (1997). The time bind: When work becomes home and home becomes work. New York: Metropolitan.

Hofmann, D. A., Jacobs, R., \& Landy, F. (1995). High reliability process industries: 
Individual, micro, and macro organizational influences on safety performance. Journal of Safety Research, 26, 131-149.

Hofmann, D. A., \& Morgeson, F. P. (1999). Safety-related behavior as a social exchange: The role of perceived organizational support and leader-member exchange. Journal of Applied Psychology, 84, 286-296.

Hofmann, D. A., Morgeson, F. P., \& Gerras, S. (2003). Climate as a moderator of the relationship between LMX and content specific citizenship: Safety climate as an exemplar. Journal of Applied Psychology, 88, 170-178.

Hofmann, D. A., \& Stetzer, A. (1996). A cross-level investigation of factors influencing unsafe behaviors and accidents. Personnel Psychology, 49, 307-339.

Holman, D., Clegg, C., \& Waterson, P. (2002). Navigating the territory of job design. Applied Ergonomics, 33, 197-205.

Holroyd, K. A., \& Lazarus, R. S. (1982). Stress, coping, and somatic adaptation. In L. Goldberger \& S. Breznitiz (Eds.), Handbook of stress (pp. 21-35). New York: Free Press.

Hopkins, K. (2005). Supervisor support and work-life integration: A social identity perspective. In E. E. Kossek (Ed.), Work and life integration: Organizational, cultural, and individual perspectives (pp. 445-467). Mahwah, NJ: Lawrence Erlbaum Associates.

House, J. S. (1981). Work stress and social support. Reading, MA: Addison-Wesley. House, R., Rousseau, D. M., \& Thomas-Hunt, M. (1995). The meso paragdigm: A framework for the integration of micro and macro organizational behavior. In L. 
L. Cummings, \& B. M. Staw (Eds.), Research in organizational behavior (Vol. 17, pp. 71-114). Greenwich, CT: JAI Press.

Hu, L., \& Bentler, P. M. (1999). Cutoff criteria for fit indexes in covariance structure analysis: Conventional criteria versus new alternatives. Structural Equation Modeling, 6, 1-55.

Huang, Y-H., Chen, P. Y., \& Grosch, J. W. (2010). Safety climate: New developments in conceptualization, theory, and research. Accident Analysis and Prevention, 42, 1421-1422.

Huang, Y.-H., Ho, M., Smith, G. S., \& Chen, P. Y. (2006). Safety climate and selfreported injury: Assessing the mediating role of employee safety control. Accident Analysis and Prevention, 38, 425-433.

Humphrey, S. E., Nahrgang, J. D., \& Morgeson, F. P. (2007). Integrating motivational, social, and contextual work design features: A meta-analytic summary and theoretical extension of the work design literature. Journal of Applied Psychology, $92,1332-1356$.

Imada, A. S. (2002). A macroergonomics approach to reducing work-related injuries. In H. W. Hendrick \& B. M. Kleiner (Eds.), Macroergonomics: Theory, methods, and applications (pp. 151-171). Mahwah, NJ: Lawrence Erlbaum Associates.

Inness, M., Turner, N., Barling, J., \& Stride, C. G. (2010). Transformational leadership and employee safety performance: A within-person, between-jobs design. Journal of Occupational Health Psychology, 15, 279-290.

Institute for Work \& Health (IWH). (2006a). Nonfatal injuries in young workers. 
Retrieved October 17, 2010. http://www.iwh,on.ca/media/images/IWH_ youngworkers.pdf

Institute for Work \& Health (IWH). (2006b). The guide for evaluating the effectiveness of strategies for preventing work injuries. Retrieved October 17, 2010. http://www. iwh.on.ca/products/evai.php

International Ergonomics Association (2000). Retrieved December 5, 2010. http://www.iea.cc/01_what/What is Ergonomics.html

Ivancevich, J. M., \& Matteson, M. T. (1980). Stress and work. Glenview, IL: Scott, Foresman.

Jackson, P. R., Wall, T. D., Martin, R., \& Davids, K. (1993). New measures of job control, cognitive demand, and production responsibility. Journal of Applied Psychology, 78, 753-762.

Jacobs, J. A., \& Gerson, K. (2004). The time divide: Work, family, and gender inequality. Cambridge, MA : Harvard University Press.

Johns, G. (2006). The essential impact of context on organizational behavior. Academy of Management Review, 31, 386-408.

Jones, B. L., Scovile, P., Hill, E. J., Childs, G. Leishman, J. M., \& Nally, K. S. (2008). Perceived versus used workplace flexibility in Singapore: Predicting work-family fit. Journal of Family Psychology, 22, 774-783.

Karasek, R. A. (1979). Job demands, job decision latitude, and mental strain: Implications for job redesign. Administrative Science Quarterly, 24, 285-308. 
Karasek, R. A., \& Theorell, T. (1990). Healthy work: Stress, productivity, and the reconstruction of working life. New York: Basic Books.

Karwowski, W., Kantola, J., Rodrick, D., \& Salvendy, G. (2002). Macroergonomic aspects of manufacturing. In H. W. Hendrick \& B. M. Kleiner (Eds.), Macroergonomics: Theory, methods, and applications (pp. 223-248). Mahwah, NJ: Lawrence Erlbaum Associates.

Katz-Navon, T., Naveh, E., \& Stern, Z. (2009). Active learning: When is more better? The case of resident physicians' medical errors. Journal of Applied Psychology, $94,1200-1209$.

Kelloway, E. K., \& Gottlieb, B. H. (1998). The effects of alternative work arrangements on women's well-being: A demand-control model. Women's Health: Research on Gender, Behavior, and Policy, 4, 1-18.

Kelloway, E. K., Gottlieb, B. H., \& Barham, L. (1999). The source, nature, and direction of work and family conflict: A longitudinal investigation. Journal of Occupational Health Psychology, 4, 337-346.

Kelly, E. L., \& Kalev, A. (2006). Managing flexible work arrangements in US organizations: Formalized discretion or "a right to ask." Socio-Economic Review, 4, 379-416.

Kelly, E. L., \& Moen, P. (2007). Rethinking the clockwork of work: Why schedule control may pay off at work and at home. Advances in Developing Human Resources, 9, 487-506. 
Kessler, R. C., Price, R. H., \& Wortman, C. B. (1985). Social factors in psychopathology: Stress, social support and coping processes. Annual Review of Psychology, 36, 531-572.

Kickul, J., \& Posig, M. (2001). Supervisory emotional support and burnout: An explanation of reverse buffering effects. Journal of Managerial Issues, 13, 328344.

Kinnunen, U., \& Mauno, S. (1998). Antecedents and outcomes of work-family conflict among employed women and men in Finland. Human Relations, 51, 157-177.

Kinnunen, U., \& Natti, J. (1994). Job insecurity in Finland: Antecedents and consequences. European Work and Organizational Psychologist, 4, 157-177.

Klauss, R., \& Bass, B. M. (1982). Interpersonal communication in organizations. New York: Academic Press.

Kleiner, B. M. (2008). Macroergnomics: Work system analysis and design. Human Factors: The Journal of the Human Factors and Ergonomics Society, 50, 461467.

Kline, R. B. (2011). Principles and practice of structural equation modeling. New York: The Guilford Press.

Kondo, J. (1996). The spirit of safety-oriented safety culture. Nuclear Engineering and Design, 165, 281-287.

Kopelman, R. E., Greenhaus, J. H., \& Connolly, T. F. (1983). A model of work, family, and interrole conflict: A construct validation study. Organizational Behavior and Human Decision Processes, 32, 198-215. 
Kossek, E. E. (2005). Workplace policies and practices to support work and families. In S. M. Bianchi, L. M. Casper, \& R. B. King (Eds.), Work, family, health, and wellbeing (pp.97-115). Mahwah, NJ: Lawrence Erlbaum Associates.

Kossek, E. E. (2006). Work and family in America: Growing tensions between employment policy and a changing workforce. In E. Lawler \& J. O’Toole (Eds.), America at work: Choices and challenges (pp. 53-72). New York: Palgrave Macmillan.

Kossek, E. E., \& Lambert, S. (2005). Work-family Scholarship: Voice \& context. In E. E. Kossek \& S. J. Lambert (Eds.), Work and life integration: Organizational, cultural, and psychological perspectives (pp. 3-18). Mahwah, NJ: Lawrence Erlbaum Associates.

Kossek, E. E., \& Ozeki, C. (1998). Work-family conflict, policies, and the job-life satisfaction relationship: A review and directions for organizational behaviorhuman resources research. Journal of Applied Psychology, 83, 139-149.

Kossek, E. E., Pichler, S., Bodner, T., \& Hammer, L. B. (2011). Workplace social support and work-family conflict: A meta-analysis clarifying the influence of general and work-family specific supervisor and organizational support. Personnel Psychology, 64, 289-313.

Kozlowski, S. W. J., \& Doherty, M. L. (1989). Integration of climate and leadership: Examination of a neglected issue. Journal of Applied Psychology, 74, 546-553. 
Krause, T. R. (1997). Foundation concepts of behavior-based safety management. In T. R. Krause (Ed.), The behavior-based safety process: Managing involvement for an injury-free culture (pp. 29-54). New York: Wiley.

Lambert, E. G., Hogan, N. L., \& Barton, S. M. (2004). The nature of work-family conflict among correctional staff: An exploratory examination. Criminal Justice Review, 29, 145-172.

Landrigan, C. P., Rothschild, J. M., Cronin, J. W., Kaushal, R., Burdick, E., Katz, J. T., ... Czeisler, C. A. (2004). Effect of reducing interns' work hours on serious medical errors in intensive care units. New England Journal of Medicine, 351, 1838-1848.

Lee, M. D., MacDermid, S. M., \& Buck, M. L. (2000). Organizational paradigms of reduced-load work: Accommodation, elaboration, and transformation. Academy of Management Journal, 43, 1211-1226.

Leiter, M. P., \& Robichaud, L. (1997). Relationships of occupational hazards with burnout: An assessment of measures and models. Journal of Occupational Health Psychology, 2, 35-44.

Liao, H., Arvey, R. D., Butler, R. J., \& Nutting, M. (2001). Correlates of work injury frequency and duration among firefighters. Journal of Occupational Health Psychology, 6, 229-242.

Liberty Mutual Research Institute for Safety. (2010). Liberty Mutual Workplace Safety Index, 1-2.

Lockley, S. W., Cronin, J. W., Evans, E. E., Cade, B. E., Lee, C. J., Landrigan, C. P., ... 
Czeisler, C. A. (2004). Effect of reducing interns' weekly work hours on sleep and attentional failures. New England Journal of Medicine, 351, 1829-1837.

Loughlin, C., \& Barling, J. (2001). Young workers' work values, attitudes, and behaviors. Journal of Occupational and Organizational Psychology, 74, 543-558.

Loughlin, C., \& Frone, M. R. (2004). Young workers' occupational safety. In J. Barling \& M. Frone (Eds.), The psychology of workplace safety, (pp. 107-125). Washington, DC: American Psychological Association.

MacCallum, R. C., Browne, M. W., \& Sugawara, H. M. (1996). Power analysis and determination of sample size for covariance structure modeling. Psychological Methods, 1, 130-149.

MacEwen, K. E., \& Barling, J. (1994). Daily consequences of work interference with family and family interference with work. Work \& Stress, 8, 244-254.

Major, V. S., Klein, K. J., \& Ehrhart, M. G. (2002). Work time, work interference with family, and psychological distress. Journal of Applied Psychology, 87, 427-436.

MacKinnon, D. P., Krull, J. L., \& Lockwood, C. M. (2000). Equivalence of the mediation, confounding, and suppression effects. Prevention Science, 1, 173-181.

MacKinnon, D. P., Lockwood, C. M., Hoffman, J. M., West, S. G., \& Sheets, V. (2002). A comparison of methods to test mediation and other intervening variable effects. Psychological Methods, 7, 83-104.

MacKinnon, D. P., Lockwood, C. M., \& Williams, J. (2004). Confidence limits for the indirect effect: Distribution of the product and resampling methods. Multivariate Behavioral Research, 39, 99-128. 
MacKinnon, D. P., Warsi, G., \& Dwyer, J. H. (1995). A simulation study of mediated effect measures. Multivariate Behavioral Research, 30, 41-62.

Mearns, K., Hope, L., Ford, M. T., \& Tetrick, L. E. (2010). Investment in workforce health: Exploring the implications for workforce safety climate and commitment. Accident Analysis and Prevention, 42, 1445-1454.

Mearns, K., Whitaker, S. M., \& Flin, R. (2001). Benchmarking safety climate in hazardous environments: A longitudinal, interorganizational approach. Risk Analysis, 21, 771-786.

Mesmer-Magnus, J. R., \& Viswesvaran, C. (2005). Convergence between measures of work-to-family and family-to-work conflict: A meta-analytic examination. Journal of Vocational Behavior, 67, 215-232.

Mesmer-Magnus, J. R., \& Viswesvaran, C. (2006). How family-friendly work environments affect work/family conflict: A meta-analytic examination. Journal of Labor Research, 27, 555-574.

Meyer, J., \& Rowan, B. (1977). Institutionalized organizations: Formal structure, myth and ceremony. American Journal of Sociology, 83, 340-363.

Mischel, W. (1968). Personality and assessment. New York: Wiley.

Moen, P., \& Roehling, P. (2005). The career mystique: Cracks in the American dream. Boulder, CO: Rowman and Littlefield.

Morgeson, F. P., Campion, M. A. (2003). Work design. In W. C. Borman, D. R. Ilgen, \& R. J. Klimoski (Eds.), Handbook of psychology: Industrial and organizational psychology (Vol. 12, pp. 423-452). Hoboken, NJ: Wiley. 
Morgeson, F. P., Dierdorff, E. C., \& Hmurovic, J. L. (2010). Work design in situ:

Understanding the role of occupational and organizational context. Journal of Organizational Behavior, 31, 351-360.

Morgeson, F. P., \& Humphrey, S. E. (2006). The work design questionnaire (WDQ):

Developing and validating a comprehensive measure for assessing job design and the nature of work. Journal of Applied Psychology, 91, 1321-1339.

Motowidlo, S. J., Borman, W. C., \& Schmit, M. J. (1997). A theory of individual differences in task and contextual performance. Human Performance, 10, 71-83.

Muller, D., Judd, C. M., \& Yzerbyt, V. Y. (2005). When moderation is mediated and mediation is moderated. Journal of Personality and Social Psychology, 89, 852863.

Murphy, L. R., DuBois, D., \& Hurrell, J. J. (1986). Accident reduction through stress management. Journal of Business and Psychology, 1, 5-18.

Murphy, L. R., \& Hurrell, J. J. (1986). Stress measurement and management in organizations: Development and current status. In A. W. Riley, S. Zaccaro, \& R. Rosen (Eds.), Occupational stress and organizational effectiveness. New York: Praeger.

National Alliance for Caregiving and American Association of Retired Persons. (2004). Caregiving in the U.S. Bethesda, MA, and Washington, DC: Authors. Retrieved May 2, 2011, from http://assets.aarp.org/rgcenter/il/us_caregiving.pdf National Research Council (2004). Health and safety needs of older workers. Washington, DC: National Academies Press. 
National Safety Council. (2006). Injury Facts ${ }^{\circledR}, 2005-2006$ Edition. Itasca, IL: National Safety Council.

Neal, A., \& Griffin, M. A. (2002). Safety climate and safety behavior. Australian Journal of Management, 27, 67-75.

Neal, A., Griffin, M. A., \& Hart, P. M. (2000). The impact of organizational climate on safety climate and individual behavior. Safety Science, 34, 99-109.

Neal, M. B., \& Hammer, L. B. (2007). Working couples caring for children and aging parents: Effects on work and well-being. Mahwah, NJ: Lawrence Erlbaum Associates.

Netemeyer, R. C., Boles, J. S., \& McMurrian R. (1996). Development and validation of work-family conflict and family-work conflict scales. Journal of Applied Psychology, 81, 400-410.

Neumark, D., Polsky, D., \& Hansen, D. (1997). Has job stability declined yet? New evidence for the 1990's. Cambridge, MA: National Bureau of Economic Research, Working Paper No. 6330.

Nicholson, N., Soane, E., Fenton-O’Creevy, M. \& Willman, P. (2005). Personality and domain-specific risk taking. Journal of Risk Research, 8, 157-176.

Nomaguchi, K. M. (2009). Change in work-family conflict among employed parents between 1977 and 1997. Journal of Family and Marriage, 71, 15-32.

Occupational Safety \& Health Administration (OSHA). (2010). OSH Act of 1970. Retrieved November 20, 2010. http://www.osha.gov/pls/oshaweb/owadisp.show_ document?p_table=OSHACT\&p_id=3355 
O’Dea, A., \& Flin, R. (2001). Site managers and safety leadership in the offshore oil and gas industry. Safety Science, 37, 39-57.

Ostroff, C., Kinicky, A. J., \& Clark, M. A. (2002). Substantive and operational issues of response bias across levels of analysis: An example of climate-satisfaction relationships. Journal of Applied Psychology, 87, 355-368.

Parasuraman, S., Greenhaus, J. H., \& Granrose, C. S. (1992). Role stressors, social support, and well-being among two-career couples. Journal of Organizational Behavior, 13, 339-356.

Parasuraman, S. Pruohit, Y. S., Godshalk, V. M., \& Beutell, N. J. (1996). Work and family variables, entrepreneurial career success, and psychological well-being. Journal of Vocational Behavior, 48, 275-300.

Parasuraman, S., \& Simmers, C. A. (2001). Type of employment, work-family conflict and well being: A comparative study. Journal of Organizational Behavior, 22, 551-568.

Parker, S. K., Axtell, C. M., \& Turner, N. (2001). Designing a safer workplace: Importance of job autonomy, communication quality, and supportive supervisors. Journal of Occupational Health Psychology, 6, 211-228.

Parker, S. K., \& Wall, T. D. (1998). Job and work design: Organizing work to promote well-being and effectiveness. Thousand Oaks, CA: Sage.

Pasmore, W., \& Friedlander, F. (1982). An action research program for increasing employee involvement in problem solving. Administrative Science Quarterly, 27, 343-362. 
Paul, P. S., \& Maiti, J. (2008). The synergic role of sociotechnical and personal characteristics on work injuries in mines. Ergonomics, 51, 737-767.

Peeters, M. C. W., Montgomery, A. J., Bakker, A. B., \& Schaufeli, W. B. (2005).

Balancing work and home: How job demands and home demands are related to burnout. International Journal of Stress Management, 12, 43-61.

Perlow, L. (1997). Finding time: How corporations, individuals, and families can benefit from new work practices. Ithaca, Cornell University Press.

Perlow, L. A. (2001). Time to coordinate: Toward an understanding of work-time standards and norms in a multi-country study of software engineers. Work \& Occupations, 28, 91-111.

Perrow, C. (1984). Normal Accidents. New York: Basic Books.

Pool, I. (1990). Technologies without boundaries: On telecommunications in a global age. Harvard University Press, Cambridge, MA.

Preacher, K. J., Rucker, D. D., Hayes, A. F. (2007). Addressing moderated mediatio hypotheses: Theory, methods, and prescriptions. Multivariate Behavioral Research, 42, 185-227.

Presser, H. B. (2003). Working in a 24/7 economy. New York: Russell Sage Foundation.

Probst, T. M. (2002). Layoffs and tradeoffs: Production, quality, and safety demands under the threat of job loss. Journal of Occupational Health Psychology, 7, 211220.

Probst, T. M., \& Brubaker, T. L. (2001). The effects of job insecurity on employee 
safety outcomes: Cross-sectional and longitudinal explorations. Journal of Occupational Health Psychology, 6, 139-159.

Probst, T. M., Brubaker, T. L., \& Barsotti, A. (2008). Organizational injury rate underreporting: The moderating effect of organizational safety climate. Journal of Applied Psychology, 93, 1147-1154.

Reason, J. (1990). Human Error. Cambridge, MA: Cambridge University Press.

Reason, J. T. (1997). Managing the risks of organizational accidents. Aldershot: Ashgate.

Richman, A., Johnson, A., \& Buxbaum, L. (2006). Workplace Flexibility for Lower-wage workers. Washington, DC: Corporate Voices for Working Families.

Robertson, M. M. (2002). Macroergonomics of training systems development. In H. W. Hendrick \& B. M. Kleiner (Eds.), Macroergonomics: Theory, methods, and applications (pp. 249-272). Mahwah, NJ: Lawrence Erlbaum Associates.

Rodgers, F.S., \& Rodgers, C. (1989). Business and the facts of family life. Harvard Business Review, 89, 121-129.

Ronen, S. (1981). Arrival and departure patterns of public sector employees before and after implementation of flexitime. Personnel Psychology, 34, 817-822.

Ronen, S. (1984). Alternative work schedules: Selecting, implementing, and evaluating . Homewood, IL: Dow Jones-Irwin.

Rones, P. L., Ilg, R. E., \& Gardner, J. M. (1997). Trends in hours of work since the mid-1970s. Monthly Labor Review, 120(4), 3-13.

Rosenman, K. D., Kalush, A., Reilly, M. J., Gardiner, J. C., Reeves, M., \& Luo, Z. 
(2006). How much work-related injury and illness is missed by the current national surveillance system? Journal of Occupational \& Environmental Medicine, 48, 357-365.

Rousseau, D. M. (1977). Technological differences in job characteristics, employee satisfaction, and motivation: A synthesis of job design research and sociotechnical systems theory. Organizational Behavior and Human Performance, 19, 18-42.

Rousseau, D. M., \& Fried, Y. (2001). Location, location, location: Contextualizing organizational research. Journal of Organizational Behavior, 22, 1-13.

Rubin, B. A., \& Brody, C. (2005). Contradictions of commitment in the new economy: Insecurity, time, and technology. Social Science Research, 34, 843-861.

Ryan, A. M., \& Kossek, E. E. (2003). Work-life policy implementation: Breaking down or creating barriers to inclusiveness? Human Resource Management, 47, 295-310.

Sauter, S., et al., (2002). The changing organization of work and the safety and health of working people. DHHS (NIOSH) Publication No. 2002-116. Retrieved December 30, 2010. http://www.cdc.gov/niosh/docs/2002-116/

Sawacha, E., Naoum, S., \& Fong, D. (1999). Factors affecting safety performance on construction sites. International Journal of Project Management, 17, 309-315.

Sayer, L. C. (2005). Gender, time, and inequality: Trends in women's and men's paid work, unpaid work, and free time. Social Forces, 84, 285-303.

Schieman, S., Milkie, M. A., \& Glavin, P. (2009). When work interferes with life: The social distribution of work-nonwork interference and the influence of workrelated demands and resources. American Sociological Review, 74, 966-988. 
Schulte, P. A., Stephenson, C. M., Okun, A. H., Palassis, J., \& Biddle, E. (2005). Integrating occupational safety and health information into vocational and technical education and other workforce preparation programs. American Journal of Public Health, 95, 404-411.

Selye, H. (1976). Stress in health and disease. London: Butterworth Publishers, Inc.

Shaffer, M. A., \& Joplin, J. R. W. (2001). Work-family conflict on international assignments: Time- and strain-based determinants and performance effort consequences. Academy of Management Proceedings, 11-16.

Shahnavaz, H. (2002). Macroergnomic considerations in technology transfer. In H. W. Hendrick \& B. M. Kleiner (Eds.), Macroergonomics: Theory, methods, and applications (pp. 311-322). Mahwah, NJ: Lawrence Erlbaum Associates.

Shannon, H. S., Mayr, J., \& Haines, T. (1997). Overview of the relationship between organizational and workplace factors and injury rates. Safety Science, 26, 201217.

Shinn, M., Wong, N. W., Simko, P. A., \& Ortiz-Torres, B. (1989). Promoting the well being of working parents: Coping, social support, and flexible job schedules. American Journal of Community Psychology, 17, 31-55.

Shirom, A. (2003). Job-related burnout: A review. In J. C. Quick \& L. E. Tetrick (Eds.), Handbook of occupational health psychology, (pp. 245-264). Washington, DC: American Psychological Association.

Shrout, P. E., \& Bolger, N. (2002). Mediation in experimental and non-experimental 
studies: New procedures and recommendations. Psychological Methods, 7, 422445.

Siu, O.-L., Phillips, D. R., \& Leung, T. (2003). Age differences in safety attitudes and safety performance in Hong Kong construction workers. Journal of Safety Research, 34, 199-205.

Sobel, M. E. (1982). Asymptotic confidence intervals for indirect effects in structural equation models. In S. Leinhart (Ed.), Sociological methodology 1982 (pp. 290312). San Francisco: Jossey-Bass.

Society for Occupational Health Psychology (2005). What is Occupational Health Psychology. Retrieved May 23, 2011, from http://sohp.psy.uconn.edu/Field.htm Sonnentag, S. (2001). Work, recovery activities, and individual well-being: A diary study. Journal of Occupational Health Psychology, 6, 196-210.

Spector, P. (1987). Method variance as an artifact in self-reported affect and perceptions at work: Myth or significant problem? Journal of Applied Psychology, 72, 438443.

Spector, P. E., \& Brannick, M T. (2011). Methodological urban legends: The misuse of statistical control variables. Organizational Research Methods, 14, 287-305.

Spink, P. (1975). Some comments on the quality of working life. Journal of Occupational Psychology, 48, 179-184.

Swanberg, J. E. (2008). Workplace structure and its impact on hourly workers and their 
families. Presentation at Working for Change: A Conversation on Workplace Flexibility Research, Business Practice, and Public Policy, Georgetown Law, May 28-30.

Ten Brummelhuis, L. L., Bakker, A. B., \& Euwema, M. C. (2010). Is family-to-work interference related to co-workers' work outcomes? Journal of Vocational Behavior, 77, 461-469.

Thomas, L. T., \& Ganster, D. C. (1995). Impact of family-supportive work variables on work-family conflict and strain: A control perspective. Journal of Applied Psychology, 80, 6-15.

Thompson, C. A., Beauvais, L. L., \& Lyness, K. S. (1999). When work-family benefits are not enough: The influence of work-family culture on benefit utilization, organizational attachment, and work-family conflict. Journal of Vocational Behavior, 54, 392-415.

Thompson, C. A., \& Prottas, D. J. (2005). Relationships among organizational family support, job autonomy, perceived control, and employee well-being. Journal of Occupational Health Psychology, 10, 100-118.

Torraco, R. J. (2005). Work design theory: A review and critique with implications for human resource development. Human Resource Development Quarterly, 16, 85109.

Torp, S., \& Grogaard, J. B. (2009). The influence of individual and contextual work factors on workers' compliance with health and safety routines. Applied Ergonomics, 40, 185-193. 
Trade Union Congress. (2007). Work life balance case studies. London: Author.

Retrieved March 2, 2011, from http://www.tuc.org.uk/work_life

Trist, E. (1981). The evolution of sociotechnical systems. In A. Van de Ven \& W.

Boyce (Eds.), Perspectives on organization and design (pp. 19-75). New York:

Wiley.

U.S. Government Accountability Office. (2009). Workplace safety and health (GAO 10-10). Washington, DC: Author.

Vandenberg, R. J., \& Lance, C. E. (2000). A review and synthesis of the measurement invariance literature: Suggestions, practices, and recommendations for organizational research. Organizational Research Methods, 3, 4-70.

Viswesvaran, C., Sanchez, J. I., \& Fisher, J. (1999). The role of social support in the process of work stress: A meta-analysis. Journal of Vocational Behavior, 54, 314334.

Voydanoff, P. (2004). The effects of work demands and resources on work-to-family conflict and facilitation. Journal of Marriage and Family, 66, 398-412.

Voydanoff, P. (2005). Toward a conceptualization of perceived work-family fit and balance: A demands and resources approach. Journal of Marriage and Family, $67,822-836$.

Wall, T. D., Corbett, J. M., Clegg, C. W., Jackson, P. R., \& Martin, R. (1990). Advanced manufacturing technology and work design: Towards a theoretical framework. Journal of Organizational Behavior, 11, 201-219.

Wall, T. D., \& Jackson, P. R. (1995). New manufacturing initiatives and shopfloor work 
design. In A. Howard (Ed.), The changing nature of work (pp. 139-174). San Francisco, CA: Jossey-Bass.

Wall, T. D., Jackson, P. R., \& Davids, K. (1992). Operator work design and robotics system performance: A serendipitous field study. Journal of Applied Psychology, $77,353-362$.

Warren, J., \& Johnson, P. (1995). The impact of workplace support on work-family role strain. Family Relations, 44, 163-169.

Weeden, K. A. (2005). Is there a flexiglass ceiling? Flexible work arrangements and wages in the United States. Social Science Research, 34, 454-482.

Weick, K. E. (1990). The vulnerable system: Analysis of the Tenerife air disaster. Journal of Management, 16, 571-593.

West, S. G., Finch, J. F., \& Curran, P. J. (1995). Structural equation models with nonnormal variables: Problems and remedies. In R. Hoyle (Ed.), Structural equation modeling: Concepts, issues, and applications (pp. 56-75). Newbury Park, CA: Sage.

Wethington, E., \& Kessler, R. C. (1986). Perceived support, received support, and adjustment to stressful life events. Journal of Health and Social Behavior, 27, 7889.

Wetzels, M. G. M., de Ruyter, J. C., \& Bloemer, J. M. M. (2000). Antecedents and consequences of role stress of retail sales persons. Journal of Retail and Consumer Services, 7, 65-75.

Williams, H., Turner, N., \& Parker, S. (2000). The compensatory role of transformational 
leadership in promoting safety behaviors. Paper presented at the annual meeting of the Academy of Management, Toronto, Ontario, Canada.

Winfield, I., \& Rushing, B. (2005). Bridging the border between work and family: The effects of supervisor-employee similarity. Sociological Inquiry, 75, 55-80.

Workplace Flexibility. (2010). Lower-wage workers and flexible work arrangements.

Retrieved March 3, 2011 from

Wright, C. (1993). The effect of work group organization on responses to a total emergency in the offshore industry. Proceedings of the workforce involvement in health and safety offshore: Power, language and information technology (pp. 5962). Glasgow: Scottish Trades Union Congress.

Wright, B. M., \& Cordery, J. L. (1999). Production uncertainty as a contextual moderator of employee reactions to job design. Journal of Applied Psychology, 84, 456-463.

Yakovlev, P., \& Sobel, R. S. (2010). Occupational safety and profit maximization: Friends or foes? The Journal of Socio-Economics, 39, 429-435.

Yukl, G. (1998). Leadership in organizations (4 ${ }^{\text {th }}$ ed.). Saddle River, NJ: Prentice Hall. Yung, Y.-F., \& Bentler, P. M. (1996). Bootstrapping techniques in analysis of mean and covariance structures. In G. A. Marcoulides \& R. E. Schumacker (Eds.), Advanced structural equation modeling: Issues and techniques (pp. 195-226). Mahwah, NJ: Lawrence Erlbaum Associates.

Zink, K. J. (2002). A vision of the future of macro-ergonomics. In H. W. Hendrick \& B. M. Kleiner (Eds.), Macroergonomics: Theory, methods, and applications (pp. 347-358). Mahwah, NJ: Lawrence Erlbaum Associates. 
Zohar, D. (1980). Safety climate in industrial organizations: Theoretical and applied applications. Journal of Applied Psychology, 65, 96-102.

Zohar, D. (2000). A group-level model of safety climate: Testing the effect of group climate on microaccidents in manufacturing jobs. Journal of Applied Psychology, $85,587-596$.

Zohar, D. (2002a). The effects of leadership dimensions, safety climate, and assigned priorities on minor injuries in work groups. Journal of Organizational Behavior, $23,75-92$.

Zohar, D. (2002b). Modifying supervisory practices to improve subunit safety: A leadership based intervention model. Journal of Applied Psychology, 87, 156-163.

Zohar, D. \& Luria, G. (2004). Climate as a social-cognitive construction of supervisory safety practices: Scripts as proxy of behavior patterns. Journal of Applied Psychology, 89, 322-333.

Zohar, D., \& Tenne-Gazit, O. (2008). Transformational leadership and group interaction as climate antecedents: A social network analysis. Journal of Applied Psychology, 93, 744-757.

Zohar, D., Tzischinski, O., \& Epstein, R. (2003). Effects of energy availability on immediate and delayed emotional reactions to work events. Journal of Applied Psychology, 88, 1082-1093. 